RENAN BERNARDI KALIL

CAPITALISMO DE PLATAFORMA E DIREITO DO TRABALHO:

CROWDWORK E TRABALHO SOB DEMANDA POR MEIO DE APLICATIVOS

TESE DE Doutorado

Orientador: Professor Associado Dr. Otavio Pinto e Silva

UNIVERSIDADE DE SÃO PAULO

FACULDADE DE DIREITO

São Paulo - SP

2019 
RENAN BERNARDI KALIL

\title{
CAPITALISMO DE PLATAFORMA E DIREITO DO TRABALHO: CROWDWORK E TRABALHO SOB DEMANDA POR MEIO DE APLICATIVOS
}

\begin{abstract}
Tese apresentada a Banca Examinadora do Programa de PósGraduação em Direito, da Faculdade de Direito da Universidade de São Paulo, como exigência parcial para obtenção do título de Doutor em Direito, na área de concentração Direito do Trabalho e da Seguridade Social, sob orientação do Prof. Associado Dr. Otavio Pinto e Silva.
\end{abstract}

UNIVERSIDADE DE SÃO PAULO

FACULDADE DE DIREITO

São Paulo - SP 


\section{FICHA CATALOGRÁFICA}

\section{Kalil, Renan Bernardi}

B523c Capitalismo de plataforma e Direito do Trabalho: crowdwork e trabalho sob demanda por meio de aplicativos / Renan Bernardi Kalil; orientador Otavio Pinto e Silva. - São Paulo, 2019. $367 \mathrm{f}$.

Tese (Doutorado)- Universidade de São Paulo, USP, Programa de Pós-Graduação em Direito, Direito do Trabalho e da Seguridade Social, 2019.

1. Capitalismo de plataforma. 2. Relações de Trabalho. 3. Crowdwork. 4. Trabalho Sob Demanda. 5. Dependência. I. Pinto e Silva, Otavio, orient. II. Título. 
BANCA EXAMINADORA

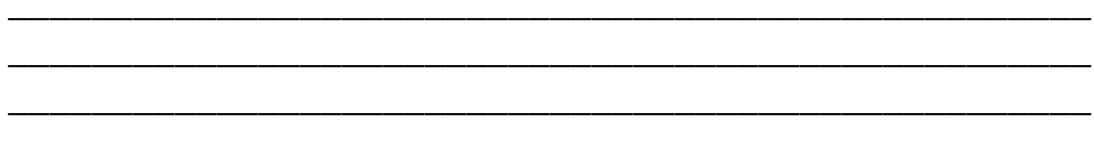




\section{AGRADECIMENTOS}

A condução da pesquisa para a elaboração desta tese de doutorado foi uma atividade desafiadora e solitária. Ambos foram superados graças ao apoio de pessoas e instituições, com as quais divido o resultado obtido. Todos os equívocos e imprecisões são de minha responsabilidade.

Ao Professor Otavio Pinto e Silva, presente e importante em minha trajetória como pesquisador desde os meus primeiros passos, pela acolhida ao longo da elaboração desta tese, pela confiança no projeto de pesquisa apresentado, pelos ensinamentos para o desenvolvimento deste trabalho e pela disponibilidade e atenção no curso da orientação desta pesquisa.

À Walküre, pelas lições sobre Direito do Trabalho e liberdade sindical que me marcaram profundamente, pelos ensinamentos a respeito da vida acadêmica (e não acadêmica), por confiar em mim como pesquisador e por acompanhar o desenvolvimento deste trabalho.

À Professora Laura Valladão de Mattos e ao Professor Antonio Rodrigues de Freitas Junior, membros da banca de qualificação, pelos comentários que estimularam relevantes reflexões para a continuidade da pesquisa e para a definição dos rumos desta tese.

Ao Professor Diogo Coutinho, pelo estímulo e pelo apoio na concretização do período de pesquisa na Escola de Direito da Universidade de Harvard.

Ao Professor Yochai Benkler, pela acolhida no período de pesquisa na Escola de Direito da Universidade de Harvard, pelas estimulantes conversas e sugestões, que foram centrais na elaboração desta tese, e pelas aulas ministradas, que despertaram em mim uma perspectiva crítica sobre a relação entre tecnologia e trabalho.

À Janine Berg e à Professora Juliet Schor, pela disponibilidade em compartilhar informações sobre as pesquisas com trabalhadores da Amazon Mechanical Turk e da Uber e pelos diálogos que foram centrais na formatação dos estudos de caso desenvolvidos nesta tese.

Ao Ministério Público do Trabalho, nas pessoas de Ronaldo Curado Fleury, Sandra Lia Simón e Fabio Fernando Pássari, pelo estímulo para pesquisar o tema objeto deste trabalho e pelo apoio institucional para o período de pesquisa na Escola de Direito da Universidade de Harvard, essencial para a elaboração desta tese. 
À minha mãe Tânia, ao meu pai Wilson e ao meu irmão Murilo, pelo amor, pelo carinho, pela compreensão nas minhas ausências e pelo suporte para que eu trilhasse o caminho que optei. Ao meu sobrinho Davi, por arrancar sorrisos mesmo nos momentos mais improváveis.

Ao André e à Laura, amigos de mais de década e fundamentais na minha opção de vida pelo Direito do Trabalho, pelo amor, pelo carinho, pelo companheirismo, pelas inúmeras horas de conversa sobre o tema pesquisado nesta tese e pela atenciosa e zelosa leitura deste trabalho.

Por último, e certamente não menos importante, à Raquel, pelo amor, pelo companheirismo, pelo carinho, pela cumplicidade, pelo conforto nos momentos difíceis, pelo estímulo para seguir o caminho da pesquisa, pela inspiração de coragem intelectual, pelas inúmeras horas de conversas sobre as ideias que conformam este trabalho e, especialmente nesses três últimos anos, por ter oferecido a mão para irmos em frente nesta estrada de fazer o sonho acontecer. 
"Você não sente não vê Mas eu não posso deixar de dizer, meu amigo Que uma nova mudança em breve vai acontecer

O que há algum tempo era novo, jovem

Hoje é antigo E precisamos todos rejuvenescer" ("Velha roupa colorida" - Belchior)

“- Você tem casa própria? - Não, não tenho.

- Você aluga uma casa ou apartamento ou vive de graça com alguém?

- Nenhum dos dois.

- Onde você mora?

- Aqui.

- No carro?

- No carro."

(Trecho de uma entrevista realizada com motorista da Uber na cidade de São Paulo entre agosto e outubro de 2018) 
KALIL, Renan Bernardi. Capitalismo de plataforma e Direito do Trabalho: crowdwork e trabalho sob demanda por meio de aplicativos. 367f. Doutorado - Faculdade de Direito, Universidade de São Paulo, São Paulo, 2019.

\section{RESUMO}

Em um contexto de transformações no mundo do trabalho pelo uso de novas tecnologias, é necessário desenvolver estudos que entendam as novas dinâmicas de trabalho e o papel do Direito do Trabalho. Esta tese identifica duas formas de trabalho no capitalismo de plataforma - o crowdwork e o trabalho sob demanda por meio de aplicativos - para investigar os efeitos concretos das inovações tecnológicas nas relações de trabalho. Pretende responder se as ferramentas do Direito do Trabalho protegem os trabalhadores que desempenham atividades nas plataformas digitais. Para tanto, combinamos revisão de literatura sobre as formas de trabalho e dois estudos de caso: um de crowdwork, com a plataforma Amazon Mechanical Turk e um de trabalho sob demanda por meio de aplicativos, com a plataforma Uber. Além da análise documental, foram conduzidas entrevistas do tipo survey com trabalhadores brasileiros nessas duas plataformas. Identificamos quatro características principais: (i) a existência de uma certa autonomia dos trabalhadores para determinar a carga horária e a jornada de trabalho; (ii) uma relação direta entre dependência e precariedade; (iii) o gerenciamento da força de trabalho pelo algoritmo, sendo que a intensidade da coordenação e do controle de mão de obra varia em cada plataforma; e (iv) uma acentuada desigualdade econômica entre os trabalhadores e as plataformas e os tomadores de serviços. Nossa análise aponta para diferenças no trabalho desenvolvido nas duas plataformas, especialmente quanto ao modo de execução de atividades. Ambas também se diferenciam parcialmente do conceito de emprego previsto na legislação brasileira. Nesse sentido, ressaltamos a necessidade de uma nova arquitetura jurídica capaz de oferecer respostas às peculiaridades das formas de trabalho no capitalismo de plataforma. Concluímos a pesquisa apresentando uma proposta de criação de uma legislação especial circunscrita ao crowdwork e ao trabalho sob demanda por meio de aplicativos. Nela, os trabalhadores são classificados em três categorias: autônomos, dependentes ou subordinados, em que cada uma atrai um conjunto de direitos. Desta forma, levamos em conta a complexidade que as inovações tecnológicas imprimem às relações de trabalho e estendemos proteção social aos trabalhadores que participam do capitalismo de plataforma.

Palavras-chave: Capitalismo de Plataforma; Relações de Trabalho; Crowdwork: Trabalho Sob Demanda; Dependência. 
KALIL, Renan Bernardi. Platform capitalism and Employment Law: crowdwork and ondemand work via apps. 2019. 367f. Doctor Degree - Law School, University of São Paulo, São Paulo, 2019.

\begin{abstract}
In a context of transformations in the world of work by new technologies, it is urgent to conduct studies to understand new labor dynamics and the role of Employment Law. This thesis identifies two forms of work in the platform capitalism - crowdwork and on-demand work via apps - to investigate the concrete effects of technological innovations in the labor relations. It aims to answer whether Employment Law categories protect workers who develop activities on digital platforms. In order to do, we combine a literature review on forms of work and two study cases: one of crowdwork, on Amazon Mechanical Turk, and other of work on-demand via apps, on Uber. We analyze documents and conduct $i$ interviews with Brazilian workers on both platforms. As a result, we identified four main characteristics: (i) the existence of a certain degree of workers autonomy in defining their amount of work and working time; (ii) a direct relationship between dependence and precarity; (iii) the management of the labor force by the algorithm, and its ability to coordinate and control workers varies according to each platform; (iv) a stark economic inequality among workers and platforms and contractors. Our analysis identifies differences between the work done on both platforms, especially on how workers execute activities. The work developed in both case studies are at least partially different from the Brazilian legal employee concept. In this sense, we highlight the need for a new legal architecture to offer answers to the peculiarities of work in the platform capitalism. We concluded our research presenting a proposal to create a special law for crowdwork and on-demand work via apps. Workers are to be classified as self-employees, dependents or employees, each category providing a set of rights for each one. In doing so, we hope to acknowledge the complexity technological innovations add to labor relations, while extending social protection for workers who join platform capitalism.
\end{abstract}

Keywords: Platform Capitalism; Labor Relations; Crowdwork; On-demand Work; Dependence. 
KALIL, Renan Bernardi Kalil. Capitalisme de plateforme et Droit du Travail: crowdwork et travail à la demande via applications mobiles. 2019. 367f. Doctorat - Faculté de Droit, Université de São Paulo, São Paulo, 2019.

\section{RÉSUMÉ}

Dans un contexte de mutation du monde du travail par l'utilisation des nouvelles technologies, il est nécessaire de développer des études qui identifient les nouvelles dynamique du travail et le rôle du Droit du Travail. Cette thèse identifie deux formes de travail dans le capitalisme de plateforme - le crowdwork et le travail à la demande via applications mobiles - pour étudier les effets concrets des innovations technologiques sur les relations de travail. Elle cherche à clarifier si les outils du Droit du Travail protègent les travailleurs qui exercent des activités sur des plateformes numériques. Pour ce faire, nous avons combiné une analyse documentaire sur les formes de travail et deux études de cas: une de crowdwork, avec la plateforme Amazon Mechanical Turk, et une autre de travail à la demande via applications mobiles, avec la plateforme Uber. En plus de l'analyse documentaire, ont été menés des entretiens de type survey avec travailleurs brésiliens sur ces deux plateformes. Nous avons identifié quatre caractéristiques principales : (i) l'existence d'une certaine autonomie des travailleurs pour déterminer leur quantité et les horaires de travail; (ii) une relation directe entre dépendance et précarité; (iii) la gestion de la maind'œuvre par l'algorithme, et l'intensité de la coordination et du contrôle du travail varient sur chaque plateforme; (iv) une inégalité économique accentuée entre les travailleurs et les plateformes et leurs clientes. Notre analyse met en évidence les différences dans le travail développé sur les deux, notamment en ce qui concerne le mode d'exécution des activités. Tous les deux se différencient en partie de la notion d'emploi prévue dans la législation brésilienne. En ce sens, nous soulignons la nécessité d'une nouvelle architecture juridique capable d'apporter des réponses aux particularités de ces formes de travail. Nous concluons la recherche en présentant une proposition visant à créer une législation spéciale circonscrite au crowdwork et au travail à la demande via applications mobiles. Les travailleurs y sont classés en trois catégories: autonomes, dépendantes ou subordonnés, dans lesquelles chacun jouit d'un ensemble de droits. De cette manière, nous prenons en compte la complexité que les innovations technologiques imposent aux relations de travail et étendons la protection sociale aux travailleurs qui participent au capitalisme de plateforme.

Mots-clefs: Capitalisme de Plateforme; Relations du Travail; Crowdwork; Travail à la demande; Dépendance. 


\section{LISTA DE ILUSTRAÇÕES}

Figura 1 - Tecnologia como integrante de um processo autônomo.......................................37

Figura 2 - Tecnologia como elemento exógeno.................................................................. 40

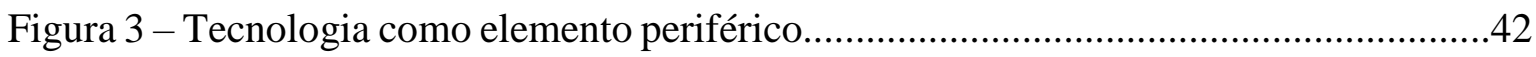

Figura 4 - Tecnologia e suas relações com outros elementos............................................48

Figura 5 - Tecnologia como parte de uma economia política multidimensional...................52 


\section{LISTA DE ABREVIATURAS E SIGLAS}

3D: Três dimensões

AMT: Amazon Mechanical Turk

APP: Asociación de Personal de Plataformas

art.: Artigo

AWS: Amazon Web Services

CEO: Chief Executive Officer

CFC: Centro de Formação de Condutores

CLT: Consolidação das Leis do Trabalho

CMUV: Comitê Municipal de Uso Viário

CNH: Carteira Nacional de Habilitação

CONAFRET: Coordenadoria Nacional de Combate às Fraudes na Relação de Trabalho

Conduapp: Cadastro Municipal de Condutores de Veículo de Aplicativo

CRLV: Certificado de Registro e Licenciamento de Veículo

CSVAPP: Certificado de Segurança do Veículo de Aplicativo

CWA local 7777: Communications Workers of America local 7777

DTP: Departamento de Transportes Públicos

EAR: Exerce Atividade Remunerada

EUA: Estados Unidos da América

FGTS: Fundo de Garantia do Tempo de Serviço

GPS: Global Positioning System

GRU: Guarulhos

INSS: Instituto Nacional do Seguro Social

LGBTQ: Lésbicas, Gays, Bissexuais, Transexuais ou Transgêneros e Queers

MIT: Massachussetts Institute of Technology

MPT: Ministério Público do Trabalho

MTurk: Amazon Mechanical Turk

n.: Número

OIT: Organização Internacional do Trabalho

PIB: Produto Interno Bruto 
SIMTRAPLIPE: Sindicato dos Motoristas de Transporte Privado Individual de Passageiros por Aplicativos de Pernambuco

SIMTRATTIPPRJ: Sindicato dos Motoristas em Transporte Terrestre Individual Privado de Passageiros por Aplicativo do Rio de Janeiro

SINDIMAAP: Sindicato dos Motoristas Autônomos de Transporte Privado Individual por Aplicativos

STATTESP: Sindicato dos Trabalhadores com Aplicativos de Transporte Terrestre Intermunicipal do Estado de São Paulo

TRT: Tribunal Regional do Trabalho

TV: Televisão

UE: União Europeia 


\section{SUMÁRIO}

INTRODUÇÃO...................................................................................................17

1. Justificativa e relevância do tema............................................................................ 19

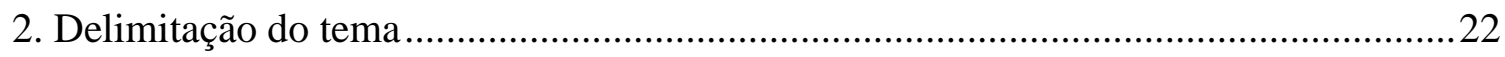

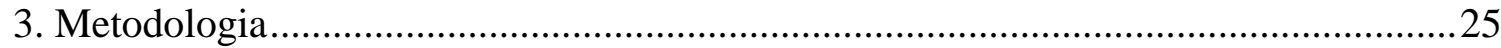

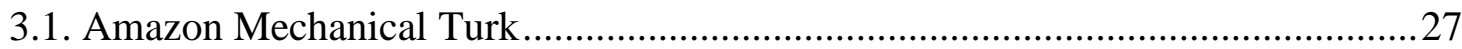

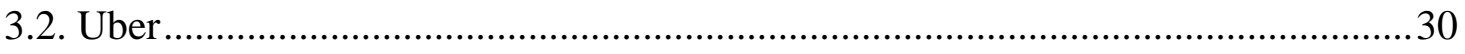

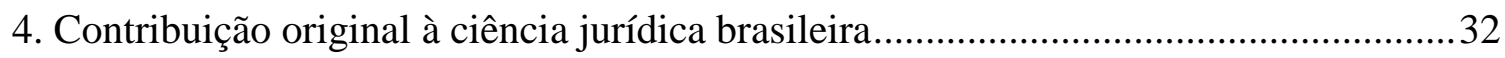

CAPÍTULO 1. CAPITALISMO DE PLATAFORMA ....................................................35

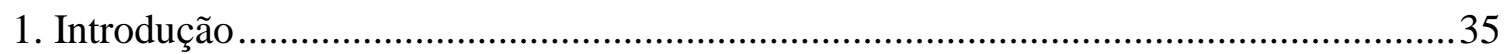

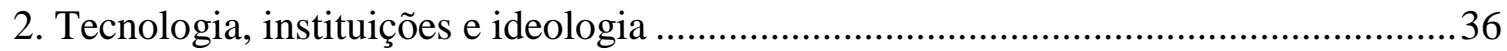

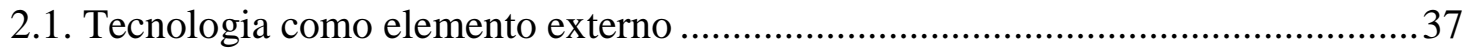

2.2. Tecnologia como elemento periférico................................................................ 42

2.3. Tecnologia e suas relações com outros elementos ................................................45

2.4. Tecnologia como parte de uma economia política multidimensional ....................50

3. Tecnologia, instituições e ideologia nos trinta anos gloriosos ....................................55

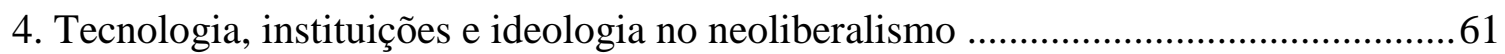

5. Tecnologia, instituições e ideologia no cenário de peças se movendo.........................70

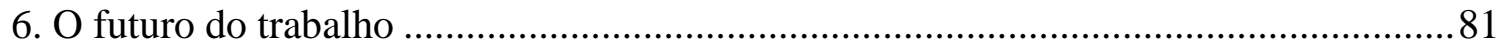

7. Inovações tecnológicas, economia e plataformas: diversidade conceitual e capitalismo

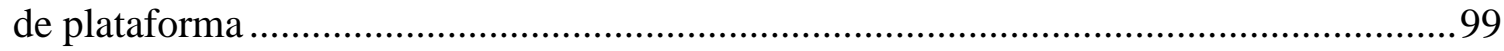

\section{CAPÍTULO 2. TRABALHO NO CAPITALISMO DE PLATAFORMA....................121}

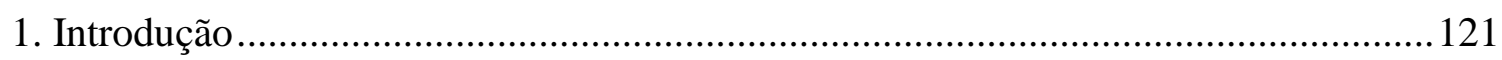

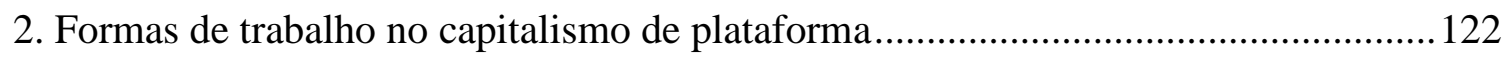

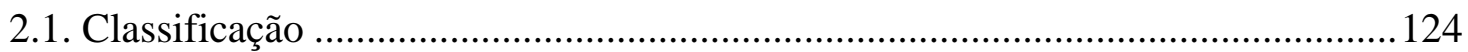

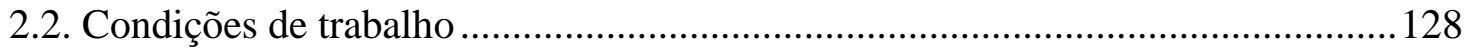

2.3. Os números de trabalhadores no trabalho sob demanda por meio de aplicativos e

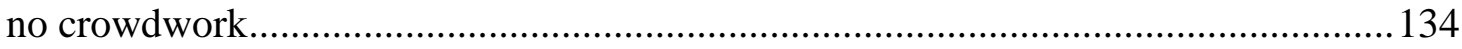

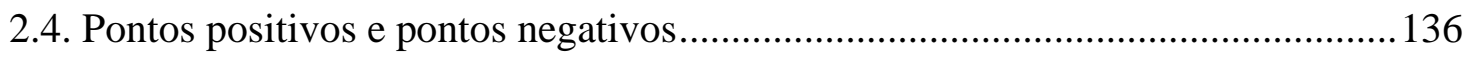

3. Trabalho sob demanda por meio de aplicativos ...................................................... 140

3.1. Dinâmicas das relações de trabalho e modo de operação das plataformas ...........141

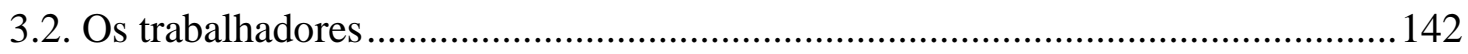

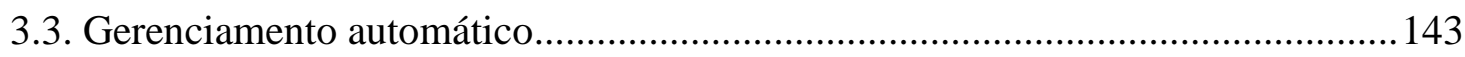

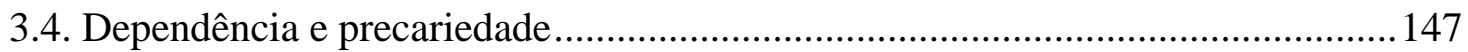

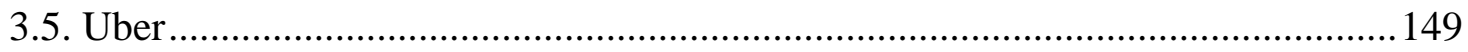


3.5.1. Dinâmicas das relações de trabalho e modo de operação 150

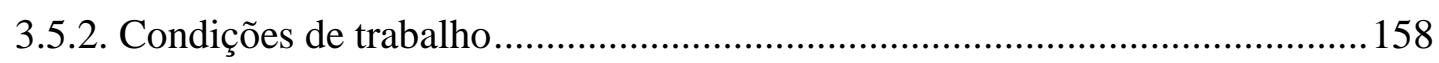

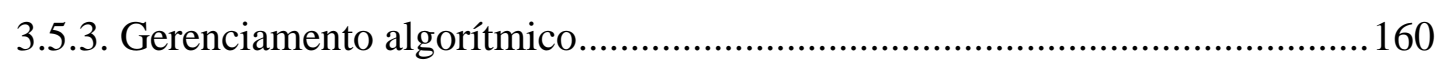

3.5.4. Empresa de tecnologia ou empresa de transportes?..................................... 167

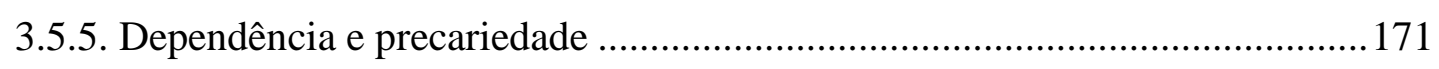

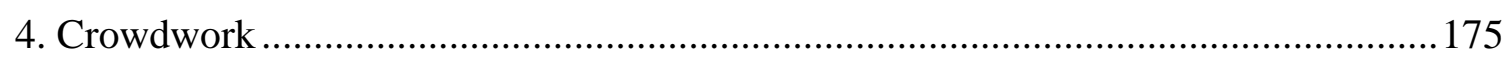

4.1. Modelos de negócios, tipos de trabalho e trabalho cultural ..................................176

4.2. Dinâmicas das relações de trabalho ................................................................. 180

4.3. Vantagens e desvantagens para trabalhadores e empresas .................................... 180

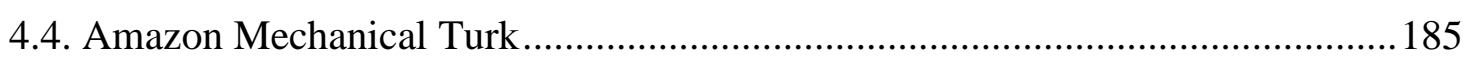

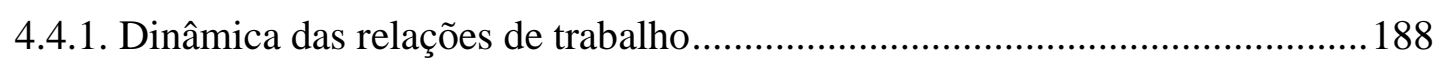

4.4.2 Condições de trabalho................................................................................. 191

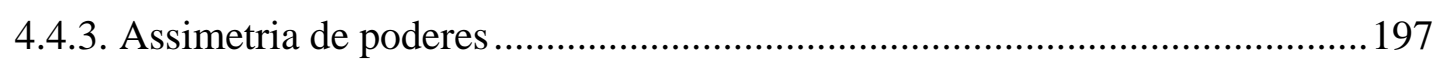

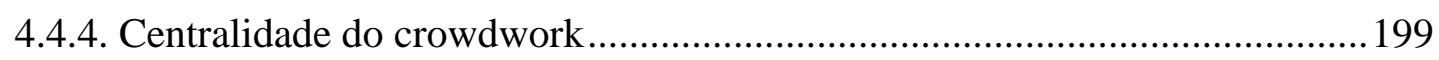

4.4.5. Dependência e precariedade .....................................................................200

5. Síntese das características das formas de trabalho no capitalismo de plataforma......202

\section{CAPÍTULO 3. O DIREITO DO TRABALHO E O CAPITALISMO DE}

PLATAFORMA ............................................................................................................207

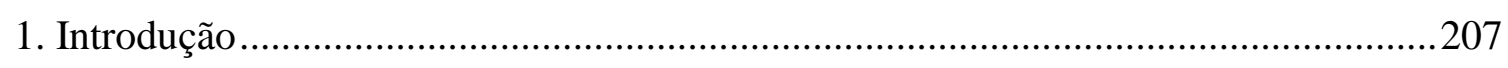

2. O papel do Direito do Trabalho no capitalismo de plataforma ...................................208

3. A regulação do trabalho no capitalismo de plataforma ............................................214

3.1. A dicotomia do trabalho: relação de emprego e autonomia................................216

3.1.1. Relação de emprego: a porta de entrada para a proteção trabalhista .............217

3.1.1.1. A não eventualidade no capitalismo de plataforma................................221

3.1.1.2. A subordinação no capitalismo de plataforma .......................................223

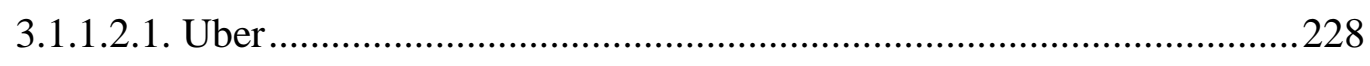

3.1.1.2.2. Amazon Mechanical Turk ...........................................................2 233

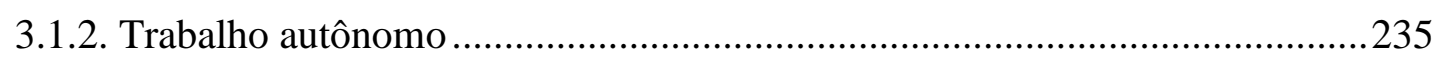

3.1.2.1. A autonomia e a liberdade do trabalhador no capitalismo de plataforma 238

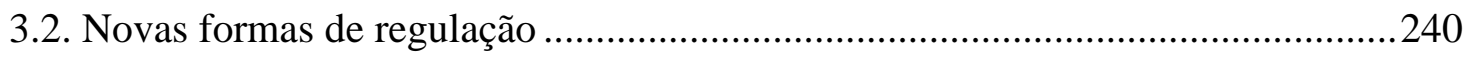

3.2.1. Uma categoria intermediária para classificar os trabalhadores .....................241

3.2.2. A reemergência da dependência ...............................................................249

3.2.3. Novas perspectivas sobre o conceito de empregador ..................................253

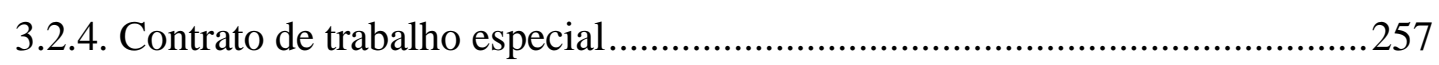

3.2.5. Ampliação subjetiva do Direito do Trabalho..............................................259

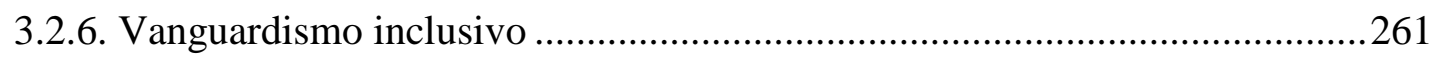


3.3. Novos direitos 263

3.3.1. Sistemas de avaliação 265

3.3.2. Sistemas de remuneração e tempo de trabalho 268

3.4. Organização e atuação coletivas dos trabalhadores ...........................................2.274

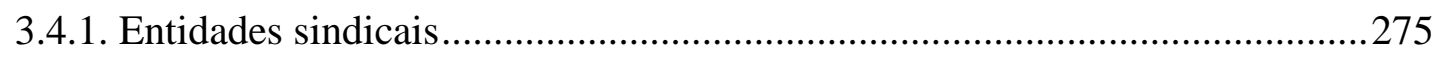

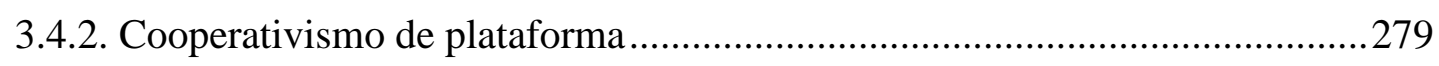

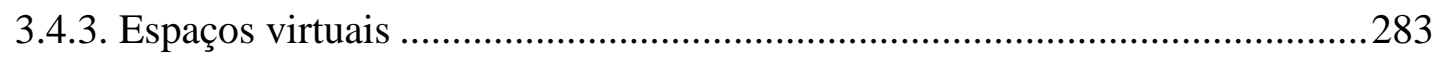

4. Como regular o trabalho no capitalismo de plataforma no Brasil ............................284

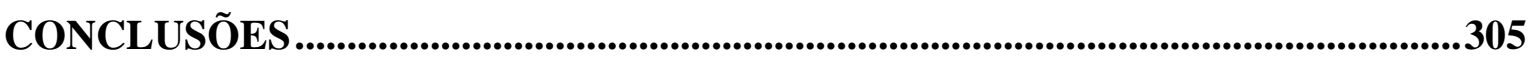

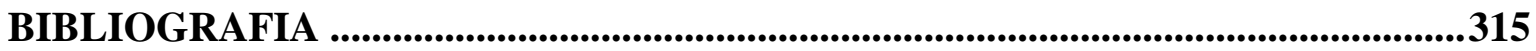

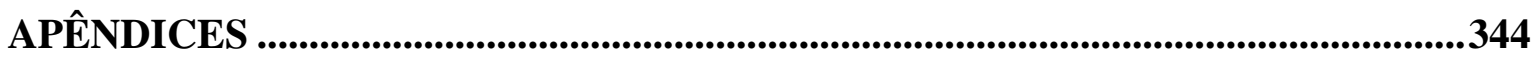

APÊNDICE A - RESULTADO DO QUESTIONÁRIO - TRABALHADORES DA

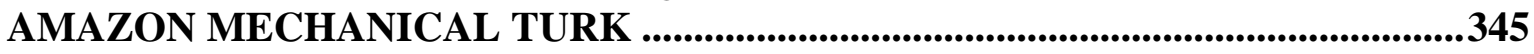
APÊNDICE B - RESULTADO DO QUESTIONÁRIO - MOTORISTAS DA UBER 358

APÊNDICE C - TERMO DE CONSENTIMENTO DE PARTICIPAÇÃO ................369 APÊNDICE D - TERMO DE CONSENTIMENTO DE PARTICIPAÇÃO ...............371 


\section{INTRODUÇÃO}

Em setembro de 2006, em apresentação no Massachussetts Institute of Technology (MIT), o Chief Executive Officer (CEO) da Amazon, Jeff Bezos, abordou os serviços tecnológicos oferecidos por sua empresa. Ao explicar o funcionamento da plataforma Amazon Mechanical Turk, afirmou "você já ouviu falar de software como um serviço. Bem, isso [a plataforma] é basicamente uma pessoa como serviço" ${ }^{1}$. Em seus 57 minutos de fala, as menções sobre os trabalhadores ocorreram em momentos pontuais.

Ainda assim, os trabalhadores são centrais para a MTurk, uma plataforma que oferece serviços online de curta duração executados por seres humanos. As condições de trabalho, no entanto, são muitas vezes invisibilizadas. Em pesquisa realizada com trabalhadores brasileiros que atuam na MTurk, não faltaram relatos sobre suas dificuldades na plataforma. A título de exemplo, destacamos dois: "é muito pouco para muito trabalho. Eu me sinto uma escrava na China. Sinto que eu realmente moro em um país de terceiro mundo, em que meu diploma não serve para nada e eu preciso me submeter a esses tipos de trabalho" e "há sempre trabalhos que remuneram muito mal, esses estão sempre bastante disponíveis e são amplamente executados por pessoas em países com condições humanas muito baixas. Os works mais bem remunerados são frequentemente restritos a determinados países (predominantemente EUA, Canadá e Reino Unido)"².

Outra plataforma digital, a Uber, afirma oferecer um aplicativo que, por meio da tecnologia, ajuda o motorista a tomar decisões sobre quando e como encontrar a demanda por serviços de transporte. Prometem promover acesso a trabalho flexível, sem turnos ou horários fixos, que permite que dirijam quando queiram. A remuneração dos motoristas, segundo a empresa, depende da demanda por viagens, sendo que nos momentos em que houver mais usuários realizando chamadas, os ganhos serão mais altos ${ }^{3}$.

Assim como a MTurk, há distância entre discurso e prática. Em nossa pesquisa feita com motoristas da Uber na cidade de São Paulo, os trabalhadores relataram diversas situações, como as seguintes: "trabalho por volta de 16 horas por dia, 7 dias da semana. Ganho em média R \$ 1.500 por semana, mas tirando todos os custos que tenho, sobra $\mathrm{R} \$ 400$.

\footnotetext{
${ }^{1}$ MASSACHUSSETTS INSTITUTE OF TECHNOLOGY. Opening keynote and keynote interview with Jeff Bezos, set. 2006. (1h02m38s). Disponível: <https://techtv.mit.edu/videos/16180-opening-keynote-andkeynote-interview-with-jeff-bezos>. Acesso: 21 dez. 2018, tradução nossa de: "You've heard of software-asa-service. Well, this is basically human-as-a-service" (11m40s-11m44s).

${ }^{2} \mathrm{~A}$ pesquisa que realizamos com os trabalhadores da Amazon Mechanical Turk será apresentada ao longo da tese.

${ }^{3}$ UBER. Open marketplace. Disponível em: <https://marketplace.uber.com/open-marketplace>. Acesso em: 07 out. 2018.
} 
O preço da tarifa está defasado em relação aos aumentos de combustível" e "o valor das corridas é baixo considerando os custos de manutenção que se tem com o veículo. Esse gasto deixará de ser feito, pois os ganhos são baixos. Não fazendo manutenção, todos ficam em risco. A Uber exige que os carros sejam fabricados a partir de determinado ano. Contudo, é muito difícil trocar de veículo com os atuais preços das tarifas"4.

A emergência e a inserção de plataformas digitais em diversas esferas da vida humana nos últimos anos produziram uma espécie de tecnoeuforia na sociedade. Nos primeiros momentos de existência dessas infraestruturas, sobressaíram-se os seus aspectos positivos: a comodidade na solicitação de um serviço, a redução do preço do trabalho e dos serviços, a facilidade na contratação de uma tarefa, a criação de postos de trabalho, a oferta de serviços de maior qualidade, o aumento da velocidade da comunicação, a diversificação das possibilidades de relacionar-se virtualmente. A popularização dos smartphones e a compatibilidade do uso das plataformas nesses aparelhos potencializou a sua disseminação e, conjuntamente, o fascínio das pessoas. O termo mais utilizado para descrever o impacto das plataformas na sociedade é disrupção, que descreve a reorganização profunda em um determinado mercado, em que atores econômicos outrora inexistentes assumem posição predominante, enquanto antigas lideranças entram em declínio ${ }^{5}$.

Ao longo do tempo, passou-se a constatar outros efeitos ocasionados pelas plataformas, que estavam distantes de serem positivos: aumento do tráfego de veículos e de congestionamento em grandes cidades ${ }^{6}$, encarecimento no preço de aluguéis de imóveis ${ }^{7}$, vazamento de dados pessoais para a manipulação de processos eleitorais ${ }^{8}$, jornadas de trabalho extensas, remunerações baixas. Esse quadro deu início a debates sobre a necessidade de regular as plataformas em distintas esferas, como urbanismo, moradia, mobilidade urbana, eleições e trabalho, dentre outros.

Esta tese analisa as inter-relações entre tecnologia e trabalho e, a partir do estudo sobre o futuro do trabalho e as inovações tecnológicas, identifica efeitos concretos que estão

\footnotetext{
${ }^{4}$ A pesquisa que realizamos com os motoristas da Uber será apresentada ao longo da tese.

${ }^{5}$ BOWER, Joseph L.; CHRISTENSEN, Clayton M. Disruptive Technologies: Catching the Wave. Harvard Business Review, v. 73, n. 1, p. 43-53, fev. 1995; CHRISTENSEN, Clayton M.; RAYNOR, Michael E.; MCDONALD, Rory. What Is Disruptive Innovation? Dezembro, 2015. Disponível em: <https://hbr.org/2015/12/what-is-disruptive-innovation>. Acesso em: 25 jun. 2017.

${ }^{6}$ SCHALLER CONSULT. The new automobility: Lyft, Uber and the future of American cities, jul. 2018. Disponível em: <http://www.schallerconsult.com/rideservices/automobility.pdf>. Acesso: 20 dez. 2018.

${ }^{7}$ BARRON, Kyle; KUNG, Edward; PROSERPIO, Davide. The sharing economy and housing affordability: Evidence from Airbnb. Abril, 2018. Disponível em: <https://bit.ly/2rKEZhf〉. Acesso em: 20 dez. 2018.

${ }^{8}$ ROSENBERG, Matthew; CONFESSORE, Nicholas; CADWALLADR, Carole. How Trump consultants exploited the Facebook data of millions. The New York Times, New York, 17 mar. 2018. Disponível em: <https://www.nytimes.com/2018/03/17/us/politics/cambridge-analytica-trump-campaign.html>. Acesso em: 25 abr. 2018.
} 
transformando as relações de trabalho, como é o caso do capitalismo de plataforma. Examina duas formas de trabalho, crowdwork e o trabalho sob demanda por meio de aplicativos, para compreender a dinâmica das relações de trabalho no capitalismo de plataforma. Por fim, esta pesquisa analisa o papel do Direito do Trabalho diante das transformações na organização da produção e da prestação de serviços.

Nesta tese, verificamos que as relações de trabalho no capitalismo de plataforma diferem parcialmente do conceito de relação de emprego previsto na legislação trabalhista brasileira. Coexistem uma certa autonomia dos trabalhadores para determinar a carga horária e a jornada de trabalho com uma relação direta entre dependência e precariedade. Os algoritmos ocupam papel de gerenciar a mão de obra, sendo que a intensidade na coordenação e controle dos trabalhadores varia conforme cada plataforma. A acentuada desigualdade econômica entre os trabalhadores e as plataformas e os tomadores de serviços indica a importância da aplicação do Direito do Trabalho nessas relações. Contudo, as características das relações de trabalho no capitalismo de plataforma apontam para a necessidade de uma nova arquitetura jurídica capaz de oferecer respostas às peculiaridades do trabalho sob demanda por meio de aplicativos e do crowdwork. A proposta apresentada nesta pesquisa é a criação de uma legislação especial com três categorias para classificar os trabalhadores: autônomos, dependentes e subordinados.

\section{Justificativa e relevância do tema}

O capitalismo de plataforma é um fenômeno contemporâneo e que está se expandindo rapidamente. $\mathrm{O}$ seu desenvolvimento, que é majoritariamente viabilizado pelas inovações tecnológicas, dá margem ao surgimento de novas atividades, reorganiza a produção e a prestação de serviços. Como consequência, ele atribui novos contornos às relações de trabalho.

Este fenômeno é uma das expressões da forma pela qual a tecnologia e o trabalho interagirão daqui em diante. $\mathrm{O}$ futuro do trabalho e o impacto que novas tecnologias terão para os trabalhadores é um tema que tem atraído muita atenção da opinião pública recentemente. Contudo, ecoa a ideia de um futuro distópico no qual os trabalhadores não terão lugar em qualquer atividade produtiva ${ }^{9}$. A capa da edição de 23 de outubro de 2017 da revista The New Yorker ilustra perfeitamente esse estado de espírito: o cartum Tech Support,

\footnotetext{
${ }^{9}$ MISHEL, Lawrence; BIVENS, Josh. The zombie robot argument lurches on: There is no evidence that automation leads to joblessness or inequality. 24 may 2017. Disponível em: <http://www.epi.org/publication/the-zombie-robot-argument-lurches-on-there-is-no-evidence-thatautomation-leads-to-joblessness-or-inequality/>. Acesso em: 27 fev. 2018.
} 
de R. Kikuo Johnson, retrata uma cena em que robôs caminham em uma rua movimentada, deslocando-se para algum lugar da cidade mexendo em seus aparelhos celulares, segurando os seus cafés, carregando suas pastas e levando os seus cachorros-robô para passear. Ao fundo, um dos robôs lança moedas no copo de um mendigo, o único ser humano na cena, que está sentando no chão junto ao seu cachorro-animal ${ }^{10}$.

O maior problema de o debate sobre o futuro do trabalho ser pautado nesses termos é consolidar a ideia de que a tecnologia é determinista, ou seja, há pouco o que fazer diante de uma força inexorável que impactará a sociedade e não existe muita margem de manobra para ação. Também, a condução do debate nesses termos ofusca os efeitos concretos que as novas tecnologias produzem no mundo do trabalho. Contudo, há estudos nas ciências sociais e na economia que apontam para um futuro do trabalho distinto, em que não se identificam grandes oscilações numéricas, mas o fechamento de postos de trabalho em determinados setores e a abertura em outros. É preciso, então, entender essas novas tecnologias e as transformações no mundo do trabalho.

O capitalismo de plataforma é uma forma de organização da produção e da prestação de serviços com enfoque na economia digital e no uso da tecnologia da informação, dados e internet, além das plataformas como infraestruturas que viabilizam negócios. Em relação ao seu tamanho, dados mais abrangentes sobre a sua extensão ainda são incipientes, mas é possível obter informações sobre a sua dimensão em alguns mercados. De acordo com pesquisa realizada pelo Pew Research Center, $8 \%$ dos norte-americanos obtiveram renda por meio da realização de trabalho em plataformas digitais em 2016. Dentre esses 8\%, mais da metade $(56 \%)$ afirmou que a remuneração é essencial ou importante para sua subsistência ${ }^{11}$.

No Brasil, a Uber, que oferece serviços de transporte de passageiros, ilustra as mudanças que a tecnologia traz a um setor. A expansão no número de motoristas e usuários ocorreu de forma exponencial na empresa que iniciou as suas atividades no país em 2014, mas que em setembro de 2015 já contava com 5 mil motoristas e 500 mil clientes inscritos na plataforma. Em outubro de 2016, a Uber contava com 50 mil trabalhadores e 4 milhões de usuários, ou seja, cresceu 10 vezes em relação aos primeiros e 8 vezes quanto aos

10 THE NEW YORKER. R. Kikuo Johnson's “Tech Support”. 23 out. 2017. Disponível em: <https://www.newyorker.com/culture/cover-story/cover-story-2017-10-23>. Acesso em: 12 nov. 2017.

${ }^{11} \mathrm{PEW}$ RESEARCH CENTER. Gig work, online selling and home sharing. 17 nov. 2016. Disponível em: <http://www.pewinternet.org/wp-content/uploads/sites/9/2016/11/PI_2016.11.17_Gig-

Workers_FINAL.pdf >. Acesso em: 20 set. 2017. 
segundos ${ }^{12}$. Em abril de 2018, a plataforma atingiu o número de 500 mil motoristas e 20 milhões de clientes, um aumento em 10 e 2,5 vezes, respectivamente, em apenas um ano e meio $^{13}$.

A Amazon Mechanical Turk não divulga os dados sobre o número de trabalhadores brasileiros e de usuários inscritos na plataforma.

Uma característica marcante do trabalho sob demanda por meio de aplicativos e do crowdwork e, consequentemente, da Uber e da Amazon Mechanical Turk, é a invisibilidade dos trabalhadores. A classificação como autônomos e a difusão da noção de liberdade no trabalho esvazia o conteúdo laboral da atividade que os trabalhadores desempenham. No caso da MTurk, isso é potencializado pelo fato de não haver contato entre o trabalhador e o tomador de serviços, dado que a relação entre ambos é totalmente online e intermediada pela plataforma. A invisibilidade das atividades nas plataformas encobre questões importantes, como as condições de trabalho.

Há forte assimetria de poderes entre os trabalhadores e as plataformas, em que parte considerável das condições de trabalho é determinada por essas. A coordenação e o controle da força de trabalho são feitos por algoritmos, existe espaço para que os trabalhadores decidam alguns aspectos das atividades que desempenham e quanto maior a dependência do trabalhador em face de uma plataforma, maior a precariedade das condições de trabalho.

A reação do Direito do Trabalho a esse cenário, em especial no Brasil, ainda apresenta grandes dissonâncias. A Uber, por ser a maior plataforma no país, monopolizou os debates até o momento. A grande maioria das análises feitas enfoca a classificação dos trabalhadores e debate se há relação de emprego ou trabalho por conta própria.

No Poder Judiciário Trabalhista, há decisões que reconhecem o vínculo entre o motorista e a plataforma e outras que identificam um trabalho autônomo. O Ministério Público do Trabalho divulgou estudo apresentando entendimento acerca da possibilidade de aplicar o Direito do Trabalho aos trabalhadores em plataformas. A Auditoria-fiscal do Trabalho aplicou multas nas plataformas Loggi e Rappido, que oferecem serviços de motoentrega por meio de aplicativos, em razão de não registrarem o contrato de trabalho dos motoqueiros ${ }^{14}$.

\footnotetext{
${ }^{12}$ DIÓGENES, Juliana. Uber cresce 10 vezes e já tem 50 mil motoristas. O Estado de São Paulo, São Paulo, 18 out. 2016. Disponível em: < https://sao-paulo.estadao.com.br/noticias/geral,uber-cresce-10-vezes-e-jatem-50-mil-motoristas,10000082769>. Acesso: 30 set. 2017.

${ }^{13}$ UBER. Fatos e dados sobre a Uber. Disponível em: <https://www.uber.com/pt-BR/newsroom/fatos-e-dadossobre-uber/>. Acesso em 23 jun. 2018.

${ }^{14}$ MINISTÉRIO DO TRABALHO. Ministério do Trabalho autua empresa que usa aplicativo para oferecer serviços de motoboys. Disponível em: <http://trabalho.gov.br/noticias/5338-ministerio-do-trabalho-autua-
} 
O debate trabalhista brasileiro enfrenta dois grandes problemas em relação a essa matéria. O primeiro é a busca, por parte da doutrina e da jurisprudência, pela figura do preposto, gerente, encarregado ou qualquer pessoa que seja responsável por dar ordens aos trabalhadores para identificar a subordinação. Procurar pela pessoa que fica na empresa coordenando pessoal e diretamente a atividade dos trabalhadores para, a partir daí, reconhecer o vínculo empregatício, é condenar o Direito do Trabalho à tutelar somente o trabalhador fabril dos séculos XIX e XX. As técnicas de gestão de mão de obra evoluíram nas últimas décadas e, sem levar em consideração o papel da programação e do algoritmo nas plataformas, não é possível entender as dinâmicas das relações de trabalho nesse modelo.

Por outro lado, a defesa irrestrita da legislação trabalhista vigente para dar respostas a uma realidade que, se não é completamente nova, apresenta características inéditas, também desconsidera as transformações na organização da produção e da prestação de serviços. A insistência em aplicar as regras vigentes, sem a promoção de um debate sobre os aspectos da lei que podem ser aperfeiçoados, pode não atender às demandas dos trabalhadores e esfacelar o conceito de relação de emprego previsto na CLT.

\section{Delimitação do tema}

O estudo do impacto das inovações tecnológicas na organização da produção e no mundo do trabalho envolve uma variedade de possibilidades, desde a abordagem de efeitos projetados sobre o que virá a ser o futuro do trabalho, como as capacidades que os trabalhadores deverão ter, até a forma pela qual deve ocorrer a interação entre o Direito e as novas formas de trabalho. Diante disso, decidimos examinar o capitalismo de plataforma, suas duas formas de trabalho - o crowdwork e o trabalho sob demanda por meio de aplicativos - e o papel do Direito do Trabalho em face desse cenário.

No primeiro capítulo, apresentamos revisão de literatura sobre as inter-relações entre tecnologia, instituições e ideologia. Enfocamos o posicionamento da tecnologia nas dimensões econômica, política e social e, consequentemente, a sua relação com o mundo do trabalho. Adotamos a economia política multidimensional desenvolvida por Yochai Benkler ${ }^{15}$ porque não trata a tecnologia como um elemento neutro ou isolado do sistema

empresa-que-usa-aplicativo-para-oferecer-servico-de-motoboys>. Acesso em: 22 dez. 2018; PORTINARI, Natalia. Grupo do iFood é multado em R \$ 1 mi por desrespeito às leis trabalhistas. Folha de São Paulo, São Paulo, 07 jun. 2018. Disponível em: <https://www1.folha.uol.com.br/mercado/2018/06/grupo-do-ifood-emultado-em-r-1-mi-por-desrespeito-as-leis-trabalhistas.shtml>. Acesso em: 22 dez. 2018.

${ }^{15}$ BENKLER, Yochai. A political economy of oligarchy: Winner-takes-all ideology, superstar norms, and the rise of the $1 \%$. Sept. 2017. Disponível em: <http://www.benkler.org /Political\%20economy\%20of\%20oligarchy\%2001.pdf>. Acesso em: 10 nov. 2017. 
socioeconômico, mas influenciando e sendo influenciada pelas mencionadas dimensões que conformam a nossa vida. Inclusive, o trabalho, suas condições e sua regulação.

Em seguida, apresentamos revisão de literatura sobre o futuro do trabalho e novas tecnologias. Há perspectivas distintas sobre o tema, por exemplo, as que preveem um futuro sem empregos e as que minimizam o impacto no número de postos de trabalho. Em seguida, tratamos dos efeitos concretos das inovações tecnológicas na organização da produção e da prestação de serviços e examinamos o capitalismo de plataforma, sendo que adotamos o conceito - dentre a grande diversidade de nomenclaturas identificadas para analisar da emergência das plataformas - em razão de situá-las no centro do debate e por ressaltar que essas mudanças ocorrem de maneira integrada ao modo de produção dominante em nossa sociedade.

No segundo capítulo aprofundamos a análise sobre os elementos constitutivos do capitalismo de plataforma, em especial em relação às formas de trabalho. A partir da classificação das formas de trabalho realizada por Valerio de Stefano ${ }^{16}$, tratamos do trabalho sob demanda por meio de aplicativos, em que há combinação de oferta e demanda de mão de obra por meio da internet e a execução das atividades ocorre presencialmente, e do crowdwork, em que a plataforma é o espaço da procura pela força de trabalho e da realização das tarefas contratadas.

Para compreender as características e o funcionamento das relações de trabalho no capitalismo de plataforma, examinamos as dinâmicas de trabalho e o modo de operação, as condições de trabalho, o gerenciamento algorítmico e as associações entre dependência e precariedade em cada uma das formas de trabalho.

A revisão de literatura é insuficiente para termos um bom panorama sobre a dinâmica dessas relações de trabalho, em razão da pouca quantidade de dados disponíveis, das poucas informações sobre determinados aspectos do trabalho e da escassez de pesquisas que tratam do tema.

Para aprofundar o estudo e entender mais pormenorizadamente a dinâmica de trabalho nas plataformas digitais, desenvolvemos dois estudos de caso. Trata-se de uma maneira de identificar as motivações na busca por essas atividades, as percepções dos trabalhadores em sua interação com a plataforma, a dimensão da segurança econômica que os ganhos proporcionam e o conteúdo da liberdade em estabelecer os seus horários de trabalho.

\footnotetext{
${ }^{16}$ DE STEFANO, Valerio. The rise of the "just-in-time workforce": on-demand work, crowdwork, and labor protection in the "gig-economy". Comparative Labor Law \& Policy Journal, v. 37, n. 3, p. 471-504, 2016.
} 
Decidimos realizar o estudo de caso da Uber em relação ao trabalho sob demanda por meio de aplicativos por diversas razões. É uma das plataformas mais proeminentes do mundo que utiliza essa forma de trabalho, tanto que passou a ser a referência desse modelo de negócios - uma série de outras plataformas adotam o seu modo de funcionamento e há estudiosos que criaram o neologismo "uberização" para descrever essa forma de organizar a prestação de serviços. É também a plataforma que tem o maior número de trabalhadores no Brasil, com crescimento exponencial a cada ano de atividade no país.

Em relação ao crowdwork, escolhemos em desenvolver o estudo de caso da Amazon Mechanical Turk por algumas razões. É uma das plataformas que foi pioneira em utilizar essa forma de trabalho, é uma das referências no mundo para o crowdwork, estabeleceu uma dinâmica de trabalho que posteriormente foi adotada por outras plataformas, tem uma grande quantidade de trabalhadores cadastrados (aproximadamente 500 mil) e permite a combinação de oferta e demanda da força de trabalho conforme a geolocalização do trabalhador, o que foi fundamental para nós identificarmos brasileiros registrados na MTurk dispostos a responderem o nosso questionário.

No terceiro capítulo, examinamos o instrumental do Direito do Trabalho para dar respostas em face do cenário apresentado nos capítulos anteriores. O objeto de análise está centrado no Direito Individual do Trabalho. Portanto, em um primeiro momento verificamos a compatibilidade entre as categorias jurídicas previstas no ordenamento jurídico - o trabalho subordinado e o trabalho autônomo - e as dinâmicas de trabalho nessas plataformas. Concluímos que, em vista do desenvolvido nos capítulos anteriores, as categorias jurídicas revelam-se insuficientes, uma vez que não levam em consideração características marcantes, como as relações entre dependência e precariedade e as peculiaridades em relação à transparência, sistema de avaliações, sistema de remuneração e de tempo de trabalho.

Por isso, investigamos propostas para regular o trabalho no capitalismo de plataforma que vão além da dicotomia existente no ordenamento jurídico brasileiro e tratamos da criação de novos direitos para os trabalhadores, sempre buscando lastro nos dados e nas manifestações colhidas nos estudos de caso. Ainda que não seja objeto desta tese, abordamos a organização e a atuação coletiva dos trabalhadores, como uma possível agenda de pesquisa a ser considerada no futuro. Finalmente, desenvolvemos a nossa proposta para regular o trabalho sob demanda por meio de aplicativos e o crowdwork.

Ao apresentarmos uma proposta para regular o trabalho sob demanda por meio de aplicativos e o crowdwork, desenvolvemos um modelo que não está previsto no ordenamento jurídico brasileiro. Ou seja, apesar de o estudo conter elementos importantes 
para o cotidiano dos atores que operam no Poder Judiciário, o destinatário principal deste trabalho são aqueles responsáveis pelo desenho inicial da proteção social no Brasil: o Poder Legislativo e os formuladores de políticas públicas, além da academia. A combinação de metodologias utilizada nessa tese e a classificação proposta oferecem instrumentos para uma estruturação de política de proteção social ${ }^{17}$.

\section{Metodologia}

A perspectiva adotada nessa pesquisa é interdisciplinar, em que trazemos instrumentos das ciências sociais para apoiar este estudo jurídico. As análises exclusivamente teóricas sobre o Direito do Trabalho têm o valor de auxiliar no avanço da doutrina, jurisprudência e legislação. Contudo, nesta pesquisa optamos por aproximar o fato social - no caso, o trabalho nas plataformas digitais - da teoria. Assim, é possível aprofundar a compreensão sobre as formas de trabalho no capitalismo de plataforma, permitindo-nos analisar o papel e as possibilidades do Direito do Trabalho no crowdwork e no trabalho sob demanda por meio de aplicativos.

No primeiro capítulo, introduzimos a economia política multidimensional, nos termos colocados por Yochai Benkler, e utilizamos seus conceitos no intuito de desenvolver o nosso entendimento sobre as interações entre tecnologia e trabalho. Nesta parte, empregamos o método analítico-descritivo para abordar como são as inter-relações entre tecnologia, instituições e ideologia e o que é o capitalismo de plataforma. A revisão da literatura partiu da obra de Yochai Benkler a respeito da matéria e de pesquisas realizadas nos sistemas Dedalus, da Universidade de São Paulo, e Hollis, da Universidade de Harvard, sobre os seguintes termos: "futuro do trabalho" e "empregos", "future of work" e "jobs", “capitalismo de plataforma", "platform capitalism", "economia de bico", "gig economy", "sharing economy", "economia de compartilhamento".

No segundo capítulo, tratamos das formas de trabalho no capitalismo de plataforma a partir da classificação realizada por Valerio de Stefano: trabalho sob demanda por meio de aplicativos e crowdwork. Nesta parte, adotamos o método analítico-descritivo, em que apontamos como é o trabalho nas plataformas digitais.

Abordamos o tema de duas formas. A primeira foi a revisão da literatura sobre o tema em pesquisas nos sistemas Dedalus e Hollis buscando os seguintes termos: "trabalho sob

\footnotetext{
${ }^{17}$ Para entender o papel que os juristas podem desempenhar na elaboração e execução de políticas públicas, ver Diogo Coutinho (COUTINHO, Diogo. O direito nas políticas públicas. In: MARQUES, Eduardo; FARIA, Carlos Aurélio Pimenta de (Orgs.). A política pública como campo multidisciplinar. São Paulo: Editora Unesp, 2013, p. 181-200).
} 
demanda por meio de aplicativos", “on-demand work via apps", "crowdwork", "trabalho" e "plataforma", "work" e "platform".

A segunda foi o estudo de caso sobre o trabalho na Uber e na Amazon Mechanical Turk. Inicialmente, fizemos revisão de literatura, a partir de procura, nos referidos sistemas, dos termos "Uber" e "trabalho", "Uber" e "work", "Amazon Mechanical Turk" e "trabalho", “Amazon Mechanical Turk" e "work". Em seguida, desenvolvemos a parte empírica da pesquisa, elaborando questionários e os aplicando em trabalhadores da Uber e da Amazon Mechanical Turk, com o objetivo de apreender as dinâmicas de trabalho nessas plataformas no Brasil e identificar a relação entre precariedade e dependência.

No terceiro capítulo, analisamos a maneira pela qual o Direito do Trabalho intervém no capitalismo de plataforma. Nesta parte, adotamos os métodos analítico-descritivo, em que abordamos a compatibilidade do ordenamento jurídico e as novas formas de trabalho, e normativo, em que tratamos de como pode ser a aplicação do Direito do Trabalho nessa seara e o que entendemos que deve ser o papel desse ramo jurídico no tema. Primeiramente, fizemos uma revisão de literatura, a partir de busca nos sistemas Dedalus e Hollis e na Biblioteca Digital da LTr procurando os termos: "trabalho sob demanda por meio de aplicativos" e "direito do trabalho", "on-demand work via apps" e "employment law", "trabalho sob demanda por meio de aplicativos" e "direito coletivo do trabalho", "ondemand work via apps" e "labor law", "crowdwork" e "direito do trabalho", "crowdwork" e "employment law", "crowdwork" e "direito coletivo do trabalho", "crowdwork" e "labor law", "Uber" e "direito do trabalho", "Uber" e employment law", "Uber" e "direito coletivo do trabalho", "Uber" e "labor law", "Amazon Mechanical Turk" e "direito do trabalho", “Amazon Mechanical Turk" e "employment law", “Amazon Mechanical Turk" e "direito coletivo do trabalho", “Amazon Mechanical Turk" e "labor law". No tocante à jurisprudência, partimos de levantamento prévio realizado em outra pesquisa sobre as reclamações trabalhistas em relação à Uber existentes no país e fizemos pesquisas nos Tribunais Regionais do Trabalho que emitem online a certidão eletrônica de ações trabalhistas para verificar o ajuizamento de reclamações em face da Amazon Mechanical Turk.

A seguir, analisaremos mais detidamente a metodologia adotada para o estudo de caso em cada uma das plataformas na parte empírica. 


\subsection{Amazon Mechanical Turk}

Inicialmente, foi realizada revisão da literatura sobre a AMT, como mencionado, e se identificaram pesquisas com trabalhadores que atuam na plataforma. Dentre as analisadas, a conduzida pela Organização Internacional do Trabalho entre novembro e dezembro de 2015 com norte-americanos e indianos foi a mais abrangente, tratando de 5 grandes temas que conformavam as relações de trabalho na plataforma ${ }^{18}$. Diante disso, decidimos utilizar a referida pesquisa como parâmetro, o que nos permitiu abarcar aspectos importantes da relação de trabalho e colocar a situação dos trabalhadores brasileiros em perspectiva com a dos norte-americanos e dos indianos.

Em fevereiro de 2018, trocamos correspondência eletrônica com Janine Berg, economista da Organização Internacional do Trabalho (OIT) e autora do artigo Income security in the on-demand economy: Findings and policy lessons from a survey of crowdworkers, ${ }^{19}$ que discute os resultados da mencionada pesquisa da OIT. Janine Berg demonstrou interesse na aplicação do questionário em trabalhadores brasileiros e nos enviou maiores informações sobre a pesquisa.

O meio factível de encontrar os trabalhadores que atuam na MTurk é pela própria plataforma, uma vez que são identificados somente por combinação de letras e números que não permite que qualquer um, com exceção da própria AMT, saiba os dados de quem executa as atividades. Desta forma, levando em conta que a MTurk não disponibiliza as informações dos trabalhadores, há necessidade de inserir o questionário como uma tarefa a ser realizada na plataforma, como as pesquisas que analisamos, dentre elas a da OIT, fizeram. Ou seja, há necessidade de pagar o trabalhador para responder o questionário.

Diante disso, em março de 2018, apresentamos um requerimento para a Comissão de Pós-Graduação, acompanhado de parecer circunstanciado elaborado pelo orientador, Professor Otavio Pinto e Silva, solicitando a aprovação ética da realização da pesquisa nesses moldes. Em maio de 2018, fomos informados que em abril o Professor José Eduardo Faria, Presidente da Comissão de Ética da Faculdade de Direito, aprovou o pedido.

No mês de maio, exploramos detidamente a plataforma, para compreender o mecanismo de oferta de tarefas e a dinâmica com os trabalhadores, com o objetivo de evitar contratempos no período em que os questionários estivessem disponíveis para serem respondidos, como a falta de geração de código ao final da pesquisa, que permite analisar se

${ }^{18}$ INTERNATIONAL LABOUR ORGANIZATION. Understanding crowdwork: a survey of crowdworkers. Geneva: ILO, 2015.

${ }^{19}$ BERG, Janine. Income Security in the On-Demand Economy: Findings and Policy Lessons from a Survey of Crowdworkers. Comparative Labor Law \& Policy Journal, v. 37, p. 543-576, 2016 
o questionário foi respondido e, consequentemente, pagar o trabalhador. Além disso, desenvolvemos o questionário, a partir da pesquisa realizada pela OIT e de reflexões com o Professor Otavio Pinto e Silva, traduzindo-o e fazendo adaptações. O questionário foi dividido em 5 blocos e as questões traziam alternativas em que os trabalhadores deveriam optar por uma (ou algumas, dependendo da pergunta) ao respondê-las.

No primeiro, colocamos 7 questões principais ${ }^{20}$ sobre temas sociodemográficos, como os estados em que viviam, ano de nascimento, sexo biológico, estado civil e grau de instrução, para obtenção de dados sobre o contexto social em que os participantes da pesquisa estavam inseridos e sobre o perfil pessoal dos trabalhadores.

No segundo, inserimos 21 questões principais sobre as condições de trabalho, como o crowdwork ser a principal atividade profissional, a frequência com que trabalham, a satisfação com a atividade, o valor da remuneração média e os motivos de terem procurado a plataforma, para compreender a dinâmica entre os trabalhadores, as plataformas e os tomadores de serviços, a centralidade do crowdwork na vida dos trabalhadores e as características mais importantes da relação de trabalho.

No terceiro, apresentamos 2 questões principais a respeito de outros trabalhos que os participantes da pesquisa tinham, como suas características, remuneração, carga horária e importância no orçamento doméstico, para analisar as demais atividades desenvolvidas pelos trabalhadores e como se relacionavam com o crowdwork.

No quarto, colocamos 2 questões principais sobre a situação profissional prévia dos trabalhadores, como as atividades que realizavam antes de iniciar o crowdwork, as razões para o término do trabalho, as características da prestação de serviço, os ganhos e o tempo em que trabalharam nessa atividade, para identificar as circunstâncias que levaram os trabalhadores a procurarem a MTurk.

No quinto, inserimos 13 perguntas principais sobre a situação socioeconômica, como o valor total do orçamento familiar, a centralidade dos ganhos obtidos pelo participante para a subsistência da família, a suficiência da remuneração e o acesso à previdência social e saúde, para conhecer de uma forma global a renda do trabalhador e de sua família.

Finalmente, foi apresentada uma pergunta acerca de mudanças que os trabalhadores gostariam que fossem implementadas no crowdwork e uma outra sobre considerações que os participantes quisessem nos apresentar. Ambas demandavam o oferecimento da resposta de forma escrita.

\footnotetext{
${ }^{20}$ Dependendo da resposta na questão principal, é possível que uma outra questão, relacionada com aquela, seja apresentada ao participante.
} 
Além disso, inserimos 5 perguntas-teste simples em cada um dos blocos mencionados para verificar a atenção dos trabalhadores. Foram as questões 1.8, 2.19, 3.3, 4.3 e 5.14. Os trabalhadores que erraram ao menos uma dessas respostas foram considerados como desatentos e não se levou em conta o seu questionário para efeitos do resultado total.

Como mencionamos, não há uma base de dados universal dos trabalhadores que atuam na AMT para que fosse possível estabelecer uma amostragem prévia. Em razão disso, ao inserirmos o questionário como tarefa a ser executada na plataforma - o que também foi feito pela OIT -, estabelecemos como único critério o trabalhador estar localizado no Brasil. Não foram colocados outros critérios, como número mínimo de tarefas realizadas, para se ter acesso ao maior número possível de trabalhadores brasileiros. Considerando que a imensa maioria de trabalhadores vive nos EUA ou na Índia, indicar um outro critério além da localização poderia restringir em demasia o número de participantes.

Antes de o trabalhador começar a responder as perguntas do questionário, foi inserida uma página inicial contendo o termo de consentimento de participação, expondo os dados do pesquisador responsável, o objeto, justificativa e procedimento da pesquisa, a inexistência de desconfortos, riscos e despesas para os participantes, os benefícios do estudo, a participação voluntária e o compromisso de assegurar o sigilo e a privacidade do trabalhador e colocou-se um e-mail para contato. Ao clicar para iniciar o questionário, o trabalhador expressava a sua concordância com o referido termo.

A pesquisa ficou no ar entre 01 e 25 de junho de 2018 e foi realizada por 56 trabalhadores. Os questionários de 4 trabalhadores não foram contabilizados em razão de terem errado ao menos uma das perguntas-teste. O tempo médio de resposta dos 52 trabalhadores foi de 18 minutos e 49 segundos. Os trabalhadores receberam US\$ 4 para responder ao questionário, o mesmo valor pago pela OIT em 2015. Não houve contratempos nos dias em que a pesquisa estava aberta para receber respostas.

Em todo o período em que a pesquisa esteve disponível para ser executada na plataforma, observamos as diretrizes para solicitantes acadêmicos criadas pelo Projeto We are Dynamo, em que se estabelecem regras para ser um bom solicitante, como descrever claramente a tarefa que deve ser executada, apresentar informações sobre a pesquisa que está sendo realizada, indicar um tempo razoável para o desenvolvimento do trabalho, aprovar a atividade com a maior brevidade possível, manter a privacidade do trabalhador, mencionar 
de forma transparente o que motiva a rejeição de uma tarefa e oferecer o pagamento de, ao menos, o valor do salário mínimo hora ${ }^{21}$.

O resultado completo da pesquisa com os trabalhadores brasileiros da Amazon Mechanical Turk está no apêndice A desta tese.

\subsection{Uber}

Primeiramente, foi realizada revisão da literatura sobre a Uber, como mencionado, e se identificaram pesquisas com trabalhadores que atuam na plataforma. Em algumas delas, verificou -se a aplicação de questionário e a condução de entrevistas com seus os motoristas. Dentre elas, interessou-nos o artigo Dependence and precarity in the platform economy, escrito por Juliet Schor, Will Attwood-Charles, Mehmet Cansoy, Isak Ladegaard e Robert Wengronowitz $^{22}$, em que se analisou dados de entrevistas feitas com trabalhadores de diversas plataformas, pela relação que se identificou entre dependência e precariedade dos motoristas da Uber.

Em um momento inicial, consideramos em adotar a referida pesquisa como padrão. Trocamos correspondências eletrônicas com a Professora Juliet Schor, da Boston College, que se mostrou receptiva em compartilhar informações e experiências sobre a pesquisa. Em março de 2018, reunimo-nos com a Professora em Boston e discutimos os méritos, as limitações e as dificuldades com aquelas entrevistas.

Levando em conta a conversa com a Professora Juliet Schor e a importância em ter elementos que permitissem uma análise com indicadores semelhantes entre a Uber e a AMT, decidimos elaborar um questionário que se aproximasse daquele da Mechanical Turk e tivessem elementos da pesquisa conduzida pela Professora Juliet Schor. No mês de julho de 2018, desenvolvemos o questionário, em constante diálogo com o Professor Otavio Pinto e Silva, e também o dividimos em 5 blocos. As respostas dos trabalhadores eram oferecidas conforme alternativas previamente apresentadas.

\footnotetext{
21 WE ARE DYNAMO. Guidelines for academic requesters. Disponível em: <http://guidelines.wearedynamo.org>. Acesso em: 02 fev 2018.

22 SCHOR, Juliet; ATTWOOD-CHARLES, William; CANSOY, Mehmet; LADEGAARD, Isak; WENGRONOWITZ, Robert. Dependence and precarity in the platform economy. Feb. 2017. Disponível em:

<http://www.bc.edu/content/dam/files/schools/cas_sites/sociology/pdf/Dependence\%20and\%20Precarity\% 20Feb\%202017.pdf>. Acesso em: 13 dez. 2017, p. 1-40.
} 
No primeiro, colocamos 6 questões principais ${ }^{23}$ sobre aspectos sociodemográficos, como cidade em que moravam, ano de nascimento, estado civil e grau de instrução, para compreender o perfil pessoal dos participantes e o contexto social em que estavam inseridos.

No segundo, apresentamos 29 questões principais sobre as condições de trabalho, como há quanto tempo dirigiam na plataforma, a centralidade da atividade em sua vida profissional, a opinião sobre o sistema de avaliações, o valor da remuneração e a carga horária, para entender a dinâmica de trabalho entre o motorista, a plataforma e os clientes da Uber e as principais notas distintivas da atividade.

No terceiro, inserimos 2 perguntas principais sobre as demais atividades que os motoristas realizavam além de dirigir para a Uber, como se houve procura por uma outra ocupação e se possuía um segundo trabalho, para analisar a relação das tarefas desenvolvidas na Uber com outras que eventualmente tivessem.

No quarto, colocamos 2 perguntas principais sobre as experiências profissionais prévias, como a tarefa que realizava antes de começar na Uber e se o vínculo foi rompido para iniciar na plataforma, no intuito de apreender os motivos que levaram os trabalhadores a procurar o trabalho sob demanda por meio de aplicativos.

No quinto, apresentamos 11 questões principais sobre a situação socioeconômica do motorista, como a comparação com o quadro de um ano atrás, o valor total da renda familiar, a suficiência das remunerações para a subsistência mensal e a participação de outras pessoas no orçamento familiar, para compreender a segurança econômica do trabalhador e de sua família.

Por fim, elaboramos uma pergunta sobre os aspectos do trabalho na Uber que os motoristas mudariam e uma outra sobre comentários que o participante poderia fazer a respeito da pesquisa e do trabalho sob demanda por meio de aplicativos. Nessas duas não havia alternativas pré-estabelecidas.

Não existe uma base de dados pública dos motoristas que trabalham para a Uber. Sendo assim, optamos por abordar os motoristas para responderem ao questionário em viagens que fizemos com a Uber na cidade de São Paulo. A pesquisa conduzida pela Professora Juliet Schor adotou o mesmo método para se aproximar dos motoristas em Boston. Cogitamos ir ao espaço destinado aos trabalhadores da plataforma que aguardam chamada no Aeroporto Internacional de Guarulhos. Entretanto, as diversas restrições impostas pela

\footnotetext{
${ }^{23}$ Dependendo da resposta na questão principal, é possível que uma outra questão, relacionada com aquela, seja apresentada ao participante.
} 
Uber para acessar o local $^{24}$ e o relato feito por participantes da pesquisa sobre o rígido controle de entrada fizeram-nos desistir dessa forma de contato.

Criamos uma versão online do questionário para facilitar a compilação dos dados e a condução da pesquisa com os motoristas. Nos momentos em que precisávamos nos deslocar pela cidade, fazíamos um pedido de viagem pelo aplicativo e, ao ingressar no veículo, apresentávamo-nos, explicávamos do que se tratava a pesquisa e o termo de consentimento de participação. Em alguns casos, os motoristas pediram para que fosse lido na íntegra, o que foi realizado. Assim que o motorista concordava em participar da pesquisa, dávamos início ao questionário. No término da viagem, o participante lia o termo e o assinava, sendo-lhe fornecida uma cópia do documento. Antes do início da viagem, também avisávamos que atribuiríamos a nota máxima ao final da viagem independentemente da concordância em responder o questionário, para que a participação na pesquisa não fosse influenciada pela avaliação feita pelo passageiro ao término da corrida.

Em 11 casos, os motoristas não concordaram em participar da pesquisa, apesar da explicação do seu objeto e do conteúdo do termo de consentimento de participação. A maioria das negativas deu-se por receios de a privacidade não ser resguardada - mesmo isso sendo assegurado por nós -, a plataforma ter conhecimento de posicionamentos dos motoristas e ocorrer alguma espécie de represália. Nos casos em que houve a negativa em participar, seguimos viagem normalmente até o destino final e nenhuma informação foi coletada para essa pesquisa.

Os questionários foram aplicados entre 17 de agosto a 04 de outubro de 2018 e contou com a participação de 102 trabalhadores. O tempo médio de resposta foi de 31 minutos e 12 segundos. Não houve contratempos no período em que realizamos a pesquisa.

O resultado completo da pesquisa com os motoristas da Uber em São Paulo está no apêndice $\mathrm{B}$ desta tese.

\section{Contribuição original à ciência jurídica brasileira}

A contribuição original à ciência jurídica brasileira dada por esta tese se divide em duas. A primeira é a interdisciplinaridade do estudo desenvolvido nesta pesquisa. Os referenciais teóricos utilizados encontram-se muito pouco explorados pela academia brasileira, especialmente por aqueles que estudam o mundo do trabalho. O trabalho de sistematização e a síntese deste material podem ser utilizados para embasar outras

${ }^{24}$ UBER. Aeroporto de Guarulhos (GRU): Instruções aos motoristas parceiros. Disponível em: <https://www.uber.com/pt-BR/drive/sao-paulo/airports/guarulhos-airport/>. Acesso em: 16 dez. 2018. 
abordagens sobre a relação entre tecnologia e trabalho. Da mesma forma, os estudos de caso, com revisão de literatura e parte empírica, da Uber e da Amazon Mechanical Turk apresenta à ciência jurídica brasileira as dinâmicas de trabalho nessas plataformas em profundidade e detalhe ainda não encontrados, oferecendo maiores subsídios para o estudo jurídico da matéria.

A segunda parte da contribuição oferecida por esta tese é uma nova proposta de regular o trabalho nestas plataformas. Para tanto, é mapeado o ordenamento jurídico brasileiro, seus instrumentos, além do debate sobre alternativas possíveis no Direito do Trabalho. Acreditamos que a proposta - criação de uma legislação especial com três categorias para classificar os trabalhadores: autônomos, dependentes e subordinados, e a atribuição de direitos conforme o enquadramento - se adequa à complexidade que as inovações tecnológicas imprimem às relações de trabalho e, ao mesmo tempo, oferece proteção social àqueles que participam do capitalismo de plataforma. 


\section{CONCLUSÕES}

A tecnologia, o desenvolvimento de técnicas que transformam a organização da produção e a maneira pela qual construímos ordem em nossa sociedade impactam a forma como vivemos. A compreensão do papel da tecnologia nos âmbitos econômico, político e social é decisiva quando se verificam as possibilidades para interferir no mundo e conceber políticas públicas e regulações que produzam resultado alinhado a determinado objetivo.

As inter-relações entre tecnologia, instituições e ideologia, descritas pela economia política multidimensional e adotadas nesta tese, ocorrem mutuamente na definição dos rumos políticos, econômicos e sociais. Sob essa perspectiva, as inovações tecnológicas não são neutras ou imunes às relações de poder instituídas, mas influenciam as instituições e a ideologia, assim como são moduladas por ambas.

A análise do presente momento pela economia política multidimensional aponta para um cenário de peças se movendo. Nesse contexto existem tensões entre o neoliberalismo e o combate às desigualdades, a emergência de novas tecnologias da informação e comunicação e a busca das instituições pelo seu papel. Se o quadro não nos permite indicar com precisão caminhos que serão trilhados, abre-nos a possibilidade de analisarmos a posição que os elementos componentes das referidas dimensões ocuparão.

Nessa conjuntura, uma das matérias que atrai maior atenção, em razão do impacto das novas tecnologias na organização da produção, é o futuro do trabalho. Do ponto de vista qualitativo, há razoável consenso quanto ao fato de que mudanças estão em curso. Não há o mesmo consenso em sua análise. Alguns estudos priorizam o viés da fragmentação e fissuração do trabalho, ao passo que outros enfatizam as novas qualificações necessárias para encontrar ocupações no mercado de trabalho. Da perspectiva quantitativa, existem trabalhos indicando uma queda expressiva do número de empregos, enquanto outros apresentam dados que apontam poucas mudanças substantivas, além de uma terceira vertente sugerir que ocorre um movimento de abertura de postos de trabalho que exigem novas qualificações e de fechamento daqueles não especializados, repetitivos e que não demandam quaisquer aptidões - nela, o saldo final é favorável à geração de empregos.

A adoção de inovações tecnológicas na organização da produção produz impactos diversos no mercado de trabalho, como o uso de plataformas para trocar produtos ou serviços entre pessoas ou pessoas e empresas. Há uma diversidade de denominações utilizadas para retratar esse fenômeno. Adotamos o conceito de capitalismo de plataforma por enfatizar o fato de operar na lógica do modo de produção predominante na sociedade e a centralidade 
das plataformas no desenvolvimento das atividades econômicas. Também, o uso do termo é associado a contraposição à uma narrativa convencional excessivamente acrítica sobre as trocas intermediadas pelas plataformas, ressaltando, dentre outros aspectos, a manutenção das desigualdades econômicas e a precarização do trabalho, bem como a imposição de disponibilidade constante dos trabalhadores.

As principais características do trabalho sob demanda por meio de aplicativos são: (i) as relações de trabalho são triangulares, em que a plataforma ocupa papel importante no desenvolvimento da atividade econômica comercializada; (ii) o algoritmo tem função central no gerenciamento automático das tarefas executadas pelos trabalhadores, sendo que a dimensão do controle é variável entre as plataformas; (iii) os sistemas de avaliações têm atribuições distintas, desde servirem como referência para a contratação de trabalhadores pelos usuários até determinarem as suas permanências na plataforma; (iv) o trabalhador detém certo grau de liberdade para estabelecer os seus horários de trabalho; (v) em geral, há uma relação entre dependência e precariedade, em que quanto maior a primeira, maior a segunda.

A plataforma mais famosa que utiliza o trabalho sob demanda por meio de aplicativos é a Uber, que oferece serviços de transporte. De acordo com a pesquisa realizada com os seus motoristas em São Paulo, o perfil médio do trabalhador é do sexo masculino (96,1\%), casado (47\%), com aproximadamente 40 anos e ensino médio completo $(61,8 \%)$, tendo iniciado as atividades há menos de um ano $(56,9 \%)$ e com intenção de permanecer indefinidamente na plataforma (76,5\%). Os motoristas estão satisfeitos com a Uber em razão de ser a fonte de renda que lhes permite sobreviverem em um contexto em que ou não se encontra outra ocupação $(28,4 \%)$ ou os valores oferecidos no mercado de trabalho são muito baixos $(32,4 \%)$. Os trabalhadores são economicamente dependentes da plataforma $(77,5 \%)$, trabalham mais de 10 horas por dia $(53 \%)$, realizam 19 viagens diárias, recebem entre $\mathrm{R} \$ 20,00$ a $\mathrm{R} \$ 25,00$ por hora e definem a carga horária conforme a meta de ganhos, estabelecida de acordo com suas necessidades de subsistência (55,9\%).

A partir da condução do estudo de caso, pudemos verificar que além das características acima mencionadas, o trabalho ocorre especificamente da seguinte maneira: (i) a plataforma determina o valor e o momento do pagamento; (ii) a combinação do sistema de avaliações, do algoritmo e do acompanhamento das atividades por meio do aplicativo permite um intenso controle das corridas realizadas pelos motoristas e disciplina a mão de obra; (iii) a coordenação das atividades é feita pelo algoritmo; (iv) existe uma série de condutas que os motoristas devem observar, sob pena de serem sancionados em caso de 
descumprimento de parte das recomendações; (v) quanto mais dependentes da Uber para sobreviverem, maior a precariedade das condições de trabalho; (vi) os motoristas determinam os seus horários de trabalho; (vii) a Uber ocupa uma posição de poder diante dos trabalhadores.

No crowdwork, a plataforma é o meio utilizado na execução do trabalho e todas as relações ocorrem virtualmente no quadro da crowdsourcing, uma espécie de terceirização online, por meio de uma chamada aberta, para um grupo indefinido, disperso, global e numeroso de trabalhadores remotos. Muitas das microtarefas se relacionam com o trabalho cultural, em que os trabalhadores classificam e processam elevadas quantidades de dados.

As principais características do crowdwork são: (i) as relações são triangulares, em que a plataforma e os seus clientes definem o conteúdo e o modo de execução da atividade; (ii) o algoritmo e o gerenciamento automático dos clientes das plataformas controlam as tarefas realizadas pelos trabalhadores; (iii) o sistema de avaliações geralmente é utilizado pelos clientes para selecionar os contratados; (iv) a definição da jornada de trabalho fica a critério do trabalhador; (v) existem relações entre dependência e precariedade.

A plataforma mais emblemática que utiliza o crowdwork é a Amazon Mechanical Turk. Segundo a pesquisa realizada com os seus trabalhadores no Brasil, o perfil médio é de homens (73\%), solteiros $(88,4 \%)$, com 30 anos de idade e ensino superior completo $(71,4 \%)$, atuando há 6 meses ou menos $(65,5 \%)$, tendo realizado até 200 tarefas $(65,3 \%)$. A principal motivação é a complementação de renda $(42,4 \%)$. Os trabalhadores têm jornada de até 10 horas semanais $(72,2 \%)$, trabalham 3 dias ou mais por semana $(78,9 \%)$ e recebem até R\$ 100,00 nesse período (76,9\%), valor que é pago por meio de vales que podem ser utilizados no site da Amazon. Os trabalhadores manifestam desejo de executar mais tarefas na plataforma $(94,2 \%)$, mas a baixa remuneração os desestimula $(30,6 \%)$. Outro foco de insatisfação é a falta de pagamento mesmo quando realizadas as tarefas.

A dinâmica do trabalho, além de incluir as acima mencionadas sobre o crowdwork, é a seguinte: (i) o preço da remuneração é fixado pelo cliente; (ii) a ocasião do pagamento é determinada pela plataforma; (iii) a coordenação do trabalho e o poder disciplinar são compartilhados pela plataforma e pelo cliente; (iv) o controle das atividades é realizado pelo cliente, com a possibilidade de não remunerar a tarefa que entender inadequada; (v) quanto mais dependentes da plataforma, menor o grau de segurança econômica; (vi) os trabalhadores têm autonomia para definirem os horários de trabalho; (vii) a MTurk e os clientes ocupam posição de poder diante dos trabalhadores. 
A disseminação da AMT, no Brasil, é bloqueada pelo fato de a grande maioria das tarefas disponíveis na plataforma ser em língua inglesa e pela falta de tomadores de serviço que demandem atividades cujas instruções sejam dadas em português. A baixa remuneração que geralmente é oferecida e o pagamento não ser em espécie somados com o fato de a compreensão do inglês, no Brasil, ser associada a um grau de escolaridade maior acaba por não tornar o trabalho na AMT tão atrativo.

Tanto no trabalho sob demanda por meio de aplicativos como no crowdwork, as plataformas e os algoritmos são centrais para o desenvolvimento da atividade econômica, são viabilizadas pelo uso da tecnologia da informação e comunicação, representam uma das novas fronteiras da fragmentação e fissuração do trabalho, contratam os trabalhadores como autônomos e frequentemente são consideradas como invisíveis.

A invisibilidade das atividades realizadas pelos trabalhadores no capitalismo de plataforma decorre do excessivo destaque dado à tecnologia na consecução das tarefas, do uso de termos que retiram o conteúdo laboral dos serviços executados e do modo de contratação. Trazer esse trabalho à tona é fundamental para assimilar os seus efeitos e debater adequadamente a necessidade de regulá-lo, sob o ponto de vista do Direito do Trabalho.

As diferenças nas projeções sobre o futuro do trabalho mencionadas acima, especialmente sob a ótica quantitativa, decorrem de recortes setoriais e espaciais distintos, entendimentos a respeito do comportamento dos atores sociais e compreensões opostas sobre a repetição de padrões históricos ou a inauguração de novos tempos. Independentemente da perspectiva que se adote, as formas de trabalho no capitalismo de plataforma já apontam para efeitos bem concretos do impacto da tecnologia na organização do trabalho: identificouse a criação de empregos sem qualquer proteção aos trabalhadores, em que as relações de trabalho operam em dinâmica distinta da tradicionalmente concebida, com maior espaço para os trabalhadores determinarem o seu horário de trabalho e nas quais dependência e precariedade caminham lado a lado.

Ou seja, para além das discussões sobre a necessidade de preparar a força de trabalho para um cenário em que as empresas demandarão novas capacidades ou de uma conjuntura na qual não haverá postos de trabalho suficientes para todas as pessoas, entendemos que os efeitos imediatos da tecnologia da informação e comunicação no mercado de trabalho são tangíveis o suficiente para que se coloque o debate sobre a importância de regulação trabalhista do crowdwork e do trabalho sob demanda por meio de aplicativos. Nesse sentido, fica patente como a tecnologia não é neutra, uma vez que são visíveis os seus impactos nas 
dinâmicas de trabalho correntes: as condições de trabalho daqueles que dependem da plataforma são precárias e a forma pela qual os algoritmos e plataformas operam criam uma acentuada assimetria de poderes entre as empresas e os trabalhadores. Contudo, entendemos ser possível pensar em maneiras alternativas de utilizar a tecnologia de forma que existam aspectos positivos para os trabalhadores.

O Direito do Trabalho, enquanto ramo jurídico concebido para responder à desigualdade econômica inerente ao contrato de trabalho, estabelecer regras para mitigar essa assimetria e balanceá-la por meio de proteção jurídica ao trabalhador, é um dos instrumentos que pode regular o trabalho sob demanda por meio de aplicativos e o crowdwork. As condições que motivaram o surgimento do Direito do Trabalho permanecem no capitalismo de plataforma, o que justifica a sua intervenção nesse âmbito para redistribuir renda e poder, promover a dignidade dos trabalhadores, democratizar o trabalho e viabilizar a organização e a atuação coletivas.

As dinâmicas do trabalho no capitalismo de plataforma não apontam a necessidade de transformação da essência, dos paradigmas ou da estrutura do Direito do Trabalho. Entretanto, há espaço para mudar o seu funcionamento, colocando-se em debate a suficiência de seus conceitos, a necessidade de redefinição de categorias, a criação de novas regulações e as perspectivas hermenêuticas, sempre tendo em vista os princípios e funções desse ramo jurídico, assim como o objetivo de proteger o trabalhador que atua nas plataformas.

Como regra geral, a regulação do trabalho, no Brasil, é diretamente relacionada com a classificação dos trabalhadores: o enquadramento como empregado é regido pela Constituição Federal, CLT e leis esparsas, enquanto o autônomo é disciplinado pelo texto constitucional e pelo Código Civil. Como debatido no Capítulo 3, nenhuma das categorias é capaz de dar conta completamente das novas dinâmicas de trabalho no capitalismo de plataforma.

Para ter acesso aos direitos trabalhistas previstos na legislação, é necessário que a relação de trabalho tenha as seguintes características: pessoa natural, pessoalidade, onerosidade, não eventualidade e subordinação. A pesquisa realizada com os motoristas da Uber em São Paulo e a análise dos estudos já feitos sobre a plataforma destacam que a caracterização do vínculo empregatício depende dos casos concretos e da identificação da não eventualidade. Além disso, nas demais plataformas que utilizam o trabalho sob demanda por meio de aplicativos, a depender da intensidade da coordenação e do controle das atividades realizadas pelos trabalhadores, do monitoramento das tarefas e da centralidade do 
sistema de avaliações, é possível que não se verifique o elemento fático-jurídico subordinação.

A pesquisa com os trabalhadores da Amazon Mechanical Turk, no Brasil, e a análise dos estudos desenvolvidos sobre a plataforma apontam que a caracterização da relação de emprego também depende da identificação da não eventualidade e da concepção adotada sobre a subordinação. Em outras plataformas de crowdwork, a maior liberdade para a escolha de tarefas pode mitigar as visões da subordinação objetiva ou estrutural no caso concreto.

A principal consequência do não enquadramento do trabalhador como empregado é a sua classificação como autônomo, deixando-o completamente desprovido de proteção em um cenário no qual, independentemente da constatação dos cinco elementos fático-jurídicos que caracterizam a relação de emprego, encontra-se em posição de desigualdade diante da plataforma. Ou seja, no sistema binário da regulação do trabalho brasileira, a ausência de algum elemento fático-jurídico deixa o trabalhador completamente desamparado.

E mesmo que o trabalhador seja classificado como empregado, há peculiaridades do trabalho sob demanda por meio de aplicativos e do crowdwork não previstos na legislação vigente. As possibilidades dos trabalhadores em determinarem os seus horários de trabalho operam em uma lógica distinta da regulação geral do tempo de trabalho prevista na CLT. Além disso, demandas que surgiram a partir dessas novas formas de trabalho, como a regulação do sistema de avaliações com a portabilidade e o contraditório em casos de discordância de notas atribuídas pelos clientes, ficam sem qualquer amparo do ponto de vista legal.

As insuficiências do modelo de regulação do trabalho no Brasil para o trabalho sob demanda por meio de aplicativos e para o crowdwork - os critérios da relação de emprego que não se adequam plenamente às dinâmicas de trabalho e a falta de previsões para regrar aspectos que surgiram com essas novas formas - acabam por afastar da tutela do Direito do Trabalho os trabalhadores em situação de vulnerabilidade. Ou seja, aqueles em situação de desigualdade econômica em uma relação de trabalho ficam sem proteção jurídica apropriada.

Em face desse cenário, apresentamos uma proposta que protege o trabalhador sem desnaturar o modelo de negócios das plataformas. Entendemos que a intervenção mais adequada do Direito do Trabalho nas formas de trabalho do capitalismo de plataforma analisadas nesta tese é a criação de uma legislação específica em que o trabalhador pode ser classificado em três categorias: autônomo, dependente e subordinado.

Primeiramente, destacamos que há um núcleo de direitos aplicados a todo e qualquer trabalhador que realize atividades em plataformas: liberdade sindical e o reconhecimento 
efetivo da negociação coletiva, a erradicação de todas as formas de discriminação em matéria de emprego e ocupação, a eliminação de todas as formas de trabalho forçado e a abolição efetiva do trabalho infantil - todos considerados como direitos fundamentais do trabalho pela OIT -, além do direito à portabilidade das avaliações entre as plataformas, ao contraditório, à informação ao preço e oferta de trabalho e à transparência quanto à importância das avaliações para a plataforma.

A proposta de incluir os trabalhadores autônomos na regulação e estender a eles os direitos acima mencionados decorre de os direitos fundamentais do trabalho terem abrangência subjetiva ampla, cuja aplicação não está sujeita à identificação do vínculo empregatício. Além disso, a portabilidade, o contraditório, a informação e a transparência são elementos que gravitam em torno do sistema de avaliações, característica das formas de trabalho no capitalismo de plataforma que são determinantes independentemente da classificação do trabalho. Ou seja, caso o trabalhador decida executar atividades em outra modalidade contratual que não a da autonomia, o histórico de avaliações do trabalhador continua a ser relevante em termos profissionais e pode influenciar decisivamente o seu desempenho.

A segunda categoria é o trabalhador dependente. Não se trata de uma figura intermediária entre o autônomo e o subordinado, mas uma outra categoria com características distintas de ambas. Adotamos o entendimento apresentado na proposta coordenada por Emmanuel Dockès, em que o trabalhador se encontra em situação de vulnerabilidade e, para executar as suas tarefas, depende da vontade ou dos meios do tomador de serviços.

Por conta da dependência dos trabalhadores da plataforma, sugerimos, além daqueles direitos indicados no núcleo do trabalho no capitalismo de plataforma, a previsão dos seguintes: (i) escolher como, quando e quanto trabalhar; (ii) salário mínimo (ou piso salarial estabelecido em instrumento coletivo) proporcional à carga horária mensal e um preço dinâmico para o cálculo da remuneração; (iii) o pagamento de salário com periodicidade máxima mensal; (iv) $13^{\circ}$ salário e férias, proporcionais ou integrais, conforme a carga horária; (v) FGTS; (vi) regramento sobre término do contrato e remuneração de salário in natura e utilidade conforme as regras vigentes na CLT; (vii) limitação da jornada de trabalho em 44 horas semanais e 8 diárias, podendo realizar até 2 horas extraordinárias por dia, sendo que o cálculo do tempo de trabalho leva em consideração o período em que o trabalhador desempenhar a atividade; (viii) descanso semanal remunerado; (ix) reembolso dos custos 
necessários para a prestação do trabalho, como combustível e manutenção de veículos para os casos das plataformas de transporte; (x) regras de segurança e saúde no trabalho.

A terceira categoria é a do trabalho subordinado. Nesse caso, mantém-se o conceito de empregado previsto na CLT e aplicam-se todos os direitos estabelecidos no texto consolidado. Além disso, os mencionados direitos pertencentes ao núcleo do trabalho no capitalismo de plataforma estendem-se aos empregados. E, adicionalmente, para os empregadores que decidirem contratar trabalhadores por meio dos contratos intermitentes, propõe-se um preço dinâmico, calculado a partir de um multiplicador sobre o valor do salário-hora da categoria a qual o trabalhador pertence, e o direito a uma carga horária mensal mínima, mensurada a partir da média da jornada dos quatro meses anteriores.

A regulação do trabalho sob demanda por meio de aplicativos e do crowdwork a partir de três categorias - autônomo, dependente e subordinado - é uma proposta de experimentalismo no Direito do Trabalho, em que se pretende dar uma resposta direcionada ao impacto da tecnologia da informação e comunicação no mundo do trabalho. Ademais, considerando que uma das categorias - a dependência - não está prevista no ordenamento jurídico brasileiro, entendemos ser mais adequada a sua inserção de maneira circunscrita em um primeiro momento, o que permite uma análise com maior precisão dos efeitos na prática e, consequentemente, facilita a adoção de medidas corretivas caso haja necessidade.

No tocante às inter-relações previstas na economia política multidimensional, quando analisamos a ideologia e as instituições, entendemos que a proposta se alinha às políticas centradas no combate às desigualdades e, mesmo diante de um cenário de avanço do neoliberalismo hiper-reacionário no Brasil, identificamos que uma sugestão legislativa direcionada tem maiores possibilidades de progredir. Ademais, a sua inserção no debate público pode influenciar nas disputas de ideias na sociedade.

$\mathrm{Na}$ relação entre tecnologia e instituições, a proposta apresentada leva em consideração as peculiaridades do trabalho sob demanda por meio de aplicativos e do crowdwork em razão das inovações tecnológicas e oferece soluções alternativas à regulação tradicional. Da mesma forma, o Direito do Trabalho produz efeitos na organização das plataformas, na medida em que sugere a aplicação de regras laborais para essas formas de trabalho.

A proposta apresentada para regular as formas de trabalho no capitalismo de plataforma se limita ao trabalho sob demanda por meio de aplicativos e ao crowdwork e ao Direito Individual do Trabalho, tratando da classificação dos trabalhadores e de seus direitos sob essa perspectiva. As inovações tecnológicas produzem efeitos significativos nas relações 
de trabalho e estamos em um período histórico em que as mudanças ocorrem de maneira veloz. Novos desenvolvimentos da tecnologia da informação e comunicação podem ensejar a emergência de outras formas de trabalho, o que exigirá um novo exame sobre o seu impacto e a adequação da legislação trabalhista para proteger os trabalhadores. A constatação de sinais robustos em direção de uma das tendências do futuro do trabalho também pode demandar a reavaliação dos instrumentos de tutela do trabalhador. Ainda, novas pesquisas sobre as formas de trabalho estudadas nesta tese podem apontar para a necessidade de regulação de outros aspectos não tratados nesta pesquisa.

A agenda de pesquisa futura para as relações de trabalho no capitalismo de plataforma, sob a perspectiva do Direito do Trabalho, abrange o acompanhamento do impacto de novas tecnologias, o aprofundamento da proposta de regulação apresentada, o estudo de demandas ainda não identificadas e a necessidade de regulá-las e a abordagem dessas relações pelo viés do Direito Coletivo do Trabalho.

O Direito do Trabalho, para continuar a ser um instrumento de redistribuição de poder e renda e de mitigação da desigualdade econômica nas relações de trabalho, deve olhar criticamente as transformações no mundo do trabalho sem se apegar às categorias positivadas no ordenamento jurídico. Nessa tese, buscamos contribuir para a alteração dos rumos das discussões sobre a proteção do trabalho no capitalismo de plataforma, atualmente centrada na possibilidade de classificar os trabalhadores como empregados ou autônomos. A adoção da perspectiva da economia política multidimensional e o desenvolvimento dos estudos de caso nos permitiram identificar características do trabalho sob demanda por meio de aplicativos e do crowdwork até então pouco exploradas no debate brasileiro. Assim, pudemos apresentar um novo modelo de regulação do trabalho para o capitalismo de plataforma, com três categorias - autônomo, dependente e subordinado - e um conjunto de direitos alinhado com o impacto das novas tecnologias. 


\section{BIBLIOGRAFIA}

ABILIO, Luciana Costek. Uberização do trabalho: subsunção real da viração. Passa Palavra. São Paulo, 19 fev. 2017. Disponível em: <http://passapalavra.info/2017/02/110685>. Acesso em: 07 jun. 2017.

ABRAMOVAY, Ricardo. La urgente necesidad de democratizar el internet: mercado, Estado y sociedad civil en la era digital. In: SCANNONE, Juan Carlos (Coord.). Sociedad civil y bien común: Hacia una nueva articulación del mercado, el Estado y a sociedad civil. Córdoba, EDUCC, 2018.

ACEMOGLU, Daron; RESTREPO, Pascual. Robots and Jobs: Evidence from US Labor Markets. Mar. 2017. Disponível em: <http://www.nber.org/papers /w23285>. Acesso em: 04 abr. 2018.

ALOISI, Antonio. Commoditized workers: case study research on labor law issues arising from a set of "on-demand/gig economy" platforms. Comparative labor law and policy journal, v. 37, 2016.

ALOISI, Antonio. Dispatch n. 13 - Italy - With great power comes virtual freedom: A review of the first Italian case holding that (food-delivery) platform workers are not employees. Dezembro, 2018. Disponível em: 〈https://cllpj.law.illinois.edu/dispatches〉. Acesso em: 12 dez. 2018.

ALONI, Erez. Pluralizing the Sharing Economy. Washington Law Review, v. 91, 2016.

AMAZON MECHANICAL TURK. FAQs. Disponível em: <https://www.mturk.com/worker/help>. Acesso em 30 ago. 2018.

AMAZON MECHANICAL TURK. Human intelligence through an API. Disponível em: $<$ https://www.mturk.com>. Acesso em 05 ago. 2018.

AMAZON MECHANICAL TURK. Human intelligence through an API. Disponível em: < https://www.mturk.com/>. Acesso em 20 ago. 2018.

AMAZON MECHANICAL TURK. Overview of Mechanical Turk. Disponível em: $<$ https://docs.aws.amazon.com/AWSMechTurk/latest/RequesterUI/OverviewofMturk.htm >. Acesso em 20 ago. 2018.

AMAZON MECHANICAL TURK. Participation agreement. Disponível em: <https://www.mturk.com/worker/participation-agreement>. Acesso em 20 ago. 2018.

AMAZON MECHANICAL TURK. Pricing. Disponível em: <https://www.mturk.com/pricing>. Acesso em: 29 ago. 2018.

AMAZON MECHANICAL TURK. Worker. Disponível em: <https://www.mturk.com/worker>. Acesso em: 02 nov. 2018. 
ANTUNES, Ricardo. Os sentidos do trabalho: ensaio sobre a afirmação e a negação do trabalho. 1. ed. 9. reimpr. São Paulo: Boitempo, 2007.

ASCHOFF, Nicole. The Smartphone Society. Jacobin, New York, 17 mar. 2015. Disponível em: <http://jacobinmag.com/2015/03/smartphone-usage-technology-aschoff〉. Acesso em: 06 out. 2017.

ATKINSON, Robert D.; WU, John. False alarmism: Technological disruption and the U.S. labor market, 1850-2015. May 2017. Disponível em: <http://www2.itif.org/2017-falsealarmism-technological-disruption.pdf>. Acesso em: 02 dez. 2017.

AUVERGNON, Philippe. Angustias de uberización y retos que plantea el trabajo digital al derecho laboral. Revista Derecho Social y Empresa, n. 6, Dez. 2016.

BABOIN, José Carlos de Carvalho. Trabalhadores sob demanda: o caso "Uber". Revista da $L T r$, v. 81, n. 3, Mar. 2017.

BAILEY, Issac. J. "Identity Politics," Not Trump Voters, Will Save Democrats. Vice, New York, 10 oct. 2017. Disponível em: <https://www.vice.com/en_us/article/43aekn/identitypolitics-not-trump-voters-will-save-democrats $>$. Acesso em: 26 mar. 2018.

BARBAGELATA, Héctor-Hugo. A evolução do pensamento do Direito do Trabalho. Tradução de Sidnei Machado. São Paulo: LTr, 2012.

BARRON, Kyle; KUNG, Edward; PROSERPIO, Davide. The sharing economy and housing affordability: Evidence from Airbnb. Abril, 2018. Disponível em: <https://bit.ly/2rKEZhf>. Acesso em: 20 dez. 2018.

BENJAMIN, Cid. A antipolítica e o risco de uma tempestade. MARINGONI, Gilberto; MEDEIROS, Juliano; RAMOS, Adriana. (Orgs.). Cinco mil dias: o Brasil na era do lulismo. São Paulo, SP: Boitempo Editorial, 2017.

BENKLER, Yochai. A political economy of oligarchy: Winner-takes-all ideology, superstar norms, and the rise of the 1\%. Sept. 2017. Disponível em: <http://www.benkler.org/Political\%20economy\%20of\%20oligarchy\%2001.pdf>. Acesso em: 10 nov. 2017.

BENKLER, Yochai. Network pragmatism: Towards an open social economy. May 2017. Disponível em:

$<\mathrm{http}: / / \mathrm{www} \cdot$ benkler.org /Benkler\%20Network\%20Pragmatism\%20Open\%20Social\%20Economy\%20PASS\%20Pr oceedings\%202017.pdf>. Acesso em: 10 nov. 2017.

BENKLER, Yochai. The realism of cooperativism. In: SCHOLZ, Trebor; SCHNEIDER, Nathan (Eds.). Ours to hack and to own: the rise of platform cooperativism, a new vision for the future of work and a fairer internet. New York: OR Books, 2016.

BENSUSÁN, Graciela; EICHHORST, Werner; RODRÍGUEZ, Juan Manuel. Las transformaciones tecnológicas y sus desafios para el empleo, las relaciones laborales y la identificación de la demanda de cualificaciones. Novembro, 2017. Disponível em: 
<https://repositorio.cepal.org/bitstream/handle/11362/42613/S1700870_es.pdf?sequence=1 \&isAllowed=y>. Acesso em: 09 nov. 2018.

BERG, Janine. Income Security in the On-Demand Economy: Findings and Policy Lessons from a Survey of Crowdworkers. Comparative Labor Law \& Policy Journal, v. 37, 2016.

BÉROUD, Sophie; BOUFFARTIGUE, Paul. Introduction. In: BÉROUD, Sophie; BOUFFARTIGUE, Paul (Dirs.). Quand le travail se précarise, quelles résistances collectives? Paris: La Dispute, 2009.

BOTSMAN, Rachel. The Sharing Economy Lacks A Shared Definition. Fast Company, New York, 21 nov. 2013. Disponível em: <https://www.fastcompany.com/3022028/thesharing-economy-lacks-a-shared-definition>. Acesso em: 03 jun. 2017.

BOWER, Joseph L.; CHRISTENSEN, Clayton M. Disruptive Technologies: Catching the Wave. Harvard Business Review, v. 73, n. 1, p. 43-53, fev. 1995.

BRASIL. Constituição da República Federativa do Brasil de 1988. Disponível em: < http://www.planalto.gov.br/ccivil_03/Constituicao/Constituicao.htm>. Acesso em: $10 \mathrm{fev}$. 2016.

BRASIL. Decreto n. 3.048, de 6 de maio de 1999. Aprova o Regulamento da Previdência Social, e dá outras providências. Diário Oficial da União, Brasília, DF, 7 maio 1999. Disponível em: <http://www.planalto.gov.br/ccivil_03/decreto/D3048.htm>. Acesso em: 20 out. 2018.

BRASIL. Decreto-Lei n. 5.452, de $1^{\circ}$ de maio de 1943. Aprova a Consolidação das Leis do Trabalho. Diário Oficial da União, Rio de Janeiro, 9 ago. 1943. Disponível em: <http://www.planalto.gov.br/ccivil_03/Decreto-lei/Del5452.htm>. Acesso em: 5 set. 2016.

BRASIL. Lei Complementar n. 150, de $1^{\circ}$ de junho de 2015. Dispõe sobre o contrato de trabalho doméstico; altera as Leis no 8.212, de 24 de julho de 1991, no 8.213, de 24 de julho de 1991, e no 11.196, de 21 de novembro de 2005; revoga o inciso I do art. 3o da Lei no 8.009, de 29 de março de 1990, o art. 36 da Lei no 8.213, de 24 de julho de 1991, a Lei no 5.859, de 11 de dezembro de 1972, e o inciso VII do art. 12 da Lei no 9.250, de 26 de dezembro 1995; e dá outras providências. Diário Oficial da União. Brasília, DF, 2 jun. 2015. Disponível : <http://www.planalto.gov.br/ccivil_03/leis/LCP/Lcp150.htm>. Acesso em: 27 jul. 2017.

BRASIL. Lei n. 10.406, de 10 de janeiro de 2002. Institui o Código Civil. Diário Oficial da União, Brasília, DF, 11 jan. 2002. Disponível em: <http://www.planalto.gov.br/ccivil_03/leis/2002/110406.htm>. Acesso em: 20 set. 2017.

BRASIL. Lei n. 12.288, de 20 de junho de 2010. Institui o Estatuto da Igualdade Racial; altera as Leis nos 7.716, de 5 de janeiro de 1989, 9.029, de 13 de abril de 1995, 7.347, de 24 de julho de 1985, e 10.778, de 24 de novembro de 2003. Diário Oficial da União, Brasília, DF, 21 jul. 2010. Disponível em: <http://www.planalto.gov.br/ccivil_03/_Ato20072010/2010/Lei/L12288.htm>. Acesso em: 29 out. 2018. 
BRASIL. Lei n. 12.551, de 15 de dezembro de 2011. Altera o art. 6o da Consolidação das Leis do Trabalho (CLT), aprovada pelo Decreto-Lei no 5.452, de 1o de maio de 1943, para equiparar os efeitos jurídicos da subordinação exercida por meios telemáticos e informatizados à exercida por meios pessoais e diretos. Diário Oficial da União, Brasília, DF, 16 dez. 2011. Disponível em: <http://www.planalto.gov.br/ccivil_03/_Ato20112014/2011/Lei/L12551.htm\#art1>. Acesso em: 29 out. 2018.

BRASIL. Lei n. 12.587, de 3 de janeiro de 2012. Institui as diretrizes da Política Nacional de Mobilidade Urbana; revoga dispositivos dos Decretos-Leis nos 3.326, de 3 de junho de 1941, e 5.405, de 13 de abril de 1943, da Consolidação das Leis do Trabalho (CLT), aprovada pelo Decreto-Lei no 5.452, de 1o de maio de 1943, e das Leis nos 5.917, de 10 de setembro de 1973, e 6.261, de 14 de novembro de 1975; e dá outras providências. Diário Oficial da União, Brasília, DF, 4 jan. 2012. Disponível em: <http://www.planalto.gov.br/CCIVIL_03/_Ato2011-2014/2012/Lei/L12587.htm>. Acesso em: 29 out. 2018.

BRASIL. Lei n. 12.815, de 5 de junho de 2013. Dispõe sobre a exploração direta e indireta pela União de portos e instalações portuárias e sobre as atividades desempenhadas pelos operadores portuários; altera as Leis nos 5.025, de 10 de junho de 1966, 10.233, de 5 de junho de 2001, 10.683, de 28 de maio de 2003, 9.719, de 27 de novembro de 1998, e 8.213, de 24 de julho de 1991; revoga as Leis nos 8.630, de 25 de fevereiro de 1993, e 11.610, de 12 de dezembro de 2007, e dispositivos das Leis nos 11.314, de 3 de julho de 2006, e 11.518, de 5 de setembro de 2007; e dá outras providências. Diário Oficial da União, Brasília, DF, 6 jun. 2015. Disponível em: <http://www.planalto.gov.br/ccivil_03/_Ato20112014/2013/Lei/L12815.htm>. Acesso em: 27 out. 2018.

BRASIL. Lei n. 13.103, de 2 de março de 2015. Dispõe sobre o exercício da profissão de motorista; altera a Consolidação das Leis do Trabalho - CLT, aprovada pelo Decreto-Lei no 5.452, de 1o de maio de 1943, e as Leis nos 9.503, de 23 de setembro de 1997 - Código de Trânsito Brasileiro, e 11.442, de 5 de janeiro de 2007 (empresas e transportadores autônomos de carga), para disciplinar a jornada de trabalho e o tempo de direção do motorista profissional; altera a Lei no 7.408, de 25 de novembro de 1985; revoga dispositivos da Lei no 12.619, de 30 de abril de 2012; e dá outras providências. Diário Oficial da União, Brasília, DF, 3 mar. 2015. Disponível em: <http://www.planalto.gov.br/ccivil_03/_Ato20152018/2015/Lei/L13103.htm>. Acesso em: 27 out. 2018.

BRASIL. Lei n. 13.467, de 13 de julho de 2017. Altera a Consolidação das Leis do Trabalho (CLT), aprovada pelo Decreto-Lei no 5.452, de 1o de maio de 1943, e as Leis nos 6.019, de 3 de janeiro de 1974, 8.036, de 11 de maio de 1990, e 8.212, de 24 de julho de 1991, a fim de adequar a legislação às novas relações de trabalho. Diário Oficial da União, Brasília, DF, 14 jul. 2017. Disponível em: <http://www.planalto.gov.br/ccivil_03/_Ato20152018/2017/Lei/L13467.htm>. Acesso em: 02 mar. 2018.

BRASIL. Lei n. 13.475, de 28 de agosto de 2017. Dispõe sobre o exercício da profissão de tripulante de aeronave, denominado aeronauta; e revoga a Lei no 7.183, de 5 de abril de 1984. Diário Oficial da União, Brasília, DF, 29 ago. 2015. Disponível em: <http://www.planalto.gov.br/ccivil_03/_ato2015-2018/2017/lei/L13475.htm>. Acesso em: 29 out. 2018. 
BRASIL. Lei n. 13.640, de 26 de março de 2018. Altera a Lei $\mathrm{n}^{\circ} 12.587$, de 3 de janeiro de 2012, para regulamentar o transporte remunerado privado individual de passageiros. Diário Oficial da União, Brasília, DF, 27 mar. 2018. Disponível em: <http://www.planalto.gov.br/ccivil_03/_Ato2015-2018/2018/Lei/L13640.htm>. Acesso em: 29 out. 2018.

BRASIL. Lei n. 13.709, de 14 de agosto de 2018. Dispõe sobre a proteção de dados pessoais e altera a Lei n. 12.965, de 23 de abril de 2014 (Marco Civil da Internet). Diário Oficial da União, Brasília, DF, 15 ago. 2018. Disponível em: <http://www.planalto.gov.br/ccivil_03/_Ato2015-2018/2018/Lei/L13709.htm>. Acesso em: 29 out. 2018.

BRASIL. Lei n. 5.889, de 8 de junho de 1973. Estatui normas reguladoras do trabalho rural. Diário Oficial da União, Brasília, DF, 11 jun. 1973. Disponível em: <http://www.planalto.gov.br/ccivil_03/LEIS/L5889.htm>. Acesso em: 29 out. 2018.

BRASIL. Lei n. 8.213, de 24 de julho de 1991. Dispõe sobre os Planos de Benefícios da Previdência Social e dá outras providências. Diário Oficial da União, Brasília, DF, 25 jul. 1991. Disponível em: <http://www.planalto.gov.br/ccivil_03/LEIS/L8213cons.htm>. Acesso em: 21 set. 2017.

BRASIL. Lei n. 8.949, de 9 de dezembro de 1994. Acrescenta parágrafo ao art. 442 da Consolidação das Leis do Trabalho (CLT) para declarar a inexistência de vínculo empregatício entre as cooperativas e seus associados. Diário Oficial da União, Brasília, DF, 12 dez. $1994 . \quad$ Disponível em: <http://www.planalto.gov.br/ccivil_03/LEIS/L8949.htm\#art1>. Acesso em: 29 out. 2018.

BRASIL. Tribunal de Justiça do Estado de São Paulo. Processo n. 100711580.2018.8.26.0016. Requerente: Edson Leandro Brugnaro. Requerida: Uber Brasil Tecnologia Ltda. Juiz: Domicio Whately Pacheco e Silva. São Paulo, 23 nov. 2018. Disponível em: <https://esaj.tjsp.jus.br/cpopg/abrirDocumentoVinculadoMovimentacao.do;jsessionid=D1 F11C61EFDAD72F382AFFFDD09AE3E6.cpopg7?processo.codigo=0G0006BD90000\&c $\mathrm{dDocumento}=65877468 \& \mathrm{nmRecurso} A$ cessado $=\mathrm{Julgada}+$ Procedente $+\mathrm{a}+\mathrm{A} \% \mathrm{C} 3 \% \mathrm{~A} 7 \% \mathrm{C} 3$ \%A3o>. Acesso em: 10 dez. 2018.

BRASIL. Tribunal Regional do Trabalho da 10a Região. Processo n. 000199546.2016.5.10.0111. Reclamante: William Miranda da Costa. Reclamadas: Uber do Brasil Tecnologia Ltda. Juíza: Tamara Gil Kemp. Brasília, 18 abr. 2017. Disponível em: $<$ https://pje.trt10.jus.br/visualizador/pages/conteudo.seam?p_tipo=2\&p_grau=1\&p_id=1ajf j\%2BdGXDY\%3D\&p_idpje=qoX8JH1n5SQ\%3D\&p_num=qoX8JH1n5SQ\%3D\&p_npag $=\mathrm{x}>$. Acesso em: 09 out. 2017.

BRASIL. Tribunal Regional do Trabalho da $1^{\mathrm{a}}$ Região. Processo n. 010035105.2017.5.01.0075. Reclamante: Carlos Renato de Souza Guerra. Reclamadas: Uber do Brasil Tecnologia Ltda., Uber International Holding B.V. e Uber International B.V. Juíza: Cissa de Almeida Biasoli. Rio de Janeiro, 31 maio 2018. Disponível em: <http://consultapje.trt1.jus.br/visualizador/pages/conteudo.seam?p_tipo=2\&p_grau=1\&p_i $\mathrm{d}=\mathrm{kpWARuHDmqrfN5 \% 2F50MAy \% 2Bw \% 3D \% 3D \& p \_ idpje=9pTO9MVOKFk \% 3D \& p \_}$ num=9pTO9MVOKFk\%3D\&p_npag=x>. Acesso em: 20 out. 2018. 
BRASIL. Tribunal Regional do Trabalho da $1^{\mathrm{a}}$ Região. Processo n. 010035105.2017.5.01.0075. Recorrentes: Uber do Brasil Tecnologia Ltda., Uber International Holding B.V. e Uber International B.V. Recorrido: Carlos Renato de Souza Guerra. Desembargadora: Tania da Silva Garcia. Rio de Janeiro, 09 out. 2018. Disponível em: <http://consultapje.trt1.jus.br/visualizador/pages/conteudo.seam?p_tipo=2\&p_grau=1\&p_i $\mathrm{d}=\mathrm{YCosUuD} 823$ vfN5\%2F5oMAy\%2Bw\%3D\%3D\&p_idpje=9pTO9MVOKFk\%3D\&p_n um=9pTO9MVOKFk\%3D\&p_npag=x>. Acesso em: 20 out. 2018.

BRASIL. Tribunal Regional do Trabalho da $2^{\mathrm{a}}$ Região. Processo n. 100149233.2016.5.02.0013. Reclamante: Fernando dos Santos Teodoro. Reclamadas: Uber do Brasil Tecnologia Ltda., Uber International Holding B.V. e Uber International B.V. Juiz: Eduardo Rockenbach Pires. São Paulo, 11 abr. 2017. Disponível em: $<$ https://consulta.pje.trtsp.jus.br/visualizador/pages/conteudo.seam?p_tipo=2\&p_grau=1\& p_id=VgJKIAQQIYffN5\%2F5oMAy\%2Bw\%3D\%3D\&p_idpje=0XsgWPEA1x8\%3D\&p_ num=0XsgWPEA1x8\%3D\&p_npag=x>. Acesso em: 20 nov. 2018.

BRASIL. Tribunal Regional do Trabalho da $2^{\mathrm{a}}$ Região. Processo n. 100157425.2016.5.02.0026. Reclamante: Rodrigo Tadeu de Souza Silva. Reclamadas: Uber do Brasil Tecnologia Ltda., Uber International Holding B.V. e Uber International B.V. Juíza: Elisa Maria Secco Andreoni. São Paulo, 07 ago. 2017. Disponível em: $<$ https://consulta.pje.trtsp.jus.br/visualizador/pages/conteudo.seam?p_tipo=2\&p_grau=1\& p_id=mlWljZANxaLfN5\%2F5oMAy\%2Bw\%3D\%3D\&p_idpje=idFncqnBE4Y\%3D\&p_n um=idFncqnBE4Y\%3D\&p_npag=x>. Acesso em: 15 out. 2018.

BRASIL. Tribunal Regional do Trabalho da $2^{\mathrm{a}}$ Região. Processo n. 100157425.2016.5.02.0026. Recorrente: Rodrigo Tadeu de Souza Silva. Recorridos: Uber do Brasil Tecnologia Ltda., Uber International Holding B.V. e Uber International B.V. Juíza: Sueli Tomás da Ponte. São Paulo, 14 dez. 2017. Disponível em: $<$ https://consulta.pje.trtsp.jus.br/visualizador/pages/conteudo.seam?p_tipo=2\&p_grau=1\& p_id=7d9bq2yXLF\%2BdZ1vXvvi9Ag\%3D\%3D\&p_idpje=idFncqnBE4Y\%3D\&p_num=i dFncqnBE4Y\%3D\&p_npag=x>. Acesso em: 15 out. 2018.

BRASIL. Tribunal Regional do Trabalho da $2^{\mathrm{a}}$ Região. Processo n. 100012389.2017.5.02.0038. Reclamante: Rodrigo Tadeu de Souza Silva. Reclamadas: Uber do Brasil Tecnologia Ltda., Uber International Holding B.V. e Uber International B.V. Juíza: Ana Carla Santana Tavares. São Paulo, 24 set. 2017. Disponível em: $<$ https://consulta.pje.trtsp.jus.br/visualizador/pages/conteudo.seam?p_tipo=2\&p_grau=1\& p_id=BVhdT7gtJ8rfN5\%2F5oMAy\%2Bw\%3D\%3D\&p_idpje=Q4wCmSz44kw\%3D\&p_n um=Q4wCmSz44kw\%3D\&p_npag=x>. Acesso em: 15 out. 2018.

BRASIL. Tribunal Regional do Trabalho da $2^{\mathrm{a}}$ Região. Processo n. 100012389.2017.5.02.0038. Recorrente: Rodrigo Tadeu de Souza Silva. Recorridas: Uber do Brasil Tecnologia Ltda., Uber International Holding B.V. e Uber International B.V. Desembargadora: Beatriz de Lima Pereira. São Paulo, 28 ago. 2017. Disponível em: $<$ https://consulta.pje.trtsp.jus.br/visualizador/pages/conteudo.seam?p_tipo=2\&p_grau=2\& p_id=DlhFm5a3ga7fN5\%2F5oMAy\%2Bw\%3D\%3D\&p_idpje=o6OktH7QAOI\%3D\&p_n um=o6OktH7QAOI\%3D\&p_npag=x>. Acesso em: 17 out. 2018.

BRASIL. Tribunal Regional do Trabalho da $3^{\text {a }}$ Região. Processo n. 001135934.2016.5.03.0112. Reclamante: Rodrigo Leonardo Silva Ferreira. Reclamada: Uber do 
Brasil Tecnologia Ltda. Juiz: Márcio Toledo Gonçalves. Belo Horizonte, 13 fev. 2017. Disponível em: <https://pjeconsulta.trt3.jus.br/visualizador/pages/conteudo.seam?p_tipo $=2 \&$ p_grau $=1 \& p \_i d=1 \mathrm{j} 1 \mathrm{mK} 4$ cU7PLfN5\%2F5oMAy\%2Bw\%3D\%3D\&p_idpje=NOwlKP\%2F\%2FCqU\%3D\&p_num= NOwlKP\%2F\%2FCqU\%3D\&p_npag=x>. Acesso em: 26 nov. 2018.

BRASIL. Tribunal Regional do Trabalho da $3^{\mathrm{a}}$ Região. Processo n. 001135934.2016.5.03.0112. Recorrente: Uber do Brasil Tecnologia Ltda. Recorrido: Rodrigo Leonardo Silva Ferreira. Desembargadora Relatora: Maria Stela Álvares da Silva Campos. Belo Horizonte, 23 maio 2017. Disponível em: <https://pjeconsulta.trt3.jus.br/visualizador/pages/conteudo.seam?p_tipo $=2 \&$ p_grau $=2 \&$ p_id $=$ ckUXz mJVhNvfN5\%2F5oMAy\%2Bw\%3D\%3D\&p_idpje=DJedstSGRrc\%3D\&p_num=DJedstS GRrc\%3D\&p_npag=x>. Acesso em: 26 nov. 2018.

BRASIL. Tribunal Regional do Trabalho da $3^{\text {a }}$ Região. Processo n. 001072956.2017.5.03.0010. Reclamante: Antônio Augusto Ribeiro. Reclamadas: Uber do Brasil Tecnologia Ltda., Uber International Holding B.V. e Uber International B.V. Juiz: Pedro Paula Ferreira. Belo Horizonte, 23 jun. 2017. Disponível em: <https://pjeconsulta.trt3.jus.br/visualizador/pages/conteudo.seam?p_tipo $=2 \&$ p_grau $=1 \& p$ _id $=$ FGFuit 8WSmzfN5\%2F5oMAy\%2Bw\%3D\%3D\&p_idpje=54Un\%2BP\%2BTr7A\%3D\&p_num=5 4Un\%2BP\%2BTr7A\%3D\&p_npag=x>. Acesso em: 17 out. 2018.

BRASIL. Tribunal Regional do Trabalho da $3^{\text {a }}$ Região. Processo n. 001186362.2016.5.03.0137. Reclamante: Artur Soares Neto. Reclamadas: Uber do Brasil Tecnologia Ltda., Uber International Holding B.V. e Uber International B.V. Juiz: Felipe de Souza Sickert. Belo Horizonte, 30 jan. 2017. Disponível em: <https://pjeconsulta.trt3.jus.br/visualizador/pages/conteudo.seam?p_tipo=2\&p_grau=1\&p_id=WdURk huvs\%2BjfN5\%2F5oMAy\%2Bw\%3D\%3D\&p_idpje=HH7W6G5UWnQ\%3D\&p_num=H H7W6G5UWnQ\%3D\&p_npag=x>. Acesso em: 16 out. 2018.

BRAVERMAN, Harry. Trabalho e capital monopolista: a degradação do trabalho no século XX. $3^{\text {a }}$. ed. Rio de Janeiro: Zahar, 1981.

BRIGNONI, Hugo Fernández. Las empresas de aplicaciones tecnológicas y el fenómeno "Uber": la llamada "Economia disruptiva". Derecho laboral, LIX, n. 261, p. 44, Jan./Mar. 2016.

BRYNJOLFSSON, Erik; MCAFEE, Andrew. The second machine age: work, progress, and prosperity in a time of brilliant technologies. $1^{\text {a }}$ edição. New York: W. W. Norton \& Company, 2014.

BURSON MARSTELLER; ASPEN INSTITUTE; TIME. The On-Demand Economy Survey. 2015. Disponível em: <https://www.burson-marsteller.com/what-we-do/our-thinking/theon-demand-economy/the-on-demand-economy-survey/>. Acesso em: 04 jun. 2018.

BUSINESS DICTIONARY. Application programming interface. Disponível em: < http://www.businessdictionary.com/definition/application-programming-interfaceAPI.html>. Acesso em: 20 ago. 2018. 
CALO, Ryan.; ROSENBLAT, Alex. The Taking Economy: Uber, Information, and Power. Columbia Law Review, v. 117, n. 6, p. 1661, Outubro 2017.

CARBONI, Megan. A new class of worker for the sharing economy. Richmond Journal of Law \& Technology, v. 22, n. 4, 2016.

CARELLI, Rodrigo de Lacerda. O caso Uber e o controle por programação: de carona para o século XIX. In: LEME, Ana Carolina Paes; RODRIGUES, Bruno Alves; CHAVES JÚNIOR, José Eduardo de Resende (Coords.). Tecnologias disruptivas e a exploração do trabalho humano: a intermediação de mão de obra a partir das plataformas eletrônicas e seus efeitos jurídicos e sociais. São Paulo: LTr, 2017.

CAUDAS AULETE. Tecnologia. Disponível em: <http://www.aulete.com.br/tecnologia $\geq$. Acesso em 20 jun. 2017.

CELIKEL ESSER, Funda et al. The european collaborative economy: A research agenda for policy support. Luxemburgo: Publications Office of the European Union, 2016.

CHAVES JUNIOR, José Eduardo de Resende; MENDES, Marcus Menezes Barberino; OLIVEIRA, Murilo Carvalho Sampaio. Subordinação, dependência e alienidade no trânsito para o capitalismo tecnológico. In: LEME, Ana Carolina Paes; RODRIGUES, Bruno Alves; CHAVES JÚNIOR, José Eduardo de Resende (Coords.). Tecnologias disruptivas e a exploração do trabalho humano: a intermediação de mão de obra a partir das plataformas eletrônicas e seus efeitos jurídicos e sociais. São Paulo: LTr, 2017.

CHERRY, Miriam. A taxonomy of virtual work. Georgia Law Review, v. 45, n. 4, 2011.

CHERRY, Miriam. Beyond Misclassification: The Digital Transformation of Work. Comparative Labor Law \& Policy Journal, v. 37, 2016.

CHERRY, Miriam. People Analytics and Invisible Labor: The Law and Business of People Analytics. Saint Louis University Law Journal, v. 61, 2016.

CHERRY, Miriam; ALOISI, Antonio. A critical examination of a third employment category for on-demand work (in comparative perspective). In: DAVIDSON, Nestor; INFRANCA, John; FINCK, Michèle. (Eds.). The Cambridge handbook of law and regulation of the sharing economy. New York: Cambridge University Press, 2018.

CHESNAIS, François. A mundialização do capital. São Paulo: Xamã, 1996.

CHRISTENSEN, Clayton M.; RAYNOR, Michael E.; MCDONALD, Rory. What Is Disruptive Innovation? Dezembro, 2015. Disponível em: <https://hbr.org/2015/12/what-isdisruptive-innovation>. Acesso em: 25 jun. 2017.

CINGOLANI, Patrick. Ubérisation, turc mécanique, économie à la demande : où va le capitalisme de plateforme? The Conversation France, Paris, 26 août 2016. Disponível em: $<$ http://theconversation.com/uberisation-turc-mecanique-economie-a-la-demande-ou-va-lecapitalisme-de-plateforme-64150>. Acesso em: 03 jun. 2017. 
CODAGNONE, Cristiano; ABADIE, Fabienne; BIAGI, Federico. The future of work in the sharing economy: Market efficiency and equitable opportunities or unfair precarisation? JCR Science for policy report. Seville: Institute for Prospective Technological Studies, 2016.

COLCLOUGH, Christina. When algorithms hire and fire. International Centre for Trade Union Rights, v. 25, n. 3, 2018.

COLLIER, Ruth Berins; DUBAL, Veena; CARTER, Christopher. Labor platforms and gig work: the failure to regulate. 17 sept. 2017. Disponível em: <http://www.irle.berkeley.edu/files/2017/Labor-Platforms-and-Gig-Work.pdf>. Acesso em: 03 out. 2017.

COLUMBU, Francesca; MASSONI, Túlio de Oliveira. Tempo de trabalho e teletrabalho. In: CONALGNO, Lorena de Mello Rezende; CHAVES JUNIOR, José Eduardo de Resende; estrada, Manuel Martín Pino (Coords.). Teletrabalho. São Paulo: LTr, 2017.

CORPORAAL, Greetje; LEHDONVIRTA, Vili. How fortune 500 firms are adopting online freelancing platforms. Oxford: Oxford Internet Institute, 2017.

COURT OF JUSTICE OF THE EUROPEAN UNION. Case C-434/15. Dec. 2017. Disponível

em:

<http://curia.europa.eu/juris/document/document.jsf;jsessionid=9ea7d0f130dcb236077b2c cb4eac82eea27b3c4d851c.e34KaxiLc3eQc40LaxqMbN4Pbh0Ke0?text=\&docid=198047\& pageIndex $=0 \&$ doclang $=$ en $\&$ mode $=1$ st $\&$ dir $=\& o c c=$ first $\&$ part $=1 \&$ cid $=634146>$. Acesso em: 20 set. 2018.

COUTINHO, Diogo. Direito e institucionalismo econômico: apontamentos sobre uma fértil agenda de pesquisa. Revista de Economia Política, v. 37, n. 3, p. 581-583, jul./set. 2017.

COUTINHO, Diogo. O direito nas políticas públicas. In: MARQUES, Eduardo; FARIA, Carlos Aurélio Pimenta de (Orgs.). A política pública como campo multidisciplinar. São Paulo: Editora Unesp, 2013, p. 181-200.

CRAIN, Marion; POSTER, Winifred; CHERRY, Miriam. Introduction: conceptualizing invisible labor. In: CRAIN, Marion; POSTER, Winifred; CHERRY, Miriam. (Eds.). Invisible labor: hidden work in the contemporary world. Oakland, California: University of California Press, 2016.

CROWDSPRING. Design done better. Disponível em: <https://www.crowdspring.com>. Acesso em: 05 ago. 2018.

CUNNINGHAM-PARMETER, Keith. From Amazon to Uber: Defining Employment in the Modern Economy. Boston University Law Review, v. 96, 2016.

DAGNINO, Emanuele. Labour and labour law in the time of the on-demand economy. Revista Derecho Social y Empresa, n. 6, Dez. 2016.

DAVIDOV, Guy. A purposive approach on labour law. New York: Oxford University Press, 2016. 
DAVIDOV, Guy. The status of Uber drivers: a purposive approach. Spanish Labour Law and Employment Relations Journal, v. 6, n. 1-2, Nov. 2017.

DAVIS, Gerald. Managed by the markets: how finance reshaped America. New York: Oxford University Press, 2009.

DE STEFANO, Valerio. "Negotiating the algorithm": automation, artificial intelligence and labour protection. Geneva: International Labour Organization, 2018.

DE STEFANO, Valerio. Collective bargaining of platform workers: domestic work leads the way. Regulating for globalization, 10 dec. 2018. Disponível em: $<$ http://regulatingforglobalization.com/2018/12/10/collective-bargaining-of-platformworkers-domestic-work-leads-the-way>. Acesso em: 12 dez. 2018.

DE STEFANO, Valerio. Crowdsourcing, the Gig-Economy, and the Law Introduction. Comparative Labor Law \& Policy Journal, v. 37, n. 3, 2016.

DE STEFANO, Valerio. The rise of the "just-in-time workforce": on-demand work, crowdwork, and labor protection in the "gig-economy". Comparative Labor Law \& Policy Journal, v. 37, n. 3, p. 471-504, 2016.

DE STEFANO, Valerio; ALOISI, Antonio; SILBERMAN, Six. A manifesto to reform the gig economy. Pagina 99, 29 magg. 2017. Disponível em: <http://www.pagina99.it/2017/05/29/a-manifesto-to-reform-the-gig-economy>. Acesso em 20 out. 2017.

DEL CONTE, Maurizio; GRAMANO, Elena. Looking to the other side of the bench: the new legal status of independent contractors under the Italian legal system. Comparative labor law \& policy journal, v. 39, n. 3, 2018.

DELGADO, Maurício Godinho. Curso de Direito do Trabalho. $17^{\mathrm{a}}$ ed. rev., atual. e ampl. São Paulo: LTr, 2018.

DELGADO, Maurício Godinho. O poder empregatício. São Paulo: LTr, 1996.

DELGADO, Maurício Godinho; DELGADO, Gabriela Neves. A reforma trabalhista no Brasil: com os comentários à Lei n. 13.467/2017. $2^{a}$ ed. rev., atual. e ampl. São Paulo: LTr, 2018.

DELGALDO, Maurício Godinho; DELGADO, Gabriela Neves. O Direito do Trabalho na contemporaneidade: clássicas funções e novos desafios. In: LEME, Ana Carolina Paes; RODRIGUES, Bruno Alves; CHAVES JÚNIOR, José Eduardo de Resende (Coords.). Tecnologias disruptivas e a exploração do trabalho humano: a intermediação de mão de obra a partir das plataformas eletrônicas e seus efeitos jurídicos e sociais. São Paulo: LTr, 2017.

DELGUE, Juan Raso. La empresa virtual: nuevos retos para el Derecho del Trabajo. Revista Internacional y Comparada de Relaciones Laborales y Derecho del Empleo, n. 1, 2017. 
DILLAHUNT, Tawanna; MALONE, Amelia. The Promise of the Sharing Economy Among Disadvantaged Communities. Apr. 2015. Disponível em: <http://doi.acm.org/10.1145/2702123.2702189>. Acesso em 03 jun. 2017.

DIÓGENES, Juliana. Uber cresce 10 vezes e já tem 50 mil motoristas. O Estado de São Paulo, São Paulo, 18 out. 2016. Disponível em: < https://saopaulo.estadao.com.br/noticias/geral,uber-cresce-10-vezes-e-ja-tem-50-milmotoristas,10000082769>. Acesso: 30 set. 2017.

DOCKÈS, Emmanuel et al. Proposition de code du travail. Paris: Dalloz, 2017.

DONOVAN, Sarah A.; BRADLEY, David H.; SHIMABUKURO, Jon O. What Does the Gig Economy Mean for Workers? Feb. 2016. Disponível em: <https://fas.org/sgp/crs/misc/R44365.pdf>. Acesso em: 10 jun. 2017.

DRAHOKOUPIL, Jan.; FABO, Brian. The Sharing Economy That Is Not: Platform Capitalism Social Europe. Jul. 2016. Disponível em: <https://www.socialeurope.eu/2016/07/sharing-economy-not-shaping-employmentplatform-capitalism/>. Acesso em: 26 mai. 2017.

DRAHOKOUPIL, Jan; FABO, Brian. The platform economy and the disruption of the employment relationship. ETUI Policy Brief, n. 5, 2016.

DYAL-CHAND, Rashmi. Regulating Sharing: The Sharing Economy as an Alternative Capitalist System. Tulane Law Review, v. 90, 2016.

ECKHARDT, Giana M.; BARDHI, Fleura. The Sharing Economy Isn't About Sharing at All. Harvard Business Review, Cambridge, 28 jan. 2015. Disponível em: <https://hbr.org/2015/01/the-sharing-economy-isnt-about-sharing-at-all>. Acesso em: 26 maio 2017.

ESTLUND, Cynthia. Why flexibility is not just a trope. OnLabor, Cambridge, 17 may 2018. Disponível em: <https://onlabor.org/why-flexibility-is-not-just-a-trope>. Acesso em: 17 mai. 2018.

EXECUTIVE OFFICE OF THE PRESIDENT OF THE UNITED STATES. Artificial Intelligence, Automation, and the Economy: a Government Report. Dec. 2016. Disponível em:

$<$ https://obamawhitehouse.archives.gov/sites/whitehouse.gov/files/documents/ArtificialIntelligence-Automation-Economy.PDF>. Acesso em: 02 maio 2017.

FABRELLAS, Anna Ginès i. Crowdsourcing sites y nuevas formas de trabajo: el caso de Amazon Mechanical Turk. Revista Derecho y Empresa, n. 6, Dez. 2016.

FELSTINER, Alek. Working the Crowd: Employment and Labor Law in the Crowdsourcing Industry. Berkeley Journal of Employment and Labor Law, v. 32, n. 1, 2011.

FERNANDÉZ, María Luiz Rodriguez. Plataformas, microworkers y otros retos del trabajo en la era digital. 2017. Disponível em: <https://www.ilo.org/wcmsp5/groups/public/--- 
europe/---ro-geneva/---ilo-madrid/documents/article/wcms_548596.pdf>. Acesso em 16 ago. 2018.

FIGUREEIGHT. We make AI work in the real world. Disponível em: <https://www.figureeight.com>. Acesso em 05 ago. 2018.

FOROOHAR, Rana. Makers and takers: how Wall Street destroyed Main Street. New York: Crown Business, 2016.

FOWLER, Susan. “What Have We Done?": Silicon Valley Engineers Fear They've Created a Monster. Vanity Fair, New York, sept. 2018. Disponível em: $<$ https://www.vanityfair.com/news/2018/08/silicon-valley-engineers-fear-they-created-amonster>. Acesso em: 11 set. 2018.

FRANCE. Loi n. 2016-1088 du 8 août 2016 relative au travail, à la modernisation du dialogue social et à la sécuritisation des parcours professionnels. Journal officiel de la République Française, Paris, 8 août 2016. Disponível em: <https://www.legifrance.gouv.fr/eli/loi/2016/8/8/ETSX1604461L/jo/article_60>. Acesso em: 25 nov. 2018.

FRASER, Nancy. From progressive neoliberalism to Trump - and beyond. American Affairs, v. 1, n. 4, inverno 2017.

FRAYSSÉ, Olivier; O'NEIL, Mathieu. Hacked in the USA: Prosumption and digital labour. In: FRAYSSÉ, Olivier; O'NEIL, Mathieu (eds.). Digital labour and prosumer capitalism: The US matrix. New York: Palgrave and Macmillan, 2015.

FREELANCER. Hire expert freelancers for any job, online. Disponível em: $<$ https://www.freelancer.com>. Acesso em 05 ago. 2018.

FREEMAN, Richard. Who Owns the Robots Rules the World. Harvard Magazine, Cambridge, maio 2016. Disponível em: <http://harvardmagazine.com/2016/05/who-ownsthe-robots-rules-the-world>. Acesso em: 06 set. 2017.

FREITAS JUNIOR, Antonio Rodrigues; SILVA, Victor Raduan. The uberizatoin of work and the legal regulation: the challenge of labor protection in semi-peripheral economies. Sept. $2017 . \quad$ Disponível em: <http://www.labourlawresearch.net/sites/default/files/papers/FINAL\%20LLRN3-1.02Freitas-Junior-Silva\%20copy.pdf >. Acesso em 06 out. 2017.

FREY, Carl Benedikt; OSBORNE, Michael. The Future of Employment: How susceptible are jobs to computerisation? Sept. 2013. Disponível em: <http://www.oxfordmartin.ox.ac.uk /publications/view/1314>. Acesso em: 06 out. 2017.

GAUTHIER, Gustavo. Nuevas tecnologías, economía colaborativa y trabajo. In: TEODORO, Maria Cecilia Máximo; VIANA, Márcio Túlio; ALMEIDA, Cleber Lúcio de; NOGUEIRA, Sabrina Colares (Orgs.). Direito material e processual do trabalho. São Paulo: LTr, 2017. 
GOLDIN, Adrián. The subjective weakening of labour law. In: DAVIDOV, Guy; LANGILLE, Brian (Orgs.). Boundaries and frontiers of labour law. Oxford: Hart, 2006.

GONÇALVES, Márcio Toledo. Uberização: um estudo de caso - as tecnologias disruptivas como padrão de organização do Trabalho no século XXI. Revista LTr, v. 81, n. 3, Mar.2017.

GRAHAM, Mark; LEHDONVIRTA, Vili; WOOD, Alex; BARNARD, Helena; HJORTH, Isis; SIMON, David Peter. Risks and rewards of online gig work at the global margins. 2017. Disponível em: 〈https://www.oii.ox.ac.uk/publications/gigwork.pdf>. Acesso em: 02 fev. 2018.

GRAMANO, Elena. Contribuición al debate sobre trabajo y gig-economy a la luz del ordenamento jurídico italiano. Jan. 2018. Disponível em: <https://ssrn.com/abstract=3109481 >. Acesso em: 25 jan. 2018.

GRAY, Mary; SURI, Siddarth. The Humans Working Behind the AI Curtain. Harvard Business Review, Cambridge, jan. 2017. Disponível em: <https://hbr.org/2017/01/thehumans-working-behind-the-ai-curtain>. Acesso em: 06 out. 2017.

GRAY, Mary; SURI, Siddarth; KINGSLEY, Sara Constance. Accounting for Market Frictions and Power Asymmetries in Online Labor Markets. Policy and Internet, v. 7, n. 4, 2015.

GRAY, Mary; SURI, Siddharth; ALI, Syed Shoaib; KULKARNI, Deepti. The Crowd is a Collaborative Network. 2015. Disponível em: <http://www.inthecrowd.org/wpcontent/uploads/2015/10/collab_paper21.pdf>. Acesso em: 5 dez. 2017.

GREENHOUSE, Steven. The Whatchamacallit Economy. The New York Times, New York, 16 dec. 2016. Disponível em: <https://www.nytimes.com/2016/12/16/opinion/thewhatchamacallit-economy.html>. Acesso em 26 mai. 2017.

GRISWOLD, Alison. The Uber economy looks a lot like the pre-industrial economy. Quartz, New York, 11 Oct. 2016. Disponível em: <https://qz.com/806117/uber-and-the-gigeconomy-look-a-lot-like-the-pre-industrial-economy/>. Acesso em: 03 jun. 2017.

HACKER, Jacob; PIERSON, Paul. Winner-take-all politics: public policy, political organization, and the precipitous rise of the top incomes in the United States. Politics \& Society, v. 38, n. 2, 2010.

HALE, Julian. In Demanrk, a historic collective agreement is turning the "bogus selfemployed" into "workers with rights". Equal Times, Brussels, 04 july 2018. Disponível em: <https://www.equaltimes.org/in-denmark-a-historic-collective?lang=en\#.W-2SBehKiM8>. Acesso em: 03 set. 2018

HALL, Jonathan. An analysis of CEEPR's paper on “The economics of ride-hailing”. 2018. Disponível em: <https://medium.com/uber-under-the-hood/an-analysis-of-ceeprs-paper-onthe-economics-of-ride-hailing-1c8bfbf1081d>. Acesso em: 11 set. 2018.

HARRIS, Seth; KRUEGER, Alan. A proposal for modernizing labor laws for twenty-firstcentury work: the "independent worker". Dezembro, 2015. Disponível em: 
<http://www.hamiltonproject.org/assets/files/modernizing_labor_laws_for_twenty_first_ce ntury_work_krueger_harris.pdf>. Acesso em 12 fev. 2016.

HARVEY, David. A condição pós-moderna: uma pesquisa sobre as origens da mudança cultural. 17a . ed. São Paulo: Loyola, 2008.

HAYEK, Friedrich A. Von. The road to serfdom. London: Routledge, 2001.

HERRERA, Beethoven. El sindicalismo en el milenio de la globalización. Lima: Oficina Internacional del Trabajo, 2001.

HILL, Steven. Raw deal: how the "Uber economy" and runaway capitalism are screwing American workers. New k: St. Martin's Press, 2015.

HITLIN, Paul. Research in crowdsourcing age, a case study. Washington: Pew Research Center, 2016.

HORAN, Hubert. Will the growth of Uber increase economic welfare? Transportation Law Journal, v. 44, 2017.

HOWE, Jeff. Crowdsourcing: A Definition. Junho, 2006. Disponível em: <http://www.crowdsourcing.com/cs/2006/06/crowdsourcing_a.html>. Acesso em: 06 jun. 2017.

HUNT, Abigail; MACHINGURA, Fortunate. A good gig? The rise of on-demand domestic work. Dec. 2016. Disponível em: <https://www.odi.org/sites/odi.org.uk/files/resourcedocuments/11155.pdf>. Acesso em: 15 jun. 2018.

HUWS, Ursula. Logged labour: a new paradigm of work organisation? Work organisation, labour \& globalisation, v. 10, n. 1, 2016.

HUWS, Ursula; JOYCE, Simon. Size of Sweden's "gig economy" revealed for the first time. 2016. Disponível em: <http://www.feps-europe.eu/assets/3f853cec-1358-4fb4-9552274b55e05ecf/crowd-working-survey-swedenpdf.pdf>. Acesso em: 04 jun. 2018.

HUWS, Ursula; JOYCE, Simon. Size of the UK's "gig economy" revealed for the first time. 2016. Disponível em: <http://www.feps-europe.eu/assets/a82bcd12-fb97-43a6-934624242695a183/crowd-working-surveypdf.pdf>. Acesso em: 04 jun. 2018.

IANNI, Octavio. As ciências sociais na época da globalização. Revista Brasileira de Ciências Sociais, v. 13, n. 37, jun. 1998.

IANNI, Octavio. Globalização: novo paradigma das ciências sociais. Estudos Avançados, São Paulo, v. 8, n. 21, p. 151, ago. 1994.

INNOCENTIVE. Innovate with InnoCentive. Disponível em: $<$ https://www.innocentive.com>. Acesso em 05 ago. 2018.

INSTACART. Get paid to shop! Disponível em: <https://shoppers.instacart.com>. Acesso em: 14 nov. 2018. 
INSTITUTO BRASILEIRO DE GEOGRAFIA E ESTATÍSTICA. Pesquisa Nacional por Amostra de Domicílios Contínua: Trimestre móvel Set.-Nov. 2018. 28 dez. 2018. Disponível em: <https://biblioteca.ibge.gov.br/visualizacao/periodicos/3086/pnacm_2018_nov.pdf>. Acesso em: 06 jan. 2019.

INSTITUTO BRASILEIRO DE GEOGRAFIA E ESTATÍSTICA. PIB avança 1,0\% em 2017 e fecha ano em $\mathrm{R} \$$ 6,6 trilhões. 01 mar. 2018. Disponível em: $<$ https://agenciadenoticias.ibge.gov.br/agencia-sala-de-imprensa/2013-agencia-denoticias/releases/20166-pib-avanca-1-0-em-2017-e-fecha-ano-em-r-6-6-trilhoes>. Acesso em: 06 jan. 2019.

INSTITUTO BRASILEIRO DE GEOGRAFIA E ESTATÍSTICA. PIB cresce $0,8 \%$ e chega a R\$ 1,716 trilhão no $3^{\circ}$ tri de 2018. 30 nov. 2018. Disponível em: $<$ https://agenciadenoticias.ibge.gov.br/agencia-sala-de-imprensa/2013-agencia-denoticias/releases/23251-pib-cresce-0-8-e-chega-a-r-1-716-trilhao-no-3-tri-de-2018>. Acesso em: 06 jan. 2019.

INTERNATIONAL LABOUR ORGANIZATION. Compilation of decisions of the Committee on Freedom of Association. 6 ${ }^{\mathrm{a}}$ edição. Geneva: ILO, 2018.

INTERNATIONAL LABOUR ORGANIZATION. Non-standard employment around the world: Understanding challenges, shaping prospects. Geneva: ILO, 2016.

INTERNATIONAL LABOUR ORGANIZATION. Understanding crowdwork: a survey of crowdworkers. Geneva: ILO, 2015.

IPEIROTIS, Panos. Analyzing the Amazon Mechanical Turk marketplace. ACM XRDS, v. 17, n. 2, 2010.

IRANI, Lilly. Difference and Dependence among Digital Workers: The Case of Amazon Mechanical Turk. South Atlantic Quarterly, v. 114, n. 1, jan. 2015.

IRANI, Lilly. Justice for “Data Janitors”. Public Books, New York, 15 jan. 2015. Disponível em: <http://www.publicbooks.org/justice-for-data-janitors>. Acesso em: 11 maio 2018.

IRANI, Lilly. The cultural work of microwork. New Media \& Society, v. 17, n. 5, may 2015.

ISAAC, Mike. Uber sells stake SoftBank, valuing ride-hailing giant at $\$ 48$ billion. The New York Times, New York, 28 dec. 2017. Disponível em: <https://www.nytimes.com/2017/12/28/technology/uber-softbank-stake.html>. Acesso em: 23 jun. 2018.

JOHNSTON, Hannah; LAND-KAZLAUSKAS, Chris. Organizing on-demand: Representation, voice, and collective bargaining in the gig economy. Geneva: International Labour Organization, 2018.

JUDICIARY. Mr Y Aslam, Mr J Farrar and Others - V - Uber. Oct. 2016. Disponível em: <https://www.judiciary.uk/wp-content/uploads/2016/10/aslam-and-farrar-v-uberemployment-judgment-20161028-2.pdf>. Acesso em: 20 set. 2018. 
JUDT, Tony. $O$ mal ronda a terra: um tratado sobre as insatisfações do presente. Tradução Celso Nogueira. Rio de Janeiro: Objetiva, 2011.

KAUFMAN, Bruce E. The global evolution of industrial relations: events, ideas and the IIRA. Geneva: International Labour Office, 2004.

KEYNES, John Maynard. Chapter 24. Concluding notes on the social philosophy towards which the general theory might lead. In: KEYNES, John Maynard. The general theory of employment, interest and money. Disponível em: <http://www.marxists.org/reference/subject/economics/keynes/general-theory/ch24.htm>. Acesso em: 08 mar. 2018

KEZUKA, Katsutoshi. Crowdwork and the Law in Japan. In: WAAS, Bernd; LIEBMAN, Wilma; LYUBARSKY, ANDREW; KEZUKA, Katsutoshi. Crowdwork: a comparative law perspective. Frankfurt am Main: Bund-Verlag, 2017.

KUEK, Siou Chew; PARADI-GUILDORD, Cecilia; FAYOMI, Toks; IMAIZUMI, Saori; IPEIROTIS, Panos. The global opportunity in online outsourcing. June 2015. Disponível em: <http://documents.worldbank.org/curated/pt/138371468000900555/pdf/ACS14228ESW-white-cover-P149016-Box391478B-PUBLIC-World-Bank-Global-OO-Study-WBRpt-FinalS.pdf>. Acesso em 06 ago. 2018.

LANDIM, Raquel. Sistema S ajuda sindicato patronal a viver sem imposto sindical. Folha de São Paulo, São Paulo, 03 maio, 2017. Disponível em: $<$ https://www1.folha.uol.com.br/mercado/2017/05/1880554-sistema-s-ajuda-sindicatopatronal-a-viver-sem-imposto-sindical.shtml>. Acesso em: 03 dez. 2018.

LANGLEY, Paul; LEYSHON, Andrew. Platform capitalism: The intermediation and capitalisation of digital economic circulation. Finance and Society, 2016.

LANGLEY, Paul; LEYSHON, Andrew. Platform capitalism: The intermediation and capitalisation of digital economic circulation. Finance and Society, 2016.

LEAGLE. Cotter v. Lyft, Inc. 2015. Disponível em: <https://www.leagle.com/decision/infdco20150312a52>. Acesso em: 01 nov. 2018.

LEE, Kai-Fu. The real threat of artificial intelligence. The New York Times, New York, 24 jun. $2017 . \quad$ Disponível em: <https://www.nytimes.com/2017/06/24/opinion/sunday/artificial-intelligence-economicinequality.html>. Acesso em: 25 jun. 2017.

LEHDONVIRTA, Vili. Flexibility in the gig economy: managing time on three online piecework platforms. New technology, work and employment, v. 33, n. 1, mar. 2018.

LEME, Ana Carolina Reis Paes. Da máquina à nuvem: caminhos para o acesso à justiça pela via de direitos dos motoristas da Uber. 2018. 157f. Dissertação (Mestrado em Direito). Faculdade de Direito, Universidade Federal de Minas Gerais, 2018.

LICHTENSTEIN, Nelson. The most dangerous man in Detroit: Walter Reuther and the fate of American labor. New York, NY: Basic Books, 1995. 
LIEBMAN, Wilma; LYUBARSKY, Andrew. Crowdworkers, the Law and the future of Work: The U.S. In: WAAS, Bernd; LIEBMAN, Wilma; LYUBARSKY, ANDREW; KEZUKA, Katsutoshi. Crowdwork: a comparative law perspective. Frankfurt am Main: Bund-Verlag, 2017.

LILLA, Mark. The End of Identity Liberalism. The New York Times, New York, 20 nov. 2016. Disponível em: <https://www.nytimes.com/2016/11/20/opinion/sunday/the-end-ofidentity-liberalism.html>. Acesso em: 26 mar. 2018.

LOBEL, Orly. The gig economy \& the future of employment and labor law. University of San Francisco Law Review, v. 51, 2017.

LOBO, Sascha. S.P.O.N. - Die Mensch-Maschine: Auf dem Weg in die Dumpinghölle. Der Spiegel, Hamburg, 03 set. 2014. Disponível em: <http://www.spiegel.de/netzwelt/netzpolitik/sascha-lobo-sharing-economy-wie-bei-uberist-plattform-kapitalismus-a-989584.html>. Acesso em 28 jun. 2017.

LOHR, Steve. For big-data scientists, "janitor work" is key hurdle to insights. The New York Times, New York, 18 ago. 2014. Disponível em: <https://www.nytimes.com/2014/08/18/technology/for-big-data-scientists-hurdle-toinsights-is-janitor-work.html>. Acesso em 08 ago. 2018.

MANNRICH, Nelson. O futuro do Direito do Trabalho, no Brasil e no mundo. Revista LTr, v. 81, n. 11, Nov. 2017.

MANNRICH, Nelson. Reinventando o Direito do Trabalho: novas dimensões do trabalho autônomo. In: FREDIANI, Yone (Org.). A valorização do trabalho autônomo e a livreiniciativa. Porto Alegre: Magister, 2015.

MARVIT, Moshe. How crowdworkers became the ghosts in the digital machine. The Nation, New York, 24 feb. 2014. Disponível em: <https://www.thenation.com/article/howcrowdworkers-became-ghosts-digital-machine>. Acesso em: 16 ago. 2018.

MASSACHUSSETTS INSTITUTE OF TECHNOLOGY. Opening keynote and keynote interview with Jeff Bezos, set. 2006. (1h02m38s). Disponível: $<$ https://techtv.mit.edu/videos/16180-opening-keynote-and-keynote-interview-with-jeffbezos>. Acesso: $21 \mathrm{dez} .2018$

MAZZOTTI, Massimo. Algorithmic life. In: PRIDMORE-BROWN, Michele; CROCKETT, Julien. The digital revolution: debating the promises and perils of the Internet, automation, and algorithmic lives in the last years of the Obama Administration. Los Angeles: Los Angeles Review of Books, 2017.

MCKINSEY GLOBAL INSTITUTE. A labor market that works: connecting talent with opportunity in the digital age - full report. 2015. Disponível em: <https://www.mckinsey.com/ /media/McKinsey/Global\%20Themes/Employment\%20and $\% 20$ Growth/Connecting $\% 20$ talent $\% 20$ with\%20opportunity\%20in\%20the $\% 20$ digital $\% 20$ a ge/MGI_Online_talent_A_labor_market_that_works_Full_report_June_2015.ashx >. Acesso em: 04 jun. 2018. 
MCKINSEY GLOBAL INSTITUTE. A labor market that works: connecting talent with opportunity in the digital age - appendix: country case studies. 2015. Disponível em: <https://www.mckinsey.com/ /media/McKinsey/Global\%20Themes/Employment\%20and $\% 20$ Growth/Connecting\%20talent\%20with\%20opportunity\%20in\%20the\%20digital\%20a ge/MGI_Online_talent_Appendix_Country_case_study.ashx>. Acesso em: 04 jun. 2018.

MEANS, Benjamin; SEINER, Joseph. Navigating the Uber economy. UC Davis Law Review, v. 49, 2016.

MIAZARA, Raphael. A Lei n. 13.640/18 e o vínculo empregatício dos motoristas em plataformas digitais. Os Trabalhistas, Teresina, 07 nov. 2018. Disponível em: $<$ http://ostrabalhistas.com.br/pela-lei-no-13-6402018-motorista-do-uber-e-afins-nao-eempregado-sera>. Acesso em: 08 nov. 2018.

MILLAND, Kristy. Crowdwork: shame, secrets, and na imminent threat to employment. Global Labour Column, june 2016. Disponível em: <http://column.global-labouruniversity.org/2016/06/crowd-work-shame-secrets-and-imminent.html>. Acesso em: 04 out. 2017.

MIMS, Christopher. How Everyone Gets the "Sharing" Economy Wrong. The Wall Street Journal, New York, 24 may 2015. Disponível em: <http://www.wsj.com/articles/howeveryone-gets-the-sharing-economy-wrong-1432495921>. Acesso em 03 jun. 2017.

MINISTÉRIO DO TRABALHO. Ministério do Trabalho autua empresa que usa aplicativo para oferecer serviços de motoboys. Disponível em: <http://trabalho.gov.br/noticias/5338ministerio-do-trabalho-autua-empresa-que-usa-aplicativo-para-oferecer-servico-demotoboys>. Acesso em: 22 dez. 2018.

MINISTÉRIO PÚBLICO DO TRABALHO. Relatório conclusivo: Grupo de Estudos "GE Uber”. Brasília: MPT, 2017.

MISHEL, Lawrence. Uber and the labor market: Uber drivers' compensation, wages, and the scale of Uber and the gig economy. 15 may 2018. Disponível em: <https://www.epi.org/files/pdf/145552.pdf>. Acesso em: 04 jun. 2018.

MISHEL, Lawrence; BIVENS, Josh. The zombie robot argument lurches on: There is no evidence that automation leads to joblessness or inequality. 24 may 2017. Disponível em: <http://www.epi.org/publication/the-zombie-robot-argument-lurches-on-there-is-noevidence- that-automation-leads-to-joblessness-or-inequality/>. Acesso em: 27 fev. 2018.

MISHEL, Lawrence; EISENBREY, Ross. Uber business model does not justify a new “independent worker" category. Março, 2016. Disponível em: $<$ https://www.epi.org/publication/uber-business-model-does-not-justify-a-newindependent-worker-category>. Acesso em: 05 dez. 2017.

MISHEL, Lawrence; SCHMITT, John; SHIERHOLZ, Heidi. Wage inequality: A story of policy choices. New Labor Forum, New York, v. 23, n. 3, Aug. 2014.

MISHEL, Lawrence; SHIERHOLZ, Heidi. Robots, or automation, are not the problem: Too little worker power is. 21 feb. 2017. Disponível em: <http://www.epi.org 
/publication/robots-or-automation-are-not-the-problem-too-little-worker-power-is/> . Acesso em: 27 fev. 2018.

MISHEL, Lawrence; SHIERHOLZ, Heidi; SCHMITT, John. Don't blame the robots: assessing the job polarization explanation of growing wage inequality. 19 nov. 2013. Disponível em: <https://www.epi.org/publication/technology-inequality-dont-blame-therobots>. Acesso em: 10 out. 2017.

MOURA, Natália das Chagas; GONÇALVES, Márcio Toledo. Atuação sindical transnacional: as redes sindicais internacionais e os acordos macro globais. In: LEME, Ana Carolina Paes; RODRIGUES, Bruno Alves; CHAVES JÚNIOR, José Eduardo de Resende (Coords.). Tecnologias disruptivas e a exploração do trabalho humano: a intermediação de mão de obra a partir das plataformas eletrônicas e seus efeitos jurídicos e sociais. São Paulo: LTr, 2017.

MTURK TRACKER. Countries. Disponível em: <http://demographics.mturktracker.com/\#/countries/all>. Acesso em: 20 ago. 2018.

MÜLLER-ARMACK, Alfred. The social market economic as an economic and social order. Review of Social Economy, v. 36, n. 3, 1978.

MUMFORD, Lewis. Authoritarian and Democratic Technics. Technology and Culture, Norman v. 5, n. 1, 1964.

MUMFORD, Lewis. Technics and civilization. New York: Harcourt, Brace and Co., 1934

MUNCK, Ronaldo. Globalisation and labour: the new 'Great Transformation'. London: Zed Books, 2002.

MURRAY, Fergus. The descentralisation of production - the decline of the mass-collective worker? Capital \& Class, v. 7, n. 1, p. 74-77, 1983.

NEWCOMER, Eric. Uber quartely sales rose $61 \%$ to $\$ 2$ billion amid heavy loss. Bloomberg, New York, 13 feb. 2018. Disponível em: <https://www.bloomberg.com/news/articles/201802-13/uber-sales-reach-7-5-billion-in-2017-despite-persistent-turmoil>. Acesso em 23 jun. 2018.

OLIVEIRA, Murilo Carvalho Sampaio. O retorno da dependência econômica no Direito do Trabalho. Revista do TST, v. 79, n. 3, Jul./Set. 2013.

PASQUALE, Frank. Two Narratives of Platform Capitalism Feature: Essays from the Law and Inequality Conference. Yale Law \& Policy Review, New Haven, v. 35, 2016.

PC MAGANIZE. Application program. Disponível em: <https://www.pcmag.com/encyclopedia/term/37919/application-program>. Acesso em: 15 jun. 2018.

PEW RESEARCH CENTER. Gig work, online selling and home sharing. 17 nov. 2016. Disponível em: <http://www.pewinternet.org/wp- 
content/uploads/sites/9/2016/11/PI_2016.11.17_Gig-Workers_FINAL.pdf >. Acesso em: 20 set. 2017.

PIKETTY, Thomas. Capital in the twenty-first century. Cambridge: Harvard University Press, 2014.

PINSOF, Jennifer. A New Take on an Old Problem: Employee Misclassification in the Modern Gig-Economy Notes. Michigan Telecommunications and Technology Law Review, v. 22, 2016.

PINTO, Maria Cecília Alves. As novas ferramentas tecnológicas de gestão de mão de obra e a necessária releitura do elemento fático-jurídico da não eventualidade na relação de emprego. In: LEME, Ana Carolina Paes; RODRIGUES, Bruno Alves; CHAVES JÚNIOR, José Eduardo de Resende (Coords.). Tecnologias disruptivas e a exploração do trabalho humano: a intermediação de mão de obra a partir das plataformas eletrônicas e seus efeitos jurídicos e sociais. São Paulo: LTr, 2017.

PLÁ RODRIGUEZ, Américo. Princípios de Direito do Trabalho. São Paulo: LTr, 2015.

POCHMANN, Marcio. Terceirização, competitividade e uberização do trabalho no Brasil. In: TEIXEIRA, Marilane Oliveira; ANDRADE, Helio Rodrigues de; COELHO, Elaine D’Ávila. Precarização e terceirização: faces da mesma realidade. São Paulo: Sindicato dos químicos, 2016.

POLANYI, Karl. The great transformation: the political and economic origins of our time. $2^{\mathrm{a}}$ ed. Boston: Beacon Press, 2001.

PORTINARI, Natalia. Grupo do iFood é multado em R \$ 1 mi por desrespeito às leis trabalhistas. Folha de São Paulo, São Paulo, 07 jun. 2018. Disponível em: $<$ https://www1.folha.uol.com.br/mercado/2018/06/grupo-do-ifood-e-multado-em-r-1-mipor-desrespeito-as-leis-trabalhistas.shtml>. Acesso em: $22 \mathrm{dez} .2018$.

PORTO, Lorena Vasconcelos. A subordinação no contrato de trabalho: uma releitura necessária. São Paulo: LTr, 2009.

PORTUGAL. Lei n. 45/2018, de 10 de agosto. Regime jurídico da atividade de transporte individual e remunerado de passageiros em veículos descaracterizados a partir de plataforma eletrónica. Diário da República, Lisboa, 10 ago. 2018. Disponível em: <https://dre.pt/web/guest/pesquisa/-/search/115991688/details/maximized>. Acesso em: 01 nov. 2018.

PRASSL, Jeremias. Humans as a service: the promises and perils of work in the gig economy. New York: Oxford University Press, 2018.

PRASSL, Jeremias. The concept of the employer. Oxford: Oxford University Press, 2016.

PRASSL, Jeremias.; RISAK, Martin. Uber, Taskrabbit, and Co.: Platforms as Employers Rethinking the Legal Analysis of Crowdwork. Comparative. Labor Law \& Policy Journal, v. 37, 2016. 
RABAY, Dario; MARTINEZ NETO, Aldo Augusto. Motoristas do Uber: empregados ou autônomos? O Estado de São Paulo, São Paulo, 22 out. 2015. Disponível em: $<$ https://politica.estadao.com.br/blogs/fausto-macedo/motoristas-do-uber-empregados-ouautonomos>. Acesso em 31 out. 2018.

REESE, Hope; HEATH, Nick. Inside Amazon's clickworker platform: How half a million people are being paid pennies to train AI. TechRepublic, San Francisco, 17 dec. 2016. Disponível em: <http://www.techrepublic.com/article/inside-amazons-clickworkerplatform-how-half-a-million-people-are-training-ai-for-pennies-per-task/>. Acesso em: 04 out. 2017.

REIS, Daniela Muradas; CORASSA, Eugênio Delmaestro. Aplicativos de transporte e plataforma de controle: o mito da tecnologia disruptiva do emprego e a subordinação por algoritmos. In: LEME, Ana Carolina Paes; RODRIGUES, Bruno Alves; CHAVES JÚNIOR, José Eduardo de Resende (Coords.). Tecnologias disruptivas e a exploração do trabalho humano: a intermediação de mão de obra a partir das plataformas eletrônicas e seus efeitos jurídicos e sociais. São Paulo: LTr, 2017.

RISAK, Martin. Fair working conditions for platform workers. Apr. 2018. Disponível em: <https://library.fes.de/pdf-files/id/ipa/14055.pdf>. Acesso em: 21 jul. 2018.

ROBINSON, Hillary C. Making a digital working class: Uber drivers in Boston, 2016-2017. 2017. Disponível em: <https://dspace.mit.edu/handle/1721.1/113946>. Acesso em 10 jul. 2018.

RODGERS, Gerry. Precarious work in Western Europe: The state of the debate. In: RODGERS, Gerry; RODGERS, Janine (Eds.). Precarious jobs in labour market regulation: the growth of atypical employment in Western Europe. Geneva: International Labour Office, 1989.

RODRIGUES, Bruno Alves. A relação de emprego no serviço de transporte de passageiros ofertado por intermédio de plataforma eletrônica. In: LEME, Ana Carolina Paes; RODRIGUES, Bruno Alves; CHAVES JÚNIOR, José Eduardo de Resende (Coords.). Tecnologias disruptivas e a exploração do trabalho humano: a intermediação de mão de obra a partir das plataformas eletrônicas e seus efeitos jurídicos e sociais. São Paulo: LTr, 2017.

ROGERS, Brishen. Employment rights in the platform economy: getting back to basics. Harvard Law and Policy Review, v. 10, 2016.

ROQUE, Tatiana. Por causa de robôs, ideia de renda básica universal ganha mais adeptos. Folha de São Paulo, São Paulo, 17 fev. 2018. Disponível em: $<$ https://www1.folha.uol.com.br/ilustrissima/2018/02/por-causa-de-robos-ideia-de-rendabasica-universal-ganha-mais-adeptos.shtml>. Acesso em: 19 fev. 2018.

ROQUE, Tatiana. Subjetividades no ponto cego da esquerda. Le Monde Diplomatique Brasil, São Paulo, 03 fev. 2017. Disponível em: <http://diplomatique.org.br/subjetividades-noponto-cego-da-esquerda/> . Acesso em: 26 mar. 2018. 
ROSENBERG, Matthew; CONFESSORE, Nicholas; CADWALLADR, Carole. How Trump consultants exploited the Facebook data of millions. The New York Times, New York, 17 mar. 2018. Disponível em: <https://www.nytimes.com/2018/03/17/us/politics/cambridge-analytica-trumpcampaign.html>. Acesso em: 25 abr. 2018.

ROSENBLAT, Alex. The Taking Economy: Uber, Information, and Power. Columbia Law Review, v. 117, n. 6, October 2017.

ROSENBLAT, Alex; STARK, Luke. Algorithmic labor and information asymmetries: a case study of Uber's Drivers. International Journal of Communication, v. 10, 2016.

SACHS, Benjamin. Do we need an "independent worker" category? OnLabor, Cambridge, 08 dez. 2015. Disponivel em: <https://onlabor.org/do-we-need-an-independent-workercategory>. Acesso em: 31 jan. 2016.

SACHS, Benjamin. Uber, flexibility and employee status. OnLabor, Cambridge, 18 may 2018. Disponível em: <https://onlabor.org/uber-flexibility-and-employee-status〉. Acesso em: 18 mai. 2018.

SADOWSKI, Christopher. Uber drivers working up to 19 hours just to get by. New York Post, New York, 07 feb. 2016. Disponível em: <https://nypost.com/2016/02/07/uberdrivers-working-up-to-19-hours-a-day-just-to-get-by/>. Acesso em 08 jul. 2018.

SÃO PAULO. Decreto n. 56.981, de 10 de maio de 2016. Dispõe sobre o uso intensivo do viário urbano municipal para exploração de atividade econômica privada de transporte individual remunerado de passageiros de utilidade pública, o serviço de carona solidária e o compartilhamento de veículos sem condutor. Diário Oficial da Cidade de São Paulo, São Paulo, SP, 112016.2 maio 2 em: <http://legislacao.prefeitura.sp.gov.br/leis/decreto-56981-de-10-de-maio-de-2016>. Acesso em: 25 out. 2017.

SÃO PAULO. Resolução Secretaria Municipal de Mobilidade de Transportes SMT/CMUV n. 16 de 11 de julho de 2017. Regulamenta os requisitos mínimos exigidos para cadastramento de condutores nas Operadoras de Tecnologia de Transporte Credenciadas - OTTCs para exploração de atividade econômica privada de transporte individual de passageiros e altera a Resolução no 09/2016. Diário Oficial da Cidade de São Paulo, São Paulo, SP, 12 jul. 2017. Disponível em: $<$ http://legislacao.prefeitura.sp.gov.br/leis/resolucao-comite-municipal-de-uso-do-viariocmuv-16-de-11-de-julho-de-2017>. Acesso em: 25 out. 2017.

SCHALLER CONSULT. The new automobility: Lyft, Uber and the future of American cities, jul. 2018. Disponível em: <http://www.schallerconsult.com/rideservices/automobility.pdf>. Acesso: 20 dez. 2018.

SCHEIBER, Noam. How Uber uses psychological tricks to push its drivers' buttons. The New York Times, New York, 02 apr. 2017. Disponível em: $<$ https://www.nytimes.com/interactive/2017/04/02/technology/uber-drivers-psychologicaltricks.html>. Acesso em 10 out. 2017. 
SCHMIDIT, Florian. Digital labour markets in the platform economy: Mapping the political challenges of crowdwork and gig work. 2017. Disponível em: <http://library.fes.de/pdffiles/wiso/13164.pdf>. Acesso em: 16 ago. 2018.

SCHOLZ, Trebor. Uberworked and underpaid: how workers are disrupting the digital economy. Malden: Polity Press, 2017.

SCHOR, Juliet. Debating the Sharing Economy. 2015. Disponível em: <http://www.greattransition.org/publication/debating-the-sharing-economy>. Acesso em: 04 jun. 2017

SCHOR, Juliet. Getting sharing right. Contexts, v. 14, n. 1, 2015.

SCHOR, Juliet; ATTWOOD-CHARLES, William; CANSOY, Mehmet; LADEGAARD, Isak; WENGRONOWITZ, Robert. Dependence and precarity in the platform economy. Feb. 2017.

Disponível em: <http://www.bc.edu/content/dam/files/schools/cas_sites/sociology/pdf/Dependence\%20an d\%20Precarity\%20Feb\%202017.pdf>. Acesso em: 13 dez. 2017.

SCHWAB, Klaus. The fourth industrial revolution. $1^{\text {a }}$ edição. New York: Crown Business, 2016.

SIDDIQUI, Faiz. Uber mandates a six-hour rest period for frequent drivers. The Washington Post, Washington, 12 feb. 2018. Disponível: <https://www.washingtonpost.com/news/drgridlock/wp/2018/02/12/uber-mandates-a-six-hour-rest-period-for-frequentdrivers/?noredirect=on\&utm_term=.76c56ae735ae>. Acesso em: 08 jul. 2018.

SILBERMAN, M. Six. Human-centered computing and the future of work: lessons from Mechanical Turk and Turkopticon, 2008-2015. Irvine: UC Irvine, 2015.

SILBERMAN, M. Six; IRANI, Lilly. Operating an Employer Reputation System: Lessons from Turkopticon, 2008-2015. Comparative Labor Law \& Policy Journal, v. 37, 2016.

SILVA, Otavio Pinto e. Subordinação, autonomia e parassubordinação nas relações de trabalho. São Paulo: LTr, 2004.

SILVA, Walküre Lopes Ribeiro da. Crise de representatividade e participação dos sindicatos em políticas ativas de emprego. 2001. Tese (Titular de Direito do Trabalho) Faculdade de Direito, Universidade de São Paulo, São Paulo, 2001.

SIMTRAPLIPE. Página inicial. Novembro, 2018. Disponível em: <https://www.facebook.com/simtraplipe/>. Acesso em: 29 nov. 2018.

SIMTRATTIPPRJ. Inicial. Novembro, 2018. Disponível em: <https://simtrattipprj.wordpress.com/>. Acesso em: 29 nov. 2018.

SINDIMAAP. Inicial. Novembro, 2018. Disponível: <http://sindmaap.org.br/>. Acesso em: 29 nov. 2018. 
SLEE, Tom. What's yours is mine: against the sharing economy. New York: OR Books, 2015.

SOUTO MAIOR, Jorge Luiz. Relação de emprego e Direito do Trabalho: no contexto da ampliação da competência da Justiça do Trabalho. São Paulo: Editora LTr, 2007.

SPEMOLLA, Gerardo Cedrola. El trabajo en la era digital: Reflexiones sobre el impacto de la digitalización en el trabajo, la regulación laboral y las relaciones laborales. Revista Internacional y Comparada de Relaciones Laborales y Derecho del Empleo, v. 5, n. 1, p. 11, ene. /mar. 2017.

SRNICEK, Nick. Platform capitalism. Cambridge: Polity, 2017.

STATTESP. Página inicial. Novembro, 2018. Disponível em: 〈http://www.stattesp.com.br〉. Acesso em: 29 nov. 2018.

STERN, Andy. Raising the floor: how a universal basic income can renew our economy and rebuild the american dream. New York: Public Affairs, 2016.

STONE, Katherine. Employment protection for boundaryless workers. In: DAVIDOV, Guy; LANGILLE, Brian (Orgs.). Boundaries and frontiers of labour law. Oxford: Hart, 2006.

SUNDARARAJAN, Aran. The sharing economy: the end of employment and the rise of crowd-based capitalism. Cambridge: The MIT Press, 2016.

SUPIOT, Alain. Et si l'on refondait le droit du travail? Le Monde Diplomatique, Paris, oct. 2017. Disponível em: < https://www.monde-diplomatique.fr/2017/10/SUPIOT/58009 >. Acesso em: 15 out. 2017.

TAYLOR, Frederick Winslow. Princípios de administração científica. Tradução Arlindo Vieira Ramos. 7a. ed. São Paulo: Atlas, 1970.

TELES, Steven Michael. The rise of the conservative legal movement: the battle for control of the law. Princeton: Princeton University Press, 2008.

TELLES, Vera da Silva. Mutações do trabalho e experiência urbana. Tempo social, n. 18, v. $1,2006$.

THALER, Richard H.; SUNSTEIN, Cass R. Nudge: improving decisions about health, wealth, and happiness. New Haven: Yale University Press, 2008.

THE NEW YORKER. R. Kikuo Johnson's “Tech Support”. 23 out. 2017. Disponível em: <https://www.newyorker.com/culture/cover-story/cover-story-2017-10-23>. Acesso em: 12 nov. 2017.

TIPPET, Elizabeth. Employee classification in the sharing economy. In: DAVIDSON, Nestor; INFRANCA, John; FINCK, Michèle. (Eds.). The Cambridge handbook of law and regulation of the sharing economy. New York: Cambridge University Press, 2018. 
TODOLÍ-SIGNES, Adrian. The "gig economy": employee, self-employed or the need for a special employment regulation? European review of labour and research, v. 23, n. 2, 2017.

TODOLÍ-SIGNES, Adrián. The end of the subordinate worker? The on-demand economy, the gig-economy, and the need for protection for crowdworkers. International journal of comparative labour law and industrial relations, v. 33, n. 2, 2017.

TOMASSETTI, Julia. Does Uber Redefine the Firm: The Postindustrial Corporation and Advanced Information Technology. Hofstra Labor \& Employment Law Journal, v. 34, 2016.

TOPCODER. Design \& build high-quality software with crowdsourcing. Disponível em: <https://www.topcoder.com>. Acesso em: 05 ago. 2018.

UBER. Aeroporto de Guarulhos (GRU): Instruções aos motoristas parceiros. Disponível em: https://www.uber.com/pt-BR/drive/sao-paulo/airports/guarulhos-airport/. Acesso em: 16 dez. 2018.

UBER. Aluguel de veículos. Disponível em: <https://www.uber.com/ptBR/drive/resources/aluguel-veiculos-uber/>. Acesso em 25 jun. 2018.

UBER. Another step to prevent drowsy driving. Disponível em: <https://www.uber.com/newsroom/drowsydriving/>. Acesso em 8 jul. 2018.

UBER. City of Chicago ordinance: operating hours cap. Disponível em: <https://www.uber.com/pt-US/drive/chicago/resources/driving-hour-limits>. Acesso em: 12 nov. 2018.

UBER. Clube 6 estrelas: o exclusivo clube de vantagens dos melhores motoristas parceiros da Uber. Disponível em: <https://www.uber.com/pt-BR/blog/rio-de-janeiro/clube-6estrelas-rio-de-janeiro-2/>. Acesso em: 07 dez. 2018.

UBER. Clube 6 estrelas: o exclusivo clube de vantagens dos melhores motoristas parceiros da Uber. Disponível em: <https://www.uber.com/pt-BR/blog/salvador/6-estrelas-ssa/>. Acesso em: 07 dez. 2018.

UBER. Código de conduta da comunidade Uber. Disponível em: <https://www.uber.com/legal/community-guidelines/br-pt/>. Acesso em: 27 jun. 2018.

UBER. Como funciona a verificação de segurança na Uber. Disponível em: $<$ https://www.uber.com/pt-BR/drive/resources/duvidas-solucoes-aluguel-veiculos-uber/>. Acesso em: 26 jun. 2018.

UBER. Como funciona o Uber VIP. Disponível em: <https://www.uber.com/ptBR/blog/saiba-como-funciona-uber-vip/>. Acesso em: 27 jun. 2018.

UBER. Como funcionam as taxas de aceitação e cancelamento. Disponível em: <https://www.uber.com/pt-BR/blog/como-funciona-taxa-aceitacao-cancelamento/>.

Acesso em: 27 jun. 2018. 
UBER. Como pedir um Uber sem precisar instalar o aplicativo. Disponível em: <https://www.uber.com/pt-BR/blog/pedir-uber-sem-baixar-aplicativo>. Acesso em: 26 jun. 2018.

UBER. Conheça mais sobre a Uber e veja por que vale a pena ser um motorista parceiro. Disponível em: <https://www.uber.com/pt-BR/blog/dirigir-uber-vale-a-pena/> . Acesso em: 01 jul. 2018.

UBER. Dúvidas e perguntas frequentes. Disponível em: <https://www.uber.com/ptBR/drive/resources/duvidas-solucoes-aluguel-veiculos-uber/>. Acesso em: 26 jun. 2018.

UBER. Em que dia é feito o repasse semanal? Disponível em: <https://help.uber.com/pt_BR/h/42973e65-45a8-4aaf-90d5-d3e97ab61267>. Acesso em: 08 set. 2018.

UBER. Everyone's private driver. Disponível em: <https://vimeo.com/58800109>. Acesso em: 07 dez. 2018.

UBER. Fatos e dados sobre a Uber. Disponível em: <https://www.uber.com/ptBR/newsroom/fatos-e-dados-sobre-uber>. Acesso em: 01 jun. 2018.

UBER. How Uber engineering increases safe driving with telematics. Disponível em: <https://ubereng.wpengine.com/telematics/>. Acesso em: 17 set. 2018.

UBER. Introducing a new feature: driving hours limit. Disponível em: <https://www.uber.com/en-ZA/blog/driving-hours-limit>. Acesso em: 12 nov. 2018.

UBER. New York City TLC's driving hours rule. Disponível em: <https://www.uber.com/pt-US/drive/new-york/resources/driving-hour-limits>. Acesso em: 12 nov. 2018;

UBER. O que é preço dinâmico. Disponível em: <https://help.uber.com/pt_BR/h/e9375d5e917b-4bc5-8142-23b89a440eec>. Acesso em: 01 jul. 2018.

UBER. Open marketplace. Disponível em: <https://marketplace.uber.com/openmarketplace>. Acesso em: 07 out. 2018.

UBER. Oportunidades em todo o lugar. Disponível em: <https://www.uber.com/br/ptbr/drive>. Acesso em: 02 nov. 2018.

UBER. Os preços das viagens incluem uma gorjeta. Disponível: <https://help.uber.com/pt_BR/h/c23aa32f-f9fc-4671-b2cc-e419d67fe8f9>. Acesso em: 08 set. 2018.

UBER. Perguntas e respostas sobre o preço dinâmico. Disponível em: $<$ https://www.uber.com/pt-BR/blog/aracaju/perguntas-e-respostas-sobre-o-precodinamico>. Acesso em: 01 jul. 2018.

UBER. Políticas e regras. Disponível em: <https://www.uber.com/ptBR/drive/resources/regras/>. Acesso em: 28 jun. 2018. 
UBER. Requisitos para os motoristas parceiros. Disponível em: <https://www.uber.com/ptBR/drive/requirements/>. Acesso em: 24 jun. 2018.

UBER. Saiba tudo sobre a documentação para o CONDUAPP. Disponível em: <https://www.uber.com/pt-BR/drive/sao-paulo/resources/conduapp/>. Acesso em: 25 jun. 2018 .

UBER. Segurança das viagens. Disponível em: 〈https://www.uber.com/pt-BR/ride/safety/>. Acesso em: 30 jun. 2018.

UBER. Seguro para passageiros e motoristas parceiros na plataforma da Uber no Brasil. Disponível em: <https://www.uber.com/pt-BR/blog/belo-horizonte/seguro-parapassageiros-e-motoristas-parceiros-na-plataforma-da-uber-no-brasil/>. Acesso em: 25 jun. 2018.

UBER. Termos e condições gerais dos serviços de intermediação digital. São Paulo, mimeo: 2018 .

UBER. UberBAG. Disponível em: <https://www.uber.com/pt-BR/blog/sao-paulo/a-ubertem-uma-grande-novidade-pra-voce/>. Acesso em: 24 jun. 2018.

UBER. UberBLACK. Disponível em: <https://www.uber.com/pt-BR/ride/uberblack/>. Acesso em: 24 jun. 2018.

UBER. UberSELECT. Disponível em: <https://www.uber.com/pt-BR/ride/uberselect/> . Acesso em: 24 jun. 2018.

UBER. UberX. Disponível em: <https://www.uber.com/pt-BR/ride/uberx/>. Acesso em: 24 jun. 2018.

UNGER, Roberto Mangabeira. The knowledge economy. 2018. Disponível em: <https://www.oecd.org/naec/THE-KNOWLEDGE-ECONOMY.pdf>. Acesso em: 20 set. 2018.

UNIÃO EUROPEIA. Regulamento (UE) 2016/679, de 27 de abril de 2016. Dispõe sobre a proteção das pessoas singulares no que diz respeito ao tratamento de dados pessoais e a livre circulação desses dados e que revoga a Diretiva 95/46/CE . Jornal Oficial da União Europeia, Bruxelas, 04 maio 2016. Disponível em: $<$ https://publications.europa.eu/pt/publication-detail/-/publication/3e485e15-11bd-11e6ba9a-01aa75ed71a1>. Acesso em: 30 out. 2018.

UNITED STATES DISTRICT COURT, N.D. CALIFORNIA. Douglas O'Connor, et. al, Plaintffs v. Uber Technologies, Inc., et. al., Defendants. Mar. 2015. Disponível em: <https://h2o.law.harvard.edu/collages/42126/export>. Acesso em: 30 set. 2017.

UPWORK. Get the talent you need in 3 days, not 30. Disponível em: <https://www.upwork.com>. Acesso em: 05 ago. 2018.

VALENDUC, Gérard; VENDRAMINI, Patricia. Work in the digital economy: sorting the old from the new. Mar. 2016. Disponível em: <http://ftu- 
namur.org/fichiers/Work_in_the_digital_economy-ETUI2016-3-EN.pdf>. Acesso em: 10 abr. 2017.

VALOR ECONÔMICO. Uber extingue taxa fixa cobrada de motoristas. Valor Econômico, São Paulo, 02 jul. 2018. Disponível em: $<$ https://www.valor.com.br/empresas/5633831/uber-extingue-taxa-fixa-cobrada-demotoristas>. Acesso em: 23 jul. 2018.

WAAS, Bernd. Crowdwork in Germany. In: WAAS, Bernd; LIEBMAN, Wilma; LYUBARSKY, ANDREW; KEZUKA, Katsutoshi. Crowdwork: a comparative law perspective. Frankfurt am Main: Bund-Verlag, 2017.

WAAS, Bernd. Introduction. In: WAAS, Bernd; LIEBMAN, Wilma; LYUBARSKY, ANDREW; KEZUKA, Katsutoshi. Crowdwork: a comparative law perspective. Frankfurt am Main: Bund-Verlag, 2017, p. 14.

WALDO, Dwight. The administrative state: a study of the political theory of American public administration. New York: The Ronald Press Company, 1948.

WALLACE, Susan. Managerialism. In: WALLACE, Susan. (Ed.) A Dictionary of Education. Oxford: Oxford University Press, 2009.

WALLERSTEIN, Immanuel. ¿el fin del gaullismo? Junho, 2007. Disponível em: <http://www.jornada.unam.mx/2007/06/30/index.php?section=opinion\&article=020a1 pol>. Acesso em: 08 mar. 2018.

WATSON, Bartholomew C. Barcode Empires: Politics, Digital Technology, and Comparative Retail Firm Strategies. Journal of Industry, Competition and Trade, v. 11, n. 3, set. 2011.

WE ARE DYNAMO. Guidelines for academic requesters. Disponível em: <http://guidelines.wearedynamo.org>. Acesso em: 02 fev 2018.

WEBER, Max. The Protestant ethic and the spirit of capitalism. New York: Routledge, 2001.

WEBSTER, Juliet. Microworkers of the Gig Economy: Separate and Precarious. New Labor Forum, v. 25, n. 3, Sept. 2016.

WEIL, David. The fissured workplace: why work became so bad for so many and what can be done to improve it. Cambridge: Harvard University Press, 2014.

WHEELER, Ryan. Ninth circuit puts the brakes on Uber unionization. OnLabor, Cambridge, 23 may 2018. Disponível em: <https://onlabor.org/ninth-circuit-puts-the-brakes-on-uberunionization>. Acesso em: 01 jun. 2018.

WINNER, Langdon. Do Artifacts Have Politics? Daedalus, v. 109, n. 1, 1980.

WISSKIRCHEN, Gerlind et al. Artificial Intelligence and Robotics and Their Impact on the Workplace. $2017 . \quad$ Apr. Disponível em: 
<https://www.ibanet.org/Document/Default.aspx?DocumentUid=c06aa1a3-d355-4866beda-9a3a8779ba6e>. Acesso em: 01 jun. 2017.

WOLFE, Jonathan; LEVINE, Alexandra. New York today: Capping Uber. The New York Times, New York, 15 ago. 2018. Disponível em: $<$ https://www.nytimes.com/2018/08/15/nyregion/new-york-today-sunglasses-eyesafety.html>. Acesso em: 01 set. 2018.

WORLD ECONOMIC FORUM. The future of jobs report. Sept. 2018. Disponível em: <http://www3.weforum.org/docs/WEF_Future_of_Jobs_2018.pdf >. Acesso em: 29 set. 2018.

ZOEPF, Stephen. The economics of ride hailing, revisited. 2018. Disponível em: <http://ceepr.mit.edu/files/papers/2018-005\%20Authors\%20Statement.pdf>. Acesso em: 11 set. 2018.

ZOEPF, Stephen; CHEN, Stella; ADU, Paa; POZO, Gonzalo. The economics of ride hailing: driver revenue, expenses and taxes. 2018. Disponível em: $<$ https://orfe.princeton.edu/ alaink/SmartDrivingCars/PDFs/Zoepf_The\%20Economics\%2 0of\%20RideHialing_OriginalPdfFeb2018.pdf>. Acesso em: 11 set. 2018. 


\section{APÊNDICES}


APÊNDICE A - RESULTADO DO QUESTIONÁRIO - TRABALHADORES DA AMAZON MECHANICAL TURK

1) Informações sociodemográficas

1.1) Onde você vive?

\begin{tabular}{|l|l|}
\hline Acre & $0 \%$ \\
\hline Alagoas & $0 \%$ \\
\hline Amapá & $0 \%$ \\
\hline Amazonas & $1,9 \%$ \\
\hline Bahia & $1,9 \%$ \\
\hline Ceará & $1,9 \%$ \\
\hline Distrito Federal & $7,6 \%$ \\
\hline Espírito Santo & $0 \%$ \\
\hline Goiás & $3,8 \%$ \\
\hline Maranhão & $0 \%$ \\
\hline Mato Grosso & $0 \%$ \\
\hline Mato Grosso do Sul & $0 \%$ \\
\hline Minas Gerais & $11,4 \%$ \\
\hline Pará & $0 \%$ \\
\hline Paraíba & $0 \%$ \\
\hline Paraná & $9,5 \%$ \\
\hline Pernambuco & $5,8 \%$ \\
\hline Piauí & $1,9 \%$ \\
\hline Rio de Janeiro & $9,6 \%$ \\
\hline Rio Grande do Norte & $0 \%$ \\
\hline Rio Grande do Sul & $11,4 \%$ \\
\hline Rondônia & $0 \%$ \\
\hline Roraima & $0 \%$ \\
\hline Santa Catarina & $0 \%$ \\
\hline São Paulo & $33,3 \%$ \\
\hline Sergipe & $0 \%$ \\
\hline Tocantins & $0 \%$ \\
\hline
\end{tabular}

1.2) Qual é o seu sexo biológico?

\begin{tabular}{|l|l|}
\hline Masculino & $73 \%$ \\
\hline Feminino & $27 \%$ \\
\hline
\end{tabular}

1.3) Qual o seu estado civil?

\begin{tabular}{|l|l|}
\hline Solteiro(a) & $88,4 \%$ \\
\hline Casado(a) & $11,6 \%$ \\
\hline Divorciado(a) & $0 \%$ \\
\hline Separado(a) & $0 \%$ \\
\hline União estável & $0 \%$ \\
\hline Viúvo (a) & $0 \%$ \\
\hline
\end{tabular}

1.4) Em que ano você nasceu? 
1.5) Como você avalia a sua saúde?

\begin{tabular}{|l|l|}
\hline Muito boa & $36,6 \%$ \\
\hline Boa & $44,3 \%$ \\
\hline Regular & $15,3 \%$ \\
\hline Ruim & $1,9 \%$ \\
\hline Muito ruim & $1,9 \%$ \\
\hline
\end{tabular}

1.6) Atualmente você tem problemas de saúde, física ou mental, ou doenças há pelo menos 12 meses ou que se espera que durem pelo menos 12 meses?

\begin{tabular}{|l|l|}
\hline Sim & $21,1 \%$ \\
\hline Não & $78,9 \%$ \\
\hline
\end{tabular}

(Se sim em 1.6) 1.6.1) Esse(s) problema(s) de saúde afeta(m) os tipos de trabalho remunerado que você pode realizar?

\begin{tabular}{|l|l|}
\hline Sim & $36,6 \%$ \\
\hline Não & $63,4 \%$ \\
\hline
\end{tabular}

(Se sim em 1.6) 1.6.2) O seu problema de saúde ou a sua doença reduz a sua capacidade de realizar atividades cotidianas?

\begin{tabular}{|l|l|}
\hline Sim & $54,6 \%$ \\
\hline Não & $45,4 \%$ \\
\hline
\end{tabular}

1.7) Qual é o seu grau de instrução?

\begin{tabular}{|l|l|}
\hline $\begin{array}{l}\text { Menos que ensino } \\
\text { médio }\end{array}$ & $0 \%$ \\
\hline Ensino médio & $13,4 \%$ \\
\hline Ensino técnico & $1,9 \%$ \\
\hline Ensino superior & $71,4 \%$ \\
\hline Mestrado & $7,6 \%$ \\
\hline Doutorado & $5,7 \%$ \\
\hline
\end{tabular}

1.7) Atualmente você está matriculado em algum curso?

\begin{tabular}{|l|l|}
\hline Sim & $36,6 \%$ \\
\hline Não & $63,4 \%$ \\
\hline
\end{tabular}

(Se sim na 1.7) 1.7.1) Você pretende se formar em qual curso?

\begin{tabular}{|l|l|}
\hline Ensino médio & $0 \%$ \\
\hline Ensino técnico & $0 \%$ \\
\hline Ensino superior & $73,6 \%$ \\
\hline Mestrado & $10,5 \%$ \\
\hline Doutorado & $15,9 \%$ \\
\hline
\end{tabular}




\section{2) Trabalho na Amazon Mechanical Turk}

2.1) Por quanto tempo você está realizando crowdwork? (Por crowdwork consideramos atividades realizadas em plataformas online em troca de compensação financeira por indivíduos executando tarefas online, como ocorre com a Amazon Mechanical Turk)

\begin{tabular}{|l|l|}
\hline Menos de um mês & $40,5 \%$ \\
\hline De 1 a 6 meses & $25 \%$ \\
\hline De 7 até 12 meses & $5,8 \%$ \\
\hline Mais de 1 ano & $28,7 \%$ \\
\hline
\end{tabular}

2.2) O trabalho sob demanda por meio de aplicativos é a sua principal atividade?

\begin{tabular}{|l|l|}
\hline Sim & $25 \%$ \\
\hline Não & $75 \%$ \\
\hline
\end{tabular}

2.3) Quão satisfeito você está com o trabalho sob demanda por meio de aplicativos?

\begin{tabular}{|l|l|}
\hline Muito satisfeito & $9,6 \%$ \\
\hline Satisfeito & $19,2 \%$ \\
\hline $\begin{array}{l}\text { Nem satisfeito nem } \\
\text { insatisfeito }\end{array}$ & $59,7 \%$ \\
\hline Insatisfeito & $9,6 \%$ \\
\hline Muito insatisfeito & $1,9 \%$ \\
\hline
\end{tabular}

2.3.1) Por favor, descreva as razões pelas quais você está satisfeito ou insatisfeito com o crowdwork

2.4) O trabalho por meio de aplicativos é a sua principal fonte de renda (por exemplo, o seu principal trabalho)?

\begin{tabular}{|l|l|}
\hline Sim & $25 \%$ \\
\hline Não & $75 \%$ \\
\hline
\end{tabular}

2.5) Qual a razão mais importante pela qual você realiza trabalho sob demanda por meio de aplicativos?

\begin{tabular}{|l|l|}
\hline Eu não consigo encontrar outro trabalho & $9,6 \%$ \\
\hline Eu só posso trabalhar de casa & $5,7 \%$ \\
\hline Eu prefiro trabalhar de casa & $15,4 \%$ \\
\hline $\begin{array}{l}\text { O pagamento é melhor do que nos outros } \\
\text { trabalhos disponíveis }\end{array}$ & $0 \%$ \\
\hline $\begin{array}{l}\text { Para complementar a renda dos outros } \\
\text { trabalhos }\end{array}$ & $42,4 \%$ \\
\hline Para ganhar dinheiro enquanto estudo & $5,7 \%$ \\
\hline Como forma de lazer & $3,8 \%$ \\
\hline Eu gosto & $9,6 \%$ \\
\hline Outros. & $7,8 \%$ \\
\hline
\end{tabular}

2.5.1) Explique o motivo da resposta indicada na pergunta 2.5. 
(Se você marcou "eu não consigo encontrar outro trabalho" na 2.5) 2.5.2) Por favor, selecione quais motivos contribuíram para você não encontrar outro trabalho.

\begin{tabular}{|l|l|}
\hline Há falta de trabalho onde eu moro & $58,3 \%$ \\
\hline Eu fui discriminado & $8,3 \%$ \\
\hline $\begin{array}{l}\text { Eu tenho qualificação maior do que a } \\
\text { necessária para os trabalhos disponíveis }\end{array}$ & $8,3 \%$ \\
\hline $\begin{array}{l}\text { Eu não tenho qualificação para os trabalhos } \\
\text { disponíveis }\end{array}$ & $16,8 \%$ \\
\hline Outros & $8,3 \%$ \\
\hline
\end{tabular}

2.7) Além da Amazon Mechanical Turk, em quantas plataformas você trabalhou desde que começou a fazer crowdwork?

\begin{tabular}{|l|l|}
\hline Nenhuma & $57,7 \%$ \\
\hline $1-2$ & $28,5 \%$ \\
\hline $3-4$ & $9,6 \%$ \\
\hline $5-8$ & $3,8 \%$ \\
\hline
\end{tabular}

(Se você marcou 1-2, 3-4 ou 3-4) 2.7.1) Em quais plataformas de crowdwork você trabalhou?

\begin{tabular}{|l|l|}
\hline CrowdFlower & $13,6 \%$ \\
\hline CrowdSource & $31,8 \%$ \\
\hline Upwork & $7,7 \%$ \\
\hline Outras & $46,9 \%$ \\
\hline
\end{tabular}

2.8) Quantas HIT (human intelligence tasks) da Amazon Mechanical Turk você já realizou?

\begin{tabular}{|l|l|}
\hline $1-50$ & $44,2 \%$ \\
\hline $51-100$ & $13,5 \%$ \\
\hline $101-200$ & $7,7 \%$ \\
\hline $201-300$ & $1,9 \%$ \\
\hline $301-400$ & $1,9 \%$ \\
\hline $401-500$ & $1,9 \%$ \\
\hline $501-700$ & $3,8 \%$ \\
\hline $701-900$ & $0 \%$ \\
\hline Mais de 900 & $25 \%$ \\
\hline
\end{tabular}

2.9) Qual das seguintes frases melhor descreve as suas habilidades em relação às atividades disponíveis na Amazon Mechanical Turk?

\begin{tabular}{|l|l|}
\hline $\begin{array}{l}\text { Eu preciso de mais treinamento para } \\
\text { completar todas as tarefas disponíveis na } \\
\text { plataforma }\end{array}$ & $17,4 \%$ \\
\hline $\begin{array}{l}\text { Eu preciso de maior conhecimento em } \\
\text { língua inglesa para completar todas as } \\
\text { tarefas disponíveis na plataforma }\end{array}$ & $3,8 \%$ \\
\hline $\begin{array}{l}\text { As minhas qualificações atuais permitem } \\
\text { que eu realize as tarefas na plataforma }\end{array}$ & $30,8 \%$ \\
\hline $\begin{array}{l}\text { Eu tenho qualificações que me permitem } \\
\text { fazer tarefas mais complexas que as } \\
\text { disponíveis na plataforma }\end{array}$ & $48 \%$ \\
\hline
\end{tabular}


2.10) Por favor, pense em todas as atividades que você realizou em crowdwork no último ano. Em uma semanal normal de trabalho, quanto tempo (em horas), você gastava fazendo atividades pagas nas plataformas?

\begin{tabular}{|l|l|}
\hline Até 10 horas & $72,2 \%$ \\
\hline Mais de 10 até 20 horas & $11,5 \%$ \\
\hline Mais de 20 até 30 horas & $7,6 \%$ \\
\hline Mais de 30 até 40 horas & $3,8 \%$ \\
\hline Mais de 40 horas & $1,9 \%$ \\
\hline
\end{tabular}

2.11) Por favor, pense em todas as atividades que você realizou em crowdwork no último ano. Em uma semana normal de trabalho, quanto tempo (em horas), você gastava fazendo atividades não pagas nas plataformas (como procurar por tarefas, ganhar qualificações, pesquisar a reputação dos solicitantes de tarefas em fórums online, etc)?

\begin{tabular}{|l|l|}
\hline Até 10 horas & $86,5 \%$ \\
\hline Mais de 10 até 20 horas & $5,7 \%$ \\
\hline Mais de 20 até 30 horas & $0 \%$ \\
\hline Mais de 30 até 40 horas & $0 \%$ \\
\hline
\end{tabular}

2.12) Em uma semana normal de trabalho, quanto você recebe realizando crowdwork (em reais)?

\begin{tabular}{|l|l|}
\hline Até 100 & $76,9 \%$ \\
\hline Mais de 100 até 250 & $11,5 \%$ \\
\hline Mais de 250 até 500 & $5,6 \%$ \\
\hline Mais de 500 & $0 \%$ \\
\hline
\end{tabular}

2.13) No último mês em que você fez crowdwork, em quantos dias você trabalhou mais de $10(\mathrm{dez})$ horas?

\begin{tabular}{|l|l|}
\hline 0 & $80,7 \%$ \\
\hline $1-2$ & $15,5 \%$ \\
\hline $3-4$ & $0 \%$ \\
\hline $5-7$ & $1,9 \%$ \\
\hline Mais de 7 & $1,9 \%$ \\
\hline
\end{tabular}

2.14) Quantos dias por semana você geralmente realizada crowdwork?

\begin{tabular}{|l|l|}
\hline 1 & $15,4 \%$ \\
\hline 2 & $5,7 \%$ \\
\hline 3 & $11,5 \%$ \\
\hline 4 & $17,3 \%$ \\
\hline 5 & $23 \%$ \\
\hline 6 & $7,8 \%$ \\
\hline 7 & $19,3 \%$ \\
\hline
\end{tabular}


2.15) Indique o período do dia em que você geralmente realiza crowdwork (selecione todas que entender pertinentes)

\begin{tabular}{|l|l|}
\hline Manhã (5:00-12:00) & $40,3 \%$ \\
\hline Tarde (12:00-18:00) & $50 \%$ \\
\hline Noite (18:00-22:00) & $67,3 \%$ \\
\hline Madrugada (22:00-5:00) & $40,3 \%$ \\
\hline
\end{tabular}

2.16) Geralmente, o seu horário de trabalho sob demanda por meio de aplicativos é compatível com seus outros compromissos familiares?

\begin{tabular}{|l|l|}
\hline Muito & $65,4 \%$ \\
\hline Médio & $25 \%$ \\
\hline Pouco & $9,6 \%$ \\
\hline Nada & $0 \%$ \\
\hline
\end{tabular}

2.17) Você gostaria de fazer mais crowdwork?

\begin{tabular}{|l|l|}
\hline Sim & $94,2 \%$ \\
\hline Não & $5,8 \%$ \\
\hline
\end{tabular}

(Se sim na 2.17) 2.17.1) Por que você não faz mais crowdwork atualmente?

\begin{tabular}{|l|l|}
\hline $\begin{array}{l}\text { Eu não sou qualificado para o trabalho } \\
\text { disponível nas plataformas }\end{array}$ & $22,5 \%$ \\
\hline Não há trabalho disponível suficiente & $20,4 \%$ \\
\hline O pagamento não é bom o suficiente & $30,6 \%$ \\
\hline $\begin{array}{l}\text { Eu não tenho mais tempo para fazer o } \\
\text { trabalho }\end{array}$ & $22,5 \%$ \\
\hline Outros & $4 \%$ \\
\hline
\end{tabular}

(Se não na 2.17) 2.17.2) Qual a principal razão para você não querer mais realizar crowdwork?

\begin{tabular}{|l|l|}
\hline $\begin{array}{l}\text { Eu sou financeiramente estável e } \\
\text { trabalho porque quero }\end{array}$ & $33,3 \%$ \\
\hline $\begin{array}{l}\text { Eu ganho dinheiro suficiente nas horas } \\
\text { que trabalho atualmente }\end{array}$ & $33,3 \%$ \\
\hline O pagamento é baixo & $33,3 \%$ \\
\hline
\end{tabular}

2.18) Você gostaria de fazer mais trabalhos que não sejam crowdwork?

\begin{tabular}{|l|l|}
\hline Sim & $90,4 \%$ \\
\hline Não & $9,6 \%$ \\
\hline
\end{tabular}

(Se sim em 2.18) 2.18.1) Por que você não faz mais trabalhos que não sejam crowdwork atualmente?

\begin{tabular}{|l|l|}
\hline $\begin{array}{l}\text { Eu não sou qualificado para o trabalho } \\
\text { disponível nas plataformas }\end{array}$ & $21,3 \%$ \\
\hline Não há trabalho disponível suficiente & $38,3 \%$ \\
\hline O pagamento não é bom o suficiente & $8,5 \%$ \\
\hline $\begin{array}{l}\text { Eu não tenho mais tempo para fazer o } \\
\text { trabalho }\end{array}$ & $25,5 \%$ \\
\hline Outros & $6,4 \%$ \\
\hline
\end{tabular}


(Se não em 2.18) 2.18.2) Por que você não gostaria de fazer mais trabalhos que não sejam crowdwork?

\begin{tabular}{|l|l|}
\hline $\begin{array}{l}\text { Eu sou financeiramente estável e trabalho } \\
\text { porque quero }\end{array}$ & $40 \%$ \\
\hline $\begin{array}{l}\text { Eu ganho dinheiro suficiente nas horas que } \\
\text { trabalho atualmente }\end{array}$ & $40 \%$ \\
\hline $\begin{array}{l}\text { Eu quero gastar mais tempo com lazer ou outras } \\
\text { atividades que envolvam trabalho não pago }\end{array}$ & $20 \%$ \\
\hline
\end{tabular}

2.19) No seu trabalho na Amazon Mechanical Turk, alguma vez você teve o trabalho rejeitado (e não recebeu pagamento?

\begin{tabular}{|l|l|}
\hline Sim & $55,8 \%$ \\
\hline Não & $44,2 \%$ \\
\hline
\end{tabular}

2.20) Qual é a sua taxa de rejeição de HIT (em \%)?

\begin{tabular}{|l|l|}
\hline Menos de 1 & $34,4 \%$ \\
\hline De 1 a 5 & $48,3 \%$ \\
\hline Mais de 5 a 10 & $10,3 \%$ \\
\hline Mais de 10 a 15 & $0 \%$ \\
\hline Mais de 15 a 20 & $3,5 \%$ \\
\hline Mais de 20 a 25 & $0 \%$ \\
\hline Mais de 25 a 30 & $3,5 \%$ \\
\hline
\end{tabular}

2.21) Geralmente, você acha que as rejeições são justificáveis?

\begin{tabular}{|l|l|}
\hline Todas foram justificáveis & $27,6 \%$ \\
\hline A maioria foi justificável & $20,7 \%$ \\
\hline Algumas foram justificáveis & $17,2 \%$ \\
\hline Poucas foram justificáveis & $27,6 \%$ \\
\hline Não foram justificáveis & $6,9 \%$ \\
\hline
\end{tabular}

(Se você respondeu qualquer que não "todas foram justificáveis") 2.21.1) Por favor, diga-nos por que você achou que a rejeição foi ou não foi justificável. Por favor, explique.

\section{3) Outros trabalhos além da Amazon Mechanical Turk}

3.1) Em qualquer momento das últimas quatro semanas, você procurou por qualquer trabalho remunerado, além do crowdwork?

\begin{tabular}{|l|l|}
\hline Sim & $51,9 \%$ \\
\hline Não & $48,1 \%$ \\
\hline
\end{tabular}

(Se sim em 3.1) 3.1.1) Qual a melhor frase descreve o que você estava procurando como outro trabalho?

\begin{tabular}{|l|l|}
\hline $\begin{array}{l}\text { Eu estava procurando por um novo trabalho para } \\
\text { substituir o crowdwork }\end{array}$ & $25,9 \%$ \\
\hline Eu estava procurando por um trabalho extra & $74,1 \%$ \\
\hline
\end{tabular}


(Se sim em 3.1) 3.1.2) Quais são os motivos que te levaram a procurar um outro trabalho?

\begin{tabular}{|l|l|}
\hline $\begin{array}{l}\text { Não há trabalho suficiente na plataforma que pague o que } \\
\text { eu preciso para viver }\end{array}$ & $34,6 \%$ \\
\hline $\begin{array}{l}\text { Eu realizo crowdwork para preencher o tempo antes de } \\
\text { encontrar outro trabalho }\end{array}$ & $26,9 \%$ \\
\hline Eu quero fazer algo diferente & $28,9 \%$ \\
\hline Outros & $9,6 \%$ \\
\hline
\end{tabular}

3.2) Além do crowdwork, você tem outro(s) trabalho(s) remunerado(s) ou é dono(a) de empresa(s)?

\begin{tabular}{|l|l|}
\hline Sim & $67,3 \%$ \\
\hline Não & $32,7 \%$ \\
\hline
\end{tabular}

(Se sim em 3.2) 3.2.1) Além do crowdwork, quantos outros trabalhos remunerados ou empresas você tem?

\begin{tabular}{|l|l|}
\hline 1 & $74,3 \%$ \\
\hline Mais de 1 & $25,7 \%$ \\
\hline
\end{tabular}

(Se sim em 3.2) 3.2.2) Algum desses trabalhos ou empresas é na economia de bico (gig economy), economia de compartilhamento ou capitalismo de plataforma (por exemplo, Uber)?

\begin{tabular}{|l|l|}
\hline Sim & $20 \%$ \\
\hline Não & $80 \%$ \\
\hline
\end{tabular}

(Se sim em 3.2) 3.2.3) Qual a melhor descrição do seu papel no seu outro trabalho remunerado ou empresa fora do crowdwork?

\begin{tabular}{|l|l|}
\hline Empregado trabalhando por salário-hora & $8,6 \%$ \\
\hline Empregado com salário mensal & $48,6 \%$ \\
\hline Autônomo & $25,7 \%$ \\
\hline Proprietário ou sócio em empresa (com empregados remunerados) & $11,4 \%$ \\
\hline Proprietário ou sócio em empresa (sem empregados remunerados) & $0 \%$ \\
\hline Trabalho sem remuneração & $2,7 \%$ \\
\hline
\end{tabular}

(Se sim em 3.2) 3.2.4) Nesse trabalho remunerado ou empresa fora do crowdwork, quanto do seu tempo você trabalha em casa?

\begin{tabular}{|l|l|}
\hline Nenhum & $37,1 \%$ \\
\hline Um pouco & $8,6 \%$ \\
\hline Algum & $34,3 \%$ \\
\hline Todo & $20 \%$ \\
\hline
\end{tabular}

(Se sim em 3.2) 3.2.5) Há quanto tempo você trabalha nesse trabalho remunerado ou tem essa empresa fora do crowdwork?

\begin{tabular}{|l|l|}
\hline De 0 até 6 meses & $11,4 \%$ \\
\hline Mais de 7 até 12 meses & $8,5 \%$ \\
\hline Mais de 1 ano & $80,1 \%$ \\
\hline
\end{tabular}


(Se sim em 3.2) 3.2.6 Considerando as semanas em que você realizou trabalho remunerado ou gerenciou a empresa fora do crowdwork no último ano, quanto você ganhava por mês em média?

\begin{tabular}{|l|l|}
\hline Menos de 1000 & $70,7 \%$ \\
\hline Mais de 1000 até 2000 & $21,7 \%$ \\
\hline Mais de 2000 até 3000 & $3,8 \%$ \\
\hline Mais de 3000 & $3,8 \%$ \\
\hline
\end{tabular}

(Se sim em 3.2) 3.2.7) Considerando o valor que você ganha por hora trabalhada, você gostaria de trabalhar mais horas nesse trabalho remunerado ou gerenciando essa empresa fora do crowdwork se tivesse a oportunidade?

\begin{tabular}{|l|l|}
\hline Sim & $51,4 \%$ \\
\hline Não & $48,6 \%$ \\
\hline
\end{tabular}

\section{4) Trabalho pré-Amazon Mechanical Turk}

4.1) Imediatamente antes de começar o crowdwork, você

\begin{tabular}{|l|l|}
\hline $\begin{array}{l}\text { Trabalhava ou gerenciava uma empresa e } \\
\text { continua a fazer atualmente }\end{array}$ & $50 \%$ \\
\hline Trabalhava em um emprego diferente & $42,3 \%$ \\
\hline $\begin{array}{l}\text { Gerenciava uma empresa que não existe } \\
\text { mais }\end{array}$ & $0 \%$ \\
\hline Estava desempregado & $32,7 \%$ \\
\hline Estava na escola & $30,8 \%$ \\
\hline $\begin{array}{l}\text { Cuidava de crianças, idosos ou pessoas } \\
\text { com deficiência }\end{array}$ & $5,7 \%$ \\
\hline
\end{tabular}

(Se trabalhava em um emprego diferente ou gerenciava uma empresa que não existe mais em 4.1) 4.1.1) Quanto tempo você trabalhou nessa atividade antes de começar o crowdwork?

\begin{tabular}{|l|l|}
\hline Até 6 meses & $14,3 \%$ \\
\hline Mais de 6 meses até 1 ano & $28,5 \%$ \\
\hline Mais de 1 ano & $57,2 \%$ \\
\hline
\end{tabular}

(Se trabalhava em um emprego diferente ou gerenciava uma empresa que não existe mais em 4.1) 4.1.2) O trabalho que você realizava antes de começar o crowdwork era a sua principal fonte de renda?

\begin{tabular}{|l|l|}
\hline Sim & $85,7 \%$ \\
\hline Não & $14,3 \%$ \\
\hline
\end{tabular}

(Se trabalhava em um emprego diferente ou gerenciava uma empresa que não existe mais em 4.1) 4.1.3) Considerando as semanas que você trabalhou antes de começar o crowdwork, quanto você ganhava por mês? (em reais)

\begin{tabular}{|l|l|}
\hline Menos de 1000 & $14,2 \%$ \\
\hline Mais de 1000 até 2000 & $28,6 \%$ \\
\hline Mais de 2000 até 3000 & $28,6 \%$ \\
\hline Mais de 3000 & $28,6 \%$ \\
\hline
\end{tabular}


4.2) Você saiu do seu trabalho antes de começar o trabalho sob demanda por meio de aplicativos?

\begin{tabular}{|l|l|}
\hline Sim & $13,4 \%$ \\
\hline Não & $86,6 \%$ \\
\hline
\end{tabular}

(Se não em 4.2) 4.2.1) O trabalho que você fazia antes de começar o crowdwork é o mesmo trabalho remunerado que você tem fora do crowdwork?

\begin{tabular}{|l|l|}
\hline Sim & $67,2 \%$ \\
\hline Não & $32,8 \%$ \\
\hline
\end{tabular}

(Se sim em 4.2) 4.2.2) Qual a razão pela qual o trabalho que você fazia antes de começar o crowdwork acabou?

\begin{tabular}{|l|l|}
\hline Eu pedi demissão & $57,1 \%$ \\
\hline Eu fui dispensado sem justa causa & $28,5 \%$ \\
\hline Eu fui dispensado por justa causa & $0 \%$ \\
\hline Eu pedi para ser mandado embora & $14,4 \%$ \\
\hline $\begin{array}{l}\text { Era um trabalho temporário que chegou } \\
\text { ao fim }\end{array}$ & $0 \%$ \\
\hline Eu me aposentei & $0 \%$ \\
\hline Outros & $0 \%$ \\
\hline
\end{tabular}

\section{5) Situação financeira}

5.1) Pensando em todos os trabalhos que você tem atualmente, se comparar as horas de trabalho que você atualmente faz por semana com as que você fazia um ano atrás, o número de horas de trabalho semanal

\begin{tabular}{|l|l|}
\hline Aumentou & $44,2 \%$ \\
\hline Manteve-se & $30,8 \%$ \\
\hline Diminuiu & $25 \%$ \\
\hline
\end{tabular}

5.2) Você é a pessoa que mais contribui para a renda do lar? (considere todas as pessoas que contribuem financeiramente para a manutenção da residência)

\begin{tabular}{|l|l|}
\hline Sim & $34,6 \%$ \\
\hline Não & $65,4 \%$ \\
\hline
\end{tabular}

5.3) Pensando na renda que você obtém de todos os seus trabalhos, se comparar o que você recebe atualmente por mês com o que recebia um ano atrás, a sua renda mensal...

\begin{tabular}{|l|l|}
\hline Aumentou & $30,8 \%$ \\
\hline Manteve-se & $34,6 \%$ \\
\hline Diminuiu & $34,6 \%$ \\
\hline
\end{tabular}

5.4) Qual o valor da renda que você obtém atualmente de todos os seus trabalhos mensalmente?

\begin{tabular}{|l|l|}
\hline Até 1000 & $28,8 \%$ \\
\hline Mais de 1000 até 2000 & $25 \%$ \\
\hline Mais de 2000 até 3000 & $13,4 \%$ \\
\hline Mais de 3000 & $32,8 \%$ \\
\hline
\end{tabular}


5.5) Considerando outras fontes de renda que você tem acesso, o(a) seu(ua) esposo(a), companheiro(a), parceiro(a) ou quem vive junto com você contribui no orçamento doméstico?

\begin{tabular}{|l|l|}
\hline Sim & $76,9 \%$ \\
\hline Não & $23,1 \%$ \\
\hline
\end{tabular}

5.6) Além da renda do seu trabalho e de outras pessoas que vivem com você, o orçamento doméstico é complementado por alguma fonte de renda (por exemplo, benefício da Previdência Social, recebimento de aluguel, pensão, dentre outros)?

\begin{tabular}{|l|l|}
\hline Sim & $32,7 \%$ \\
\hline Não & $67,3 \%$ \\
\hline
\end{tabular}

5.7) A sua família te ajuda financeiramente?

\begin{tabular}{|l|l|}
\hline Sim & $63,4 \%$ \\
\hline Não & $36,6 \%$ \\
\hline
\end{tabular}

5.8) Considerando a renda mensal do seu lar, ela é suficiente para cobrir os gastos básicos necessários para viver? (por exemplo, com moradia, alimentação, roupas, transporte)?

\begin{tabular}{|l|l|}
\hline Sim & $90,4 \%$ \\
\hline Não & $9,6 \%$ \\
\hline
\end{tabular}

5.9) Quanto você consegue economizar em média por mês?

\begin{tabular}{|l|l|}
\hline 0 & $34,6 \%$ \\
\hline Até 100 & $23,2 \%$ \\
\hline Mais de 100 até 500 & $21,1 \%$ \\
\hline Mais de 500 & $21,1 \%$ \\
\hline
\end{tabular}

5.10) Você tem casa própria?

\begin{tabular}{|l|l|}
\hline Sim & $44,2 \%$ \\
\hline Sim, mas estou pagando financiamento & $5,8 \%$ \\
\hline Não & $50 \%$ \\
\hline
\end{tabular}

(Se não em 5.10) 5.10.1) Por favor, selecione a melhor descrição de onde você vive?

\begin{tabular}{|l|l|}
\hline Eu alugo uma casa/apartamento & $50 \%$ \\
\hline Eu vivo de graça (com família, amigos, etc) & $50 \%$ \\
\hline Outros & $0 \%$ \\
\hline
\end{tabular}

5.11) Você faz parte de um sistema de aposentadoria (pública ou privada) que vai te garantir uma determinada renda quanto você se aposentar?

\begin{tabular}{|l|l|}
\hline Sim & $28,8 \%$ \\
\hline Não & $71,2 \%$ \\
\hline
\end{tabular}


5.12) Algum dos trabalhos que você faz promove o recolhimento da contribuição para a Previdência Social ou você recolhe voluntariamente para a Previdência Social?

\begin{tabular}{|l|l|}
\hline Sim & $38,5 \%$ \\
\hline Não & $61,5 \%$ \\
\hline
\end{tabular}

5.13) Você tem plano de saúde?

\begin{tabular}{|l|l|}
\hline Sim & $63,5 \%$ \\
\hline Não & $36,5 \%$ \\
\hline
\end{tabular}

(Se sim em 5.13) 5.13.1) O seu plano de saúde é financiado:

\begin{tabular}{|l|l|}
\hline por um dos seus empregadores & $36,4 \%$ \\
\hline por você e pelos seus empregadores & $0 \%$ \\
\hline Por um dos empregadores de um dos membros de sua família & $30,3 \%$ \\
\hline Somente por você & $33,3 \%$ \\
\hline
\end{tabular}

6 ) Se você pudesse mudar algo no trabalho sob demanda por meio de aplicativos, o que seria?

7) Você tem outros pensamentos que gostaria de dividir sobre a experiência no trabalho sob demanda por meio de aplicativos?

\section{Perguntas-teste} mãos?

1.8) Quantos homens já pularam do Planeta Terra e tocaram o Sol com as duas

\begin{tabular}{|l|l|}
\hline Muitos & $7,2 \%$ \\
\hline Nenhum & $92,8 \%$ \\
\hline Alguns & $0 \%$ \\
\hline
\end{tabular}

2.19) Por favor, indique o quanto você concorda ou discorda das seguintes frases

\begin{tabular}{|l|l|l|l|l|l|}
\hline & $\begin{array}{l}\text { Discorda } \\
\text { fortemente }\end{array}$ & $\begin{array}{l}\text { Discorda } \\
\text { um pouco }\end{array}$ & $\begin{array}{l}\text { Não } \\
\text { concorda } \\
\text { nem } \\
\text { discorda }\end{array}$ & $\begin{array}{l}\text { Concorda } \\
\text { um pouco }\end{array}$ & $\begin{array}{l}\text { Concorda } \\
\text { fortemente }\end{array}$ \\
\hline $\begin{array}{l}\text { Crowdwork } \\
\text { pode ser } \\
\text { divertido }\end{array}$ & $0 \%$ & $3,8 \%$ & $5,7 \%$ & $53,9 \%$ & $36,6 \%$ \\
\hline $\begin{array}{l}\text { Eu morei } \\
\text { em todos os } \\
\text { países do } \\
\text { mundo uma } \\
\text { vez por ano }\end{array}$ & $100 \%$ & $0 \%$ & $0 \%$ & $0 \%$ & $0 \%$ \\
\hline
\end{tabular}




\begin{tabular}{|l|l|l|l|l|l|}
\hline $\begin{array}{l}\text { Eu gosto de } \\
\text { responder } \\
\text { pesquisas } \\
\text { online }\end{array}$ & $0 \%$ & $7,7 \%$ & $13,5 \%$ & $48 \%$ & $30,7 \%$ \\
\hline $\begin{array}{l}\text { Um mais } \\
\text { três nunca é } \\
\text { igual a sete }\end{array}$ & $7,1 \%$ & $0 \%$ & $0 \%$ & $0 \%$ & $92,9 \%$ \\
\hline $\begin{array}{l}\text { Eu prefiro } \\
\text { responder } \\
\text { pesquisas } \\
\text { do que } \\
\text { outras } \\
\text { atividades } \\
\text { de } \\
\text { crowdwork }\end{array}$ & $7,7 \%$ & $15,4 \%$ & $30,7 \%$ & $26,9 \%$ & $19,3 \%$ \\
\hline $\begin{array}{l}\text { A resposta } \\
\text { deste item é } \\
\text { "não } \\
\text { concorda } \\
\text { nem } \\
\text { discorda" }\end{array}$ & $1,9 \%$ & $0 \%$ & $92,9 \%$ & $0 \%$ & $5,8 \%$ \\
\hline
\end{tabular}

3.3) Quantos homens moram em Saturno?

\begin{tabular}{|l|l|}
\hline Um milhão & $7,1 \%$ \\
\hline Duzentos mil & $0 \%$ \\
\hline Nenhum & $92,9 \%$ \\
\hline Cento e oitenta e nove & $0 \%$ \\
\hline
\end{tabular}

4.3) Em qual planeta você mora?

\begin{tabular}{|l|l|}
\hline Sol & $7,1 \%$ \\
\hline Lua & $0 \%$ \\
\hline Terra & $92,9 \%$ \\
\hline
\end{tabular}

5.14) $1+1=$

\begin{tabular}{|l|l|}
\hline 0 & $7,1 \%$ \\
\hline 1 & $0 \%$ \\
\hline 2 & $92,9 \%$ \\
\hline
\end{tabular}




\section{APÊNDICE B - RESULTADO DO QUESTIONÁRIO - MOTORISTAS DA UBER}

\section{1) Informações sociodemográficas}

1.1) Onde você vive?

\begin{tabular}{|l|l|}
\hline São Paulo & $57,8 \%$ \\
\hline Grande São Paulo & $41,2 \%$ \\
\hline Outra cidade & $1 \%$ \\
\hline
\end{tabular}

1.2) Qual é o seu sexo biológico?

\begin{tabular}{|l|l|}
\hline Masculino & $96,1 \%$ \\
\hline Feminino & $3,9 \%$ \\
\hline
\end{tabular}

1.3) Em que ano você nasceu?

1.4) Qual o seu estado civil?

\begin{tabular}{|l|l|}
\hline Solteiro(a) & $32,3 \%$ \\
\hline Casado(a) & $47 \%$ \\
\hline Divorciado(a) & $6,9 \%$ \\
\hline Separado(a) & $2 \%$ \\
\hline União estável & $11,8 \%$ \\
\hline Viúvo (a) & $0 \%$ \\
\hline
\end{tabular}

1.5) Qual é o seu grau de instrução?

\begin{tabular}{|l|l|}
\hline $\begin{array}{l}\text { Menos que ensino } \\
\text { médio }\end{array}$ & $11,8 \%$ \\
\hline Ensino médio & $61,8 \%$ \\
\hline Ensino técnico & $2,9 \%$ \\
\hline Ensino superior & $23,5 \%$ \\
\hline
\end{tabular}

1.6) Atualmente você está matriculado em algum curso?

\begin{tabular}{|l|l|}
\hline Sim & $88,2 \%$ \\
\hline Não & $11,8 \%$ \\
\hline
\end{tabular}

(Se sim na 1.6) 1.6.1) Você pretende se formar em qual curso?

\begin{tabular}{|l|l|}
\hline Ensino médio & $8,3 \%$ \\
\hline Ensino técnico & $0 \%$ \\
\hline Ensino superior & $91,7 \%$ \\
\hline Mestrado & $0 \%$ \\
\hline Doutorado & $0 \%$ \\
\hline
\end{tabular}




\section{2) Trabalho na Uber}

2.1) Por quanto tempo você está realizando trabalho sob demanda por meio de aplicativos? (Por trabalho sob demanda por meio de aplicativos, consideramos atividades realizadas por trabalhadores e demandadas pelos consumidores a partir de aplicativos, como ocorre com a Uber)

\begin{tabular}{|l|l|}
\hline Menos de um mês & $9,8 \%$ \\
\hline De 1 até 12 meses & $47,1 \%$ \\
\hline Mais de 1 ano & $43,1 \%$ \\
\hline
\end{tabular}

2.2) Por mais quanto tempo você pretende ficar no trabalho sob demanda por meio de aplicativos?

\begin{tabular}{|l|l|}
\hline Menos de um mês & $9,8 \%$ \\
\hline De 1 até 12 meses & $13,7 \%$ \\
\hline Indefinidamente & $76,5 \%$ \\
\hline
\end{tabular}

2.3) O trabalho sob demanda por meio de aplicativos é a sua principal atividade?

\begin{tabular}{|l|l|}
\hline Sim & $80,4 \%$ \\
\hline Não & $19,6 \%$ \\
\hline
\end{tabular}

2.4) Quão satisfeito você está com o trabalho sob demanda por meio de aplicativos?

\begin{tabular}{|l|l|}
\hline Muito satisfeito & $19,6 \%$ \\
\hline Satisfeito & $56,9 \%$ \\
\hline $\begin{array}{l}\text { Nem satisfeito nem } \\
\text { insatisfeito }\end{array}$ & $18,6 \%$ \\
\hline Insatisfeito & $4,9 \%$ \\
\hline Muito insatisfeito & $0 \%$ \\
\hline
\end{tabular}

2.4.1) Por favor, descreva as razões pelas quais você está satisfeito ou insatisfeito com o trabalho sob demanda por meio de aplicativos

2.5) O trabalho por meio de aplicativos é a sua principal fonte de renda (por exemplo, o seu principal trabalho)?

\begin{tabular}{|l|l|}
\hline Sim & $77,5 \%$ \\
\hline Não & $22,5 \%$ \\
\hline
\end{tabular}

2.6) Qual a razão mais importante pela qual você realiza trabalho sob demanda por meio de aplicativos?

\begin{tabular}{|l|l|}
\hline Eu não consigo encontrar outro trabalho & $28,4 \%$ \\
\hline $\begin{array}{l}\text { O pagamento é melhor do que nos outros } \\
\text { trabalhos disponíveis }\end{array}$ & $32,4 \%$ \\
\hline $\begin{array}{l}\text { Para complementar a renda dos outros } \\
\text { trabalhos }\end{array}$ & $26,5 \%$ \\
\hline Para ganhar dinheiro enquanto estudo & $2,9 \%$ \\
\hline Como forma de lazer & $0 \%$ \\
\hline Outros. & $9,8 \%$ \\
\hline
\end{tabular}


2.7) Além da Uber, em quais plataformas você trabalhou desde que começou a fazer trabalho sob demanda por meio de aplicativos?

\begin{tabular}{|l|l|}
\hline Nenhuma & $45,1 \%$ \\
\hline Easy & $0 \%$ \\
\hline 99 & $48 \%$ \\
\hline Cabify & $1 \%$ \\
\hline Duas dessas plataformas & $4,9 \%$ \\
\hline Mais de duas dessas plataformas & $1 \%$ \\
\hline
\end{tabular}

2.8) Quantas viagens com a Uber você já realizou?

2.9) Por favor, pense em todas as atividades que você realizou em trabalho sob demanda por meio de aplicativos no último ano. Em um dia normal de trabalho, quanto tempo (em horas), você gastava fazendo atividades nas plataformas?

\begin{tabular}{|l|l|}
\hline De 1 até 4 & $0 \%$ \\
\hline Mais de 4 até 8 & $23,5 \%$ \\
\hline Mais de 8 até 10 & $23,5 \%$ \\
\hline Mais de 10 até 12 & $21,6 \%$ \\
\hline Mais de 12 & $31,4 \%$ \\
\hline
\end{tabular}

2.10) Por favor, pense em todas as atividades que você realizou em trabalho sob demanda por meio de aplicativos no último ano. Em um dia normal de trabalho, quanto tempo (em horas), você gastava fazendo atividades não pagas nas plataformas (como esperar por chamados)?

\begin{tabular}{|l|l|}
\hline Menos de 1 & $32,4 \%$ \\
\hline De 1 até 2 & $49 \%$ \\
\hline Mais de 2 até 4 & $17,6 \%$ \\
\hline Mais de 4 & $1 \%$ \\
\hline
\end{tabular}

2.11) Em um dia normal de trabalho, quanto você recebe realizando trabalho sob demanda por meio de aplicativos (em reais), descontada a taxa do aplicativo?

\begin{tabular}{|l|l|}
\hline Até 200 & $43,1 \%$ \\
\hline Mais de 200 até 500 & $56,9 \%$ \\
\hline Mais de 500 até 1000 & $0 \%$ \\
\hline Mais de 1000 & $0 \%$ \\
\hline
\end{tabular}

2.11.1) Em um dia normal de trabalho, quanto você gasta com despesas fixas para trabalhar (como combustível, seguro, manutenção, depreciação, limpeza, telefone celular, plano de dados, etc)?

\begin{tabular}{|l|l|}
\hline Até 50 & $35,3 \%$ \\
\hline Mais de 50 até 100 & $55,9 \%$ \\
\hline Mais de 100 até 200 & $8,8 \%$ \\
\hline Mais de 200 & $0 \%$ \\
\hline
\end{tabular}

2.11.2) Você controla os gastos fixos que você tem?

\begin{tabular}{|l|l|}
\hline Sim & $72,5 \%$ \\
\hline Não & $27,5 \%$ \\
\hline
\end{tabular}


2.12) Em um dia normal de trabalho, quantas viagens você realiza?

2.13) Na última semana em que você realizou trabalho sob demanda por meio de aplicativos, em quantos dias você trabalhou por mais de 10 horas?

\begin{tabular}{|l|l|}
\hline 0 & $32,4 \%$ \\
\hline Até 2 & $13,7 \%$ \\
\hline Mais de 2 até 5 & $28,4 \%$ \\
\hline Mais de 5 & $25,5 \%$ \\
\hline
\end{tabular}

2.14) Quantos dias por semana você geralmente realiza trabalho sob demanda por meio de aplicativos?

\begin{tabular}{|l|l|}
\hline Até 2 & $0 \%$ \\
\hline Mais de 2 até 5 & $31,4 \%$ \\
\hline Mais de 5 & $68,6 \%$ \\
\hline
\end{tabular}

2.15) Por favor, indique os períodos do dia em que você geralmente realiza trabalho sob demanda por meio de aplicativos.

\begin{tabular}{|l|l|}
\hline Manhã (5:00-12:00) & $86,3 \%$ \\
\hline Tarde (12:00-18:00) & $86,3 \%$ \\
\hline Noite (18:00-22:00) & $62,7 \%$ \\
\hline Madrugada (22:00-5:00) & $15,7 \%$ \\
\hline
\end{tabular}

2.16) Como você decide quantas horas irá trabalhar em um determinado dia?_

2.17) Geralmente, o seu horário de trabalho sob demanda por meio de aplicativos é compatível com seus outros compromissos familiares?

\begin{tabular}{|l|l|}
\hline Muito & $30,4 \%$ \\
\hline Médio & $38,2 \%$ \\
\hline Pouco & $17,6 \%$ \\
\hline Nada & $13,7 \%$ \\
\hline
\end{tabular}

2.18) Como você avalia o preço dinâmico da Uber?

\begin{tabular}{|l|l|}
\hline Positivo & $67,6 \%$ \\
\hline Negativo & $8,8 \%$ \\
\hline Indiferente & $23,5 \%$ \\
\hline
\end{tabular}

2.19) Se você identifica o preço dinâmico, você dirige por mais tempo no dia?

\begin{tabular}{|l|l|}
\hline Sim & $40,2 \%$ \\
\hline Não & $59,8 \%$ \\
\hline
\end{tabular}

2.20) Você sente que a Uber te induz a realizar corridas quando há preço dinâmico?

\begin{tabular}{|l|l|}
\hline Sim & $24,5 \%$ \\
\hline Não & $75,5 \%$ \\
\hline
\end{tabular}

2.21) A Uber lhe forneceu algum dos instrumentos que você usa para trabalhar (como carro, telefone celular, seguro etc)?

\begin{tabular}{|l|l|}
\hline Sim & $0 \%$ \\
\hline Não & $100 \%$ \\
\hline
\end{tabular}


2.22) Qual é a situação do veículo que você usa para trabalhar?

\begin{tabular}{|l|l|}
\hline Proprietário antes de começar a trabalhar para a Uber & $33,3 \%$ \\
\hline Proprietário e comprei para trabalhar para a Uber & $35,3 \%$ \\
\hline Alugado & $29,4 \%$ \\
\hline Emprestado & $2 \%$ \\
\hline
\end{tabular}

2.23) Qual o modalidade de corridas pela Uber você realiza com mais frequência?

\begin{tabular}{|l|l|}
\hline UberPool & $0 \%$ \\
\hline UberX & $96,1 \%$ \\
\hline UberSelect & $2,9 \%$ \\
\hline UberBlack & $1 \%$ \\
\hline UberBag & $0 \%$ \\
\hline UberBlackBag & $0 \%$ \\
\hline
\end{tabular}

2.23.1) Qual é a melhor modalidade que você é cadastrado? Por quê?

2.23.2) Qual é a pior modalidade que você é cadastrado? Por quê?

2.24) Você gostaria de realizar mais trabalho sob demanda por meio de aplicativos?

\begin{tabular}{|l|l|}
\hline Sim & $70,6 \%$ \\
\hline Não & $29,4 \%$ \\
\hline
\end{tabular}

(Se sim em 2.24) 2.24.1) Por que você não faz mais trabalho sob demanda por meio de aplicativos atualmente?

\begin{tabular}{|l|l|}
\hline Não há trabalho suficiente disponível & $6,3 \%$ \\
\hline O pagamento não é bom o suficiente & $15,6 \%$ \\
\hline Eu não tenho mais tempo para fazer o trabalho & $59,4 \%$ \\
\hline Outros & $18,8 \%$ \\
\hline
\end{tabular}

(Se não em 2.24) 2.24.2) Por que você não gostaria de fazer mais trabalho sob demanda por meio de aplicativos?

\begin{tabular}{|l|l|}
\hline Eu sou estudante & $2,9 \%$ \\
\hline Eu sou financeiramente estável & $2,9 \%$ \\
\hline $\begin{array}{l}\text { Eu ganho dinheiro suficiente nas horas que } \\
\text { trabalho atualmente }\end{array}$ & $18,6 \%$ \\
\hline $\begin{array}{l}\text { Eu tenho compromissos diários que me } \\
\text { impedem de trabalhar mais }\end{array}$ & $11,4 \%$ \\
\hline $\begin{array}{l}\text { Eu quero gastar mais tempo com lazer ou } \\
\text { outras atividades que envolvem trabalho } \\
\text { não pago }\end{array}$ & $14,3 \%$ \\
\hline $\begin{array}{l}\text { Eu quero realizar trabalhos diferentes do } \\
\text { trabalho sob demanda por meio de } \\
\text { aplicativos }\end{array}$ & $14,3 \%$ \\
\hline Outros & $35,7 \%$ \\
\hline
\end{tabular}

2.25) Você gostaria de fazer mais trabalhos que não sejam trabalho sob demanda por meio de aplicativos?

\begin{tabular}{|l|l|}
\hline Sim & $68,6 \%$ \\
\hline Não & $31,4 \%$ \\
\hline
\end{tabular}


(Se sim em 2.25) 2.25.1) Por que você não faz mais trabalhos que não sejam trabalho sob demanda por meio de aplicativos atualmente?

\begin{tabular}{|l|l|}
\hline Não há trabalho suficiente disponível & $60 \%$ \\
\hline O pagamento não é bom o suficiente & $15,7 \%$ \\
\hline $\begin{array}{l}\text { Eu não tenho mais tempo para fazer o } \\
\text { trabalho }\end{array}$ & $1,4 \%$ \\
\hline Outros & $22,9 \%$ \\
\hline
\end{tabular}

(Se não em 2.25) 2.25.2) Por que você não gostaria de fazer mais trabalhos que não sejam trabalho sob demanda por meio de aplicativos?

\begin{tabular}{|l|l|}
\hline Eu sou estudante & $9,4 \%$ \\
\hline Eu sou financeiramente estável & $3,1 \%$ \\
\hline $\begin{array}{l}\text { Eu ganho dinheiro suficiente nas horas que trabalho } \\
\text { atualmente }\end{array}$ & $6,3 \%$ \\
\hline $\begin{array}{l}\text { Eu tenho compromissos diários que me impedem de } \\
\text { trabalhar mais }\end{array}$ & $25 \%$ \\
\hline $\begin{array}{l}\text { Eu quero gastar mais tempo com lazer ou outras } \\
\text { atividades que envolvem trabalho não pago }\end{array}$ & $0 \%$ \\
\hline $\begin{array}{l}\text { Eu quero realizar trabalhos diferentes do trabalho sob } \\
\text { demanda por meio de aplicativos }\end{array}$ & $0 \%$ \\
\hline Outros & $56,3 \%$ \\
\hline
\end{tabular}

2.26) Qual é o seu rating na Uber?

2.27) Você já foi suspenso da Uber?

\begin{tabular}{|l|l|}
\hline Sim & $92,2 \%$ \\
\hline Não & $7,8 \%$ \\
\hline
\end{tabular}

(Se sim em 2.27) 2.27.1) Você achou a suspensão justa?

\begin{tabular}{|l|l|}
\hline Sim & $88,9 \%$ \\
\hline Não. & $11,1 \%$ \\
\hline
\end{tabular}

Por quê?

2.28) Você tem receio de receber uma suspensão ou de ser excluído da Uber?

\begin{tabular}{|l|l|}
\hline Sim & $41,2 \%$ \\
\hline Não & $58,8 \%$ \\
\hline
\end{tabular}

2.29) Como você avalia o sistema de ratings da Uber?

\begin{tabular}{|l|l|}
\hline Positivo & $60,8 \%$ \\
\hline Negativo & $17,6 \%$ \\
\hline Indiferente & $21,6 \%$ \\
\hline
\end{tabular}

Por quê? 


\section{3) Outros trabalhos além da Uber}

3.1) Em qualquer momento das últimas quatro semanas, você procurou por qualquer trabalho remunerado, além do trabalho sob demanda por meio de aplicativos?

\begin{tabular}{|l|l|}
\hline Sim & $75,5 \%$ \\
\hline Não & $24,5 \%$ \\
\hline
\end{tabular}

(Se sim em 3.1) 3.1.1) Qual a melhor frase descreve o que você estava procurando como outro trabalho?

\begin{tabular}{|l|l|}
\hline $\begin{array}{l}\text { Eu estava procurando por um novo trabalho para } \\
\text { substituir o trabalho sob demanda por meio de aplicativos }\end{array}$ & $72 \%$ \\
\hline Eu estava procurando por um trabalho extra & $28 \%$ \\
\hline
\end{tabular}

(Se sim em 3.1) 3.1.2) Quais são os motivos que te levaram a procurar um outro trabalho?

\begin{tabular}{|l|l|}
\hline $\begin{array}{l}\text { Não há trabalho suficiente na plataforma que pague o que } \\
\text { eu preciso para viver }\end{array}$ & $8,7 \%$ \\
\hline $\begin{array}{l}\text { Eu realizo trabalho sob demanda por meio de aplicativos } \\
\text { para preencher o tempo antes de encontrar outro trabalho }\end{array}$ & $60,9 \%$ \\
\hline Eu quero fazer algo diferente & $13 \%$ \\
\hline Outros & $17,4 \%$ \\
\hline
\end{tabular}

3.2) Além do trabalho sob demanda por meio de aplicativos, você tem outro(s) trabalho(s) remunerado(s) ou é dono(a) de empresa(s)?

\begin{tabular}{|l|l|}
\hline Sim & $27,5 \%$ \\
\hline Não & $72,5 \%$ \\
\hline
\end{tabular}

(Se sim em 3.2) 3.2.1) Além do trabalho sob demanda por meio de aplicativos, quantos outros trabalho remunerados ou empresas você tem?

\begin{tabular}{|l|l|}
\hline 1 & $92,3 \%$ \\
\hline Mais de 1 & $7,7 \%$ \\
\hline
\end{tabular}

(Se sim em 3.2) 3.2.2) Algum desses trabalhos ou empresas é na economia de bico (gig economy), economia de compartilhamento ou capitalismo de plataforma?

\begin{tabular}{|l|l|}
\hline Sim & $0 \%$ \\
\hline Não & $100 \%$ \\
\hline
\end{tabular}

(Se sim em 3.2) 3.2.3) Qual a melhor descrição do seu papel no seu outro trabalho remunerado ou empresa fora do trabalho sob demanda por meio de aplicativos?

\begin{tabular}{|l|l|}
\hline Empregado trabalhando por salário-hora & $0 \%$ \\
\hline Empregado com salário mensal & $32,1 \%$ \\
\hline Autônomo & $42,9 \%$ \\
\hline Proprietário ou sócio em empresa (com empregados remunerados) & $7,1 \%$ \\
\hline Proprietário ou sócio em empresa (sem empregados remunerados) & $17,9 \%$ \\
\hline Trabalho sem remuneração & $0 \%$ \\
\hline
\end{tabular}


(Se sim em 3.2) 3.2.4) Há quanto tempo você trabalha nesse trabalho remunerado ou tem essa empresa fora do trabalho sob demanda por meio de aplicativos?

\begin{tabular}{|l|l|}
\hline De 0 até 6 meses & $17,9 \%$ \\
\hline Mais de 7 até 12 meses & $0 \%$ \\
\hline Mais de 1 ano & $82,1 \%$ \\
\hline
\end{tabular}

(Se sim em 3.2) 3.2.5) Considerando as semanas em que você realizou trabalho remunerado ou gerenciou a empresa fora do trabalho sob demanda por meio de aplicativos no último ano, quanto você ganhava por mês em média?

\begin{tabular}{|l|l|}
\hline Menos de 1000 & $17,9 \%$ \\
\hline Mais de 1000 até 2000 & $39,3 \%$ \\
\hline Mais de 2000 até 3000 & $7,1 \%$ \\
\hline Mais de 3000 & $35,7 \%$ \\
\hline
\end{tabular}

(Se sim em 3.2) 3.3.6) Considerando as semanas em que você realizou trabalho remunerado ou gerenciou a empresa fora do trabalho sob demanda por meio de aplicativos no último ano, quantas horas por dia você trabalhava em média?

\begin{tabular}{|l|l|}
\hline Até 10 & $32,1 \%$ \\
\hline Mais de 10 até 20 & $17,9 \%$ \\
\hline Mais de 20 até 30 & $7,1 \%$ \\
\hline Mais de 30 até 40 & $25 \%$ \\
\hline Mais de 40 até 50 & $14,3 \%$ \\
\hline Mais de 50 até 60 & $0 \%$ \\
\hline Mais de 60 & $3,6 \%$ \\
\hline
\end{tabular}

(Se sim em 3.2) 3.2.7) Considerando o valor que você ganha por hora trabalhada, você gostaria de trabalhar mais horas nesse trabalho remunerado ou gerenciando essa empresa fora do trabalho sob demanda por meio de aplicativos se tivesse a oportunidade?

\begin{tabular}{|l|l|}
\hline Sim & $57,1 \%$ \\
\hline Não & $42,9 \%$ \\
\hline
\end{tabular}

\section{4) Trabalho pré-Uber}

4.1) Imediatamente antes de começar o trabalho sob demanda por meio de aplicativos, você

\begin{tabular}{|l|l|}
\hline $\begin{array}{l}\text { Trabalhava ou gerenciava uma empresa e } \\
\text { continua a fazer atualmente }\end{array}$ & $25,5 \%$ \\
\hline Trabalhava em um emprego diferente & $69,6 \%$ \\
\hline $\begin{array}{l}\text { Gerenciava uma empresa que não existe } \\
\text { mais }\end{array}$ & $2 \%$ \\
\hline Estava desempregado & $1 \%$ \\
\hline Estava na escola & $2 \%$ \\
\hline $\begin{array}{l}\text { Cuidava de crianças, idosos ou pessoas } \\
\text { com deficiência }\end{array}$ & $0 \%$ \\
\hline
\end{tabular}


(Se trabalhava em um emprego diferente ou gerenciava uma empresa que não existe mais em 4.1) 4.1.1) Quanto tempo você trabalhou nessa atividade antes de começar o trabalho sob demanda por meio de aplicativos?

\begin{tabular}{|l|l|}
\hline Até 6 meses & $5,2 \%$ \\
\hline Mais de 6 meses até 1 ano & $10,3 \%$ \\
\hline Mais de 1 ano & $84,5 \%$ \\
\hline
\end{tabular}

(Se trabalhava em um emprego diferente ou gerenciava uma empresa que não existe mais em 4.1) 4.1.2) Considerando as semanas que você trabalhou antes de começar o trabalho sob demanda por meio de aplicativos, quanto você ganhava por mês? (em reais)

\begin{tabular}{|l|l|}
\hline Menos de 1000 & $4,1 \%$ \\
\hline Mais de 1000 até 2000 & $24,7 \%$ \\
\hline Mais de 2000 até 3000 & $26,8 \%$ \\
\hline Mais de 3000 & $44,3 \%$ \\
\hline
\end{tabular}

(Se trabalhava em um emprego diferente ou gerenciava uma empresa que não existe mais em 4.1) 4.1.3) Considerando as semanas que você trabalhou antes de começar o trabalho sob demanda por meio de aplicativos, quantas horas você trabalhava em uma semana típica de trabalho?

\begin{tabular}{|l|l|}
\hline Até 10 & $3,1 \%$ \\
\hline Mais de 10 até 20 & $3,1 \%$ \\
\hline Mais de 20 até 30 & $4,1 \%$ \\
\hline Mais de 30 até 40 & $23,7 \%$ \\
\hline Mais de 40 até 50 & $56,7 \%$ \\
\hline Mais de 50 até 60 & $4,1 \%$ \\
\hline Mais de 60 & $5,2 \%$ \\
\hline
\end{tabular}

4.2) Você saiu do seu trabalho antes de começar o trabalho sob demanda por meio de aplicativos?

\begin{tabular}{|l|l|}
\hline Sim & $74,5 \%$ \\
\hline Não & $25,5 \%$ \\
\hline
\end{tabular}

(Se não em 4.2) 4.2.1) O trabalho que você fazia antes de começar o trabalho sob demanda por meio de aplicativos é o mesmo trabalho remunerado que você tem fora do trabalho sob demanda por meio de aplicativos?

\begin{tabular}{|l|l|}
\hline Sim & $69,2 \%$ \\
\hline Não & $30,8 \%$ \\
\hline
\end{tabular}

(Se sim em 4.2) 4.2.2) Qual a razão pela qual o trabalho que você fazia antes de começar o trabalho sob demanda por meio de aplicativos acabou?

\begin{tabular}{|l|l|}
\hline Eu pedi demissão & $18,2 \%$ \\
\hline Eu fui dispensado sem justa causa & $58,4 \%$ \\
\hline Eu fui dispensado por justa causa & $0 \%$ \\
\hline Eu pedi para ser mandado embora & $3,9 \%$ \\
\hline $\begin{array}{l}\text { Era um trabalho temporário que chegou } \\
\text { ao fim }\end{array}$ & $1,3 \%$ \\
\hline Eu me aposentei & $2,6 \%$ \\
\hline Outros & $0 \%$ \\
\hline
\end{tabular}




\section{5) Situação financeira}

5.1) Pensando em todos os trabalhos que você tem atualmente, se comparar as horas de trabalho que você atualmente faz por semana com as que você fazia um ano atrás, o número de horas de trabalho semanal

\begin{tabular}{|l|l|}
\hline Aumentou & $52 \%$ \\
\hline Manteve-se & $25,5 \%$ \\
\hline Diminuiu & $22,5 \%$ \\
\hline
\end{tabular}

5.2) Você é a pessoa que mais contribui para a renda do lar? (considere todas as pessoas que contribuem financeiramente para a manutenção da residência)

\begin{tabular}{|l|l|}
\hline Sim & $70,6 \%$ \\
\hline Não & $29,4 \%$ \\
\hline
\end{tabular}

5.3) Pensando na renda que você obtém de todos os seus trabalhos, se comparar o que você recebe atualmente por mês com o que recebia um ano atrás, a sua renda mensal...

\begin{tabular}{|l|l|}
\hline Aumentou & $47,1 \%$ \\
\hline Manteve-se & $21,6 \%$ \\
\hline Diminuiu & $31,4 \%$ \\
\hline
\end{tabular}

5.4) Qual o valor da renda que você obtém atualmente de todos os seus trabalhos mensalmente?

\begin{tabular}{|l|l|}
\hline Até 1000 & $0 \%$ \\
\hline Mais de 1000 até 2000 & $4,9 \%$ \\
\hline Mais de 2000 até 3000 & $19,6 \%$ \\
\hline Mais de 3000 & $75,5 \%$ \\
\hline
\end{tabular}

5.5) Além da renda do seu trabalho e de outras pessoas que vivem com você, o orçamento doméstico é complementado por alguma fonte de renda (por exemplo, benefício da Previdência Social, recebimento de aluguel, pensão, dentre outros)?

\begin{tabular}{|l|l|}
\hline Sim & $26,5 \%$ \\
\hline Não & $73,5 \%$ \\
\hline
\end{tabular}

5.6) Considerando a renda mensal do seu lar, ela é suficiente para cobrir os gastos básicos necessários para viver? (por exemplo, com moradia, alimentação, roupas, transporte)?

\begin{tabular}{|l|l|}
\hline Sim & $72,5 \%$ \\
\hline Não & $27,5 \%$ \\
\hline
\end{tabular}

5.7) Quanto você consegue economizar em média por mês?

\begin{tabular}{|l|l|}
\hline 0 & $59,8 \%$ \\
\hline Até 100 & $5,9 \%$ \\
\hline Mais de 100 até 500 & $18,6 \%$ \\
\hline Mais de 500 & $15,7 \%$ \\
\hline
\end{tabular}


5.8) Você tem casa própria?

\begin{tabular}{|l|l|}
\hline Sim & $51 \%$ \\
\hline Sim, mas estou pagando financiamento & $6,9 \%$ \\
\hline Não & $42,1 \%$ \\
\hline
\end{tabular}

(Se não em 5.8) 5.8.1) Por favor, selecione a melhor descrição de onde você vive?

\begin{tabular}{|l|l|}
\hline Eu alugo uma casa/apartamento & $65,1 \%$ \\
\hline Eu vivo de graça (com família, amigos, etc) & $32,6 \%$ \\
\hline Outros & $2,3 \%$ \\
\hline
\end{tabular}

5.9) Você faz parte de um sistema de aposentadoria (pública ou privada) que vai te garantir uma determinada renda quanto você se aposentar?

\begin{tabular}{|l|l|}
\hline Sim & $43,1 \%$ \\
\hline Não & $56,9 \%$ \\
\hline
\end{tabular}

5.10) Algum dos trabalhos que você faz promove o recolhimento da contribuição para a Previdência Social ou você recolhe voluntariamente para a Previdência Social?

\begin{tabular}{|l|l|}
\hline Sim & $28,4 \%$ \\
\hline Não & $71,6 \%$ \\
\hline
\end{tabular}

5.11) Você tem plano de saúde?

\begin{tabular}{|l|l|}
\hline Sim & $32,4 \%$ \\
\hline Não & $67,6 \%$ \\
\hline
\end{tabular}

(Se sim em 5.11) 5.11.1) O seu plano de saúde é financiado:

\begin{tabular}{|l|l|}
\hline por um dos seus empregadores & $15,2 \%$ \\
\hline por você e pelos seus empregadores & $12,1 \%$ \\
\hline Por um dos empregadores de um dos membros de sua família & $27,3 \%$ \\
\hline Somente por você & $45,5 \%$ \\
\hline
\end{tabular}

6 ) Se você pudesse mudar algo no trabalho sob demanda por meio de aplicativos, o que seria?

7) Você tem outros pensamentos que gostaria de dividir sobre a experiência no trabalho sob demanda por meio de aplicativos? 


\section{APÊNDICE C - TERMO DE CONSENTIMENTO DE PARTICIPAÇÃO}

\section{Pesquisador responsável:}

Renan Bernardi Kalil, doutorando em direito do trabalho pela Universidade de São Paulo (USP), sob orientação do Professor Otavio Pinto e Silva, em período sanduíche na Faculdade de Direito da Universidade de Harvard, nos Estados Unidos (EUA).

Você está sendo convidado(a) para participar como voluntário(a) da pesquisa "Capitalismo de plataforma e proteção social: trabalho sob demanda por meio de aplicativos, crowdwork e direito do trabalho". Leia com atenção as informações abaixo antes de dar o seu consentimento para participar do estudo. Qualquer dúvida, entre em contato com Renan Bernardi Kalil no e-mail renankalil@usp.br.

\section{Objetivo, justificativa e procedimentos:}

O projeto de pesquisa "Capitalismo de plataforma e proteção social: trabalho sob demanda por meio de aplicativos, crowdwork e direito do trabalho" é sobre as relações de trabalho no capitalismo de plataforma (também chamado de gig-economy/economia de bico, sharing economy/economia de compartilhamento, dentre outras denominações). Estão sendo conduzidos dois estudos de caso. Um será sobre o trabalho sob demanda por meio de aplicativos.

O outro é sobre as condições de trabalho no que eu denomino de trabalho-de-multidão (crowdwork). O trabalho-de-multidão (crowdwork) é o trabalho que coloca em contato um grupo indeterminado de organizações, empresas e indivíduos por meio da Internet, permitindo o contato global de clientes e trabalhadores, a partir do uso de plataformas digitais. A plataforma de trabalho-de-multidão mais conhecida é a Amazon Mechanical Turk e o estudo de caso é sobre essa plataforma.

As questões elaboradas são uma adaptação do questionário feito pela Organização Internacional do Trabalho (OIT) em pesquisa realizada em 2015. O objetivo é compreender como se desenvolvem as relações de trabalho no trabalho-da-multidão (crowdwork) e as condições de trabalho nessas plataformas e identificar as semelhanças e diferenças desse tipo de trabalho no Brasil e em outros países. Entender como ocorre o trabalho nessas plataformas é relevante para que se formulem respostas adequadas para os trabalhadores.

\section{Desconfortos e riscos:}

Não há desconfortos ou riscos na realização dessa pesquisa.

\section{Benefícios:}

A partir das respostas apresentadas, busca-se obter maior conhecimento sobre as dinâmicas das relações de trabalho no trabalho-de-multidão (crowdwork) e, levando em conta essas bases, pensar nas formas em que o direito do trabalho pode oferecer meios de proteger os trabalhadores que desempenham atividades nesses tipos de plataformas digitais. 
Despesas do voluntário:

Todos envolvidos nessa pesquisa são isento de custos.

\section{Pagamento:}

Considerando que a resposta ao questionário está sendo colocado como tarefa a ser realizada por meio da plataforma Amazon Mechanical Turk, será realizado pagamento de US\$ 4 (quatro dólares americanos) para os trabalhadores que aceitarem participar da pesquisa. A adoção desse procedimento foi autorizada pelo Comitê de Ética da Faculdade de Direito da USP em 18 de abril de 2018.

\section{Participação voluntária:}

A sua participação nesse estudo é voluntária e você terá plena e total liberdade para desistir de participar a qualquer momento.

\section{Garantia de sigilo e privacidade:}

As informações relacionadas ao estudo são confidenciais e qualquer informação divulgada será feita sob forma codificada, para que a confidencialidade seja mantida. O pesquisador garante que o nome dos participantes não será divulgado.

Ao clicar para continuar e iniciar a pesquisa, você declara que foi esclarecido sobre os objetivos, procedimentos e benefícios do presente estudo, que participa de livre e espontânea vontade, que foi assegurado o direito de abandonar o estudo a qualquer momento, que não possui qualquer grau de dependência profissional ou educacional com o pesquisador envolvido nesse projeto, que não se sente pressionado a participar dessa pesquisa, que pode solicitar informações sobre a pesquisa a qualquer momento e que concorda em participar da pesquisa. 


\section{APÊNDICE D - TERMO DE CONSENTIMENTO DE PARTICIPAÇÃO}

Pesquisador responsável:

Renan Bernardi Kalil, doutorando em direito do trabalho pela Universidade de São Paulo (USP), sob orientação do Professor Otavio Pinto e Silva.

Você está sendo convidado(a) para participar como voluntário(a) da pesquisa "Capitalismo de plataforma e proteção social: trabalho sob demanda por meio de aplicativos, crowdwork e direito do trabalho". Leia com atenção as informações abaixo antes de dar o seu consentimento para participar do estudo. Qualquer dúvida, entre em contato com Renan Bernardi Kalil no e-mail renankalil@usp.br.

\section{Objetivo, justificativa e procedimentos:}

O projeto de pesquisa "Capitalismo de plataforma e proteção social: trabalho sob demanda por meio de aplicativos, crowdwork e direito do trabalho" é sobre as relações de trabalho no capitalismo de plataforma (também chamado de gig-economy/economia de bico, sharing economy/economia de compartilhamento, dentre outras denominações). Estão sendo conduzidos dois estudos de caso. Um será sobre o crowdwork (também chamado de trabalho-de-multidão).

O outro é sobre o trabalho sob demanda por meio de aplicativos. Trata-se de uma relação de trabalho de curto prazo, em que a plataforma viabiliza a combinação entre oferta e demanda de mão de obra por meio do software para a execução de uma atividade nas proximidades ou no próprio local em que está situado fisicamente o tomador de serviços. A plataforma de trabalho sob demanda por meio de aplicativos mais conhecida é a Uber e o estudo de caso é sobre essa plataforma.

As questões elaboradas foram divididas em 5 áreas principais: (i) informações sóciodemográficas, para entender o contexto social vivenciado pelos trabalhadores e onde estão inseridos pessoal e profissionalmente; (ii) condições de trabalho, para a compreensão das dinâmicas das relações de trabalho entre o motorista, a plataforma e o consumidor; (iii) outros trabalhos, para verificar como eventuais distintos trabalhos que os motoristas possuem, bem como a maneira com que se relacionam com o trabalho na plataforma; (iv) situação profissional prévia, para entender os motivos que levaram os trabalhadores a optarem por realizarem atividades junto à Uber; (v) situação financeira, para obter uma visão global do quadro financeiro da vida do motorista e de sua família.

Desconfortos e riscos:

Não há desconfortos ou riscos na realização dessa pesquisa.

Benefícios: 
A partir das respostas apresentadas, busca-se obter maior conhecimento sobre as dinâmicas das relações de trabalho no trabalho sob demanda por meio de aplicativos e, levando em conta essas bases, pensar nas formas em que o direito do trabalho pode oferecer meios de proteger os trabalhadores que desempenham atividades nesses tipos de plataformas digitais.

\section{Despesas do voluntário:}

Todos envolvidos nessa pesquisa são isento de custos.

\section{Participação voluntária:}

A sua participação nesse estudo é voluntária e você terá plena e total liberdade para desistir de participar a qualquer momento.

Se a participação ocorrer durante viagem de carro solicitada por meio do aplicativo Uber, a avaliação do motorista não será afetada pelas respostas apresentadas ao pesquisador.

\section{Garantia de sigilo e privacidade:}

As informações relacionadas ao estudo são confidenciais e qualquer informação divulgada será feita sob forma codificada, para que a confidencialidade seja mantida. O pesquisador garante que o nome dos participantes não será divulgado.

$\mathrm{Eu}$, declaro que fui esclarecido sobre os objetivos, procedimentos e benefícios do presente estudo, que participo de livre e espontânea vontade, que foi assegurado o direito de abandonar o estudo a qualquer momento, que não possuo qualquer grau de dependência profissional ou educacional com o pesquisador envolvido nesse projeto, que não me sinto pressionado a participar dessa pesquisa, que posso solicitar informações sobre a pesquisa a qualquer momento e que concordo em participar da pesquisa.

Nome do participante:

Assinatura do participante:

Data:

Nome do pesquisador: Renan Bernardi Kalil

Assinatura do pesquisador:

Data: I_ 